
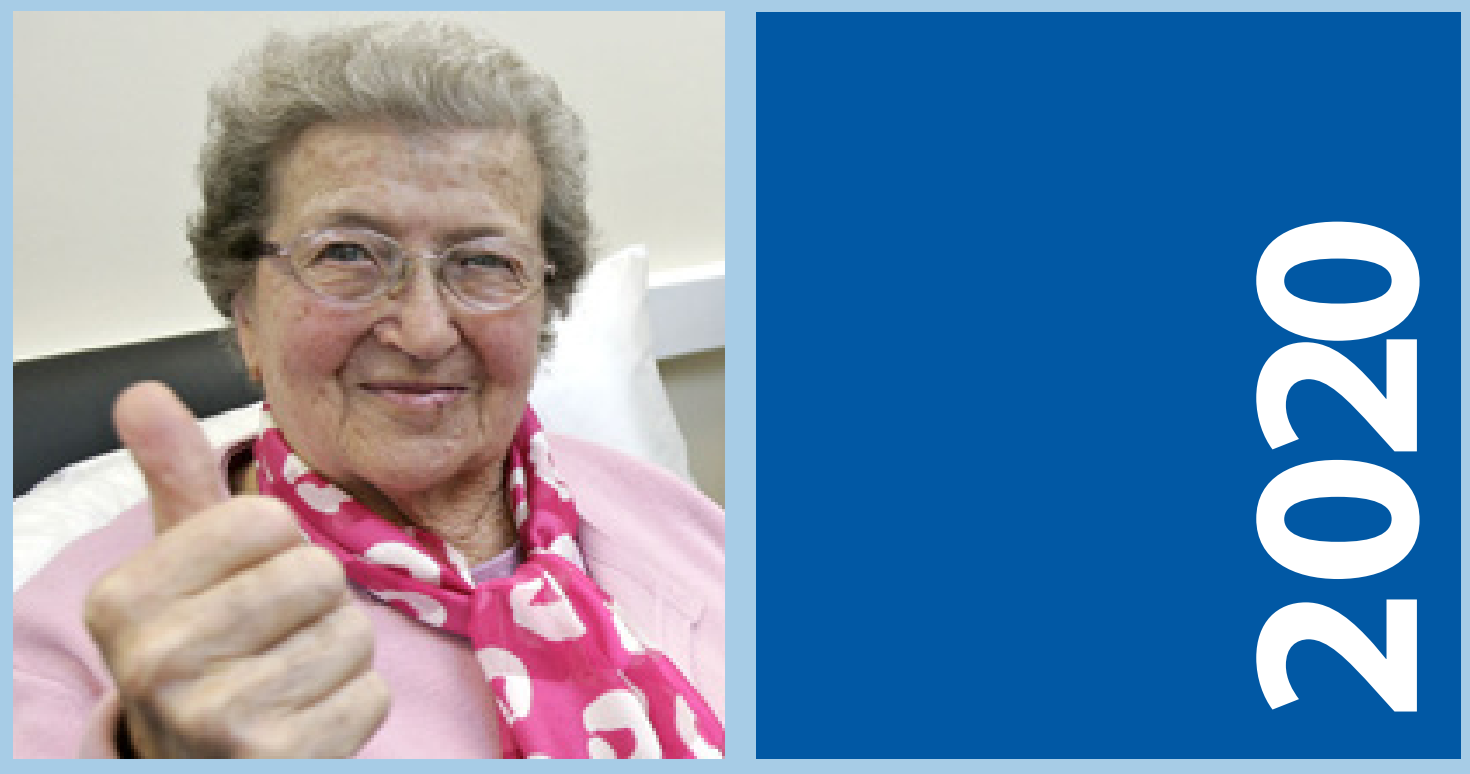

\title{
TILDA REPORT TO INFORM DEMOGRAPHICS \\ FOR OVER 50s IN IRELAND FOR COVID-19 CRISIS
}

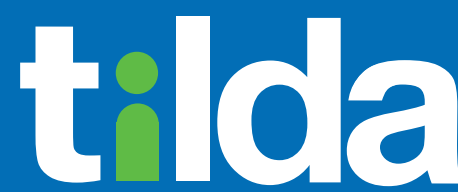

Staidéar Fadaimseartha na hÉireann um Dhul in Aois

The Irish Longitudinal Study on Ageing 


\section{TILDA REPORT TO INFORM DEMOGRAPHICS FOR OVER 50s IN IRELAND FOR COVID-19 CRISIS}

Rose Anne Kenny, Belinda Hernández, Aisling O’Halloran, Frank Moriarty, Christine McGarrigle

On behalf of the TILDA team

March 2020 
Copyright $(\subset$ The Irish Longitudinal Study on Ageing 2020

The Irish Longitudinal Study on Ageing

Trinity Central

152-160 Pearse Street

Trinity College Dublin

Dublin 2

Tel: +35318962509

Email: tilda@tcd.ie

Website: www.tilda.ie

ISBN: 978-1-907894-25-1

https://www.doi.org/10.38018/TildaRe.2020-00 


\section{Acknowledgements}

We would like to acknowledge the vision and commitment of our study funders, The Department of Health with support from the Health Research Board; The Atlantic Philanthropies and Irish Life plc. We would like to state that any views expressed in this report are not necessarily those of the Department of Health or of the Minister for Health. We would also like to thank the TILDA participants without whom this research would not be possible. 


\section{Contents}

1. Frailty, Pre-Frailty and Home Circumstances and Community Health Service Supports among the Over-50s in Ireland ....................................... 1

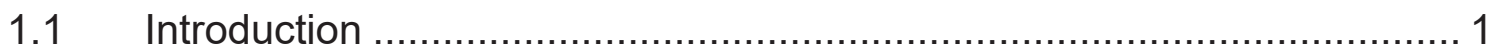

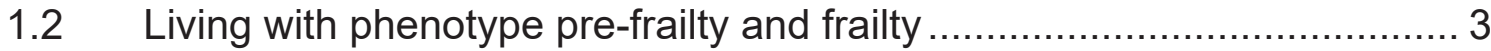

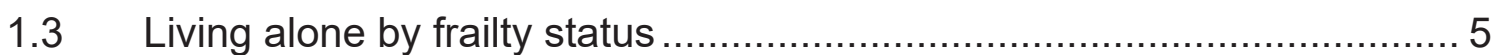

1.4 Accessing support services in the community by frailty status and age

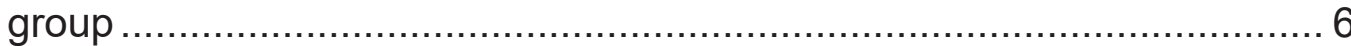

2. Cardiovascular and Chronic Diseases, Comorbidities and Medication Usage in the Over-50s in Ireland ............................................................... 9

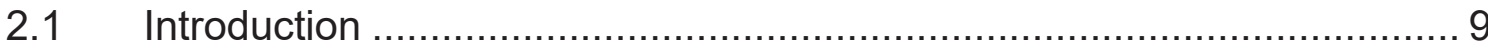

2.2 Population estimates of Cardiovasular and Chronic Diseases ..............11

$2.3 \quad$ Disease and age breakdown........................................................ 13

2.3.1 Chronic Lung Disease .................................................................... 13

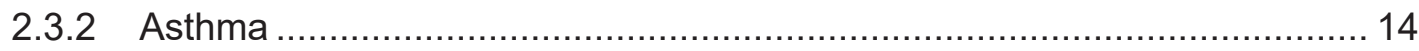

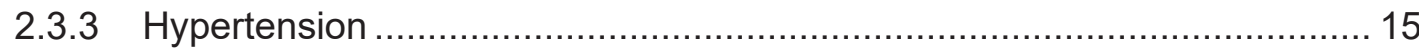

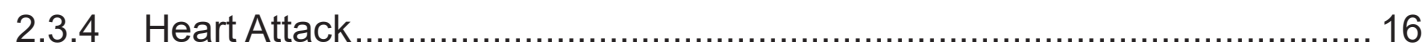

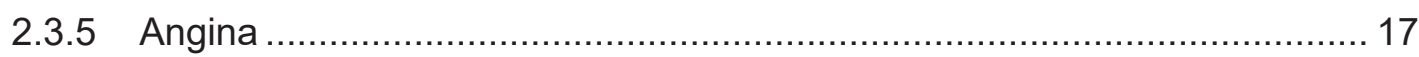

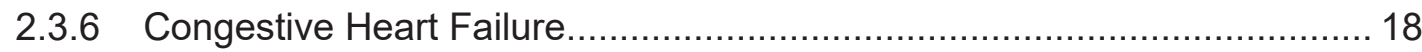

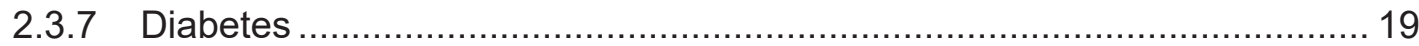

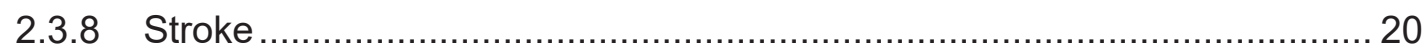

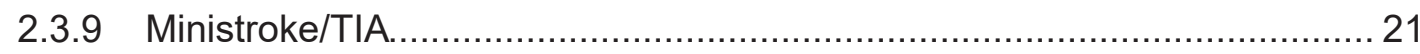

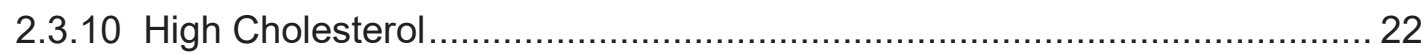

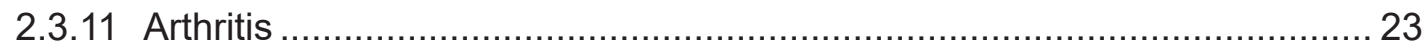

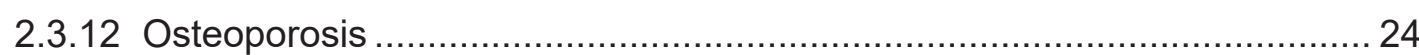

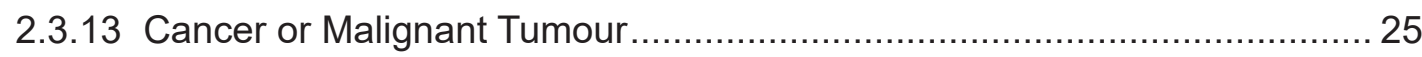

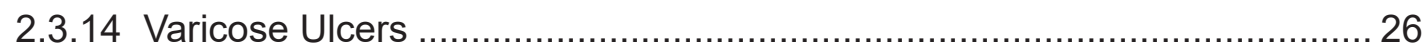

2.3.15 Cirrhosis, or serious Liver Damage ..................................................... 27

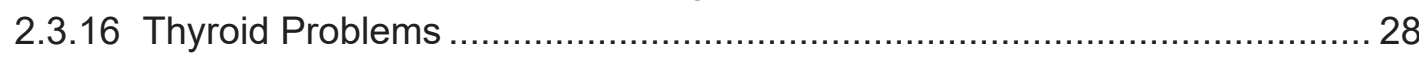

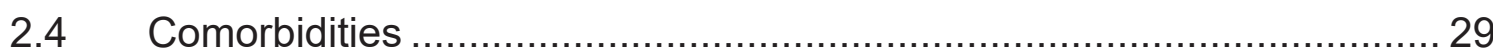

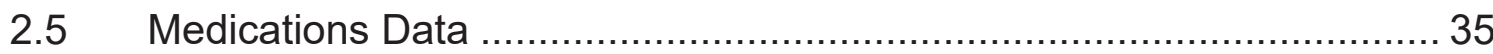

2.5.1 Blood Glucose Lowering Drug............................................................... 36

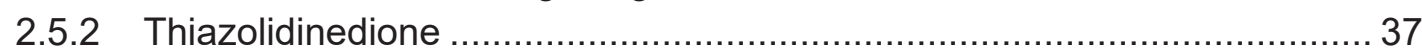

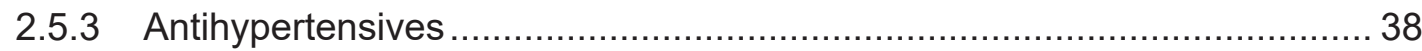

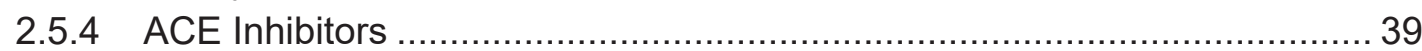

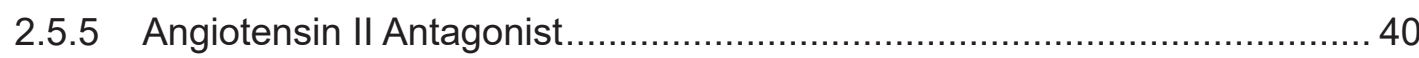

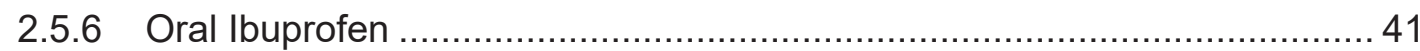

3. Grandchild care, family caregivers and disability in the population of over-

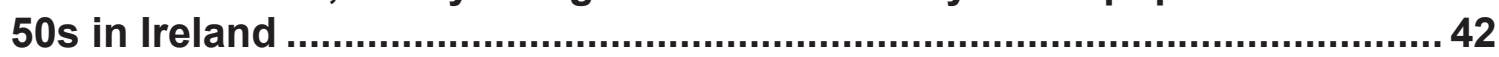

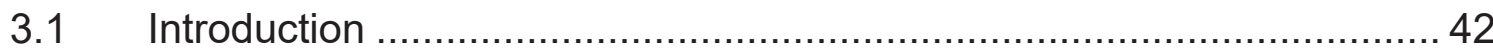

3.2 Provision of grandchild care and the numbers of hours provided .......... 43

3.3 Household composition by functional disability status and proximity to

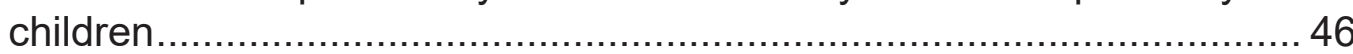

3.4 Home help, functional disability and family care giving ..................... 51

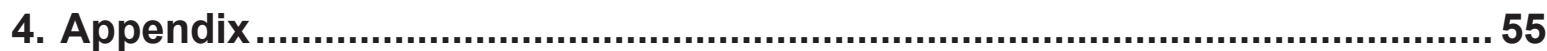

4.1 TILDA sampling frame and methods summary …............................. 55 


\section{Executive Summary}

TILDA is a Longitudinal Study on Ageing, which at Wave 1 (2009) represented 1:156 people aged 50 and older in Ireland. TILDA collects detailed subjective and objective measures of health, social circumstances and economics every two years. These interviews are delivered in participants' homes using computer assisted personal interview (CAPI). Core objective health measures are also collected at each wave in the home and more detailed health assessments are delivered at alternate data sweeps in a health assessment centre or in the participant's home. Response rates at Wave 1 were $62 \%$. Wave 1 commenced in 2009, Wave 5 in 2018.

To assist with planning for COVID-19, we have analysed the following to help identify numbers in at-risk cohorts based on extant national and international data for at-risk groups i.e. frailty, pre-frailty; cardiovascular and chronic conditions; comorbidities; possible at-risk CVD and anti-inflammatory medications*; and living/household circumstances (social isolation) including grandparenting, community social care and health service utilisation.

We find that 126,300 people aged over 50 live alone, 36,000 of whom are living with an ADL functional disability, and $\mathbf{5 7 , 8 0 0}$ are aged over 70 years. In total $16 \%$, equivalent to 234,200, have no children. For the remainder, children live in the same house (26\%), in the same county $(45 \%)$, in another county $(9 \%)$ or another country $(4 \%)$.

Of those over $\mathbf{7 0}$ years, $\mathbf{7 9 , 8 5 1}$ are frail (18.9\%), 217,101 are pre-frail (50.5\%) and 43,448 are living alone (10.8\%). Of those over 70 years who are living alone, 12,704 are frail $(28.1 \%)$ and 18,279 are pre-frail $(44.3 \%)$.

Of those over 50 years, 749,845 have Hypertension, 185,002 have Asthma, 182,833 have Diabetes Mellitus, 167,500 have Cancer past or present, 123,383 have Chronic lung disease such as chronic bronchitis or emphysema, 706,624 have 3 or more comorbidities.

Numbers prescribed possible at-risk medications for ACE2 upregulation: ACE inhibitors 247,923; ARB (angiotensin II Antagonist) 218,126; Ibuprofen 15,188.

Overall, $9 \%$ receive help from a family caregiver, the equivalent of 75,800 people. The majority of these were aged over 70 years $(\mathbf{5 4 , 5 0 0 )}$. 
Overall, $31.5 \%$ of the population aged over 50 provide childcare for their grandchildren, with the mean number of hours in the last month being 2.5 hours (interquartile range 1-4), although $9 \%$ provided more than 40 hours in the past month. This equates to 352,100 people with $\mathbf{9 3 , 0 0 0}$ providing more than 40 hours in the past month.

*"Severe acute respiratory syndrome coronavirus 2 (SARS-CoV-2) infects host cells through ACE2 receptors, leading to coronavirus disease (COVID-19)-related pneumonia, while also causing acute myocardial injury and chronic damage to the cardiovascular system. Therefore, particular attention should be given to cardiovascular protection during treatment for COVID-19...

ACE2 levels can be increased by the use of renin-angiotensin-aldosterone system inhibitors. Given that ACE2 is a functional receptor for SARS-CoV-2, the safety and potential effects of antihypertension therapy with ACE inhibitors or angiotensin-receptor blockers in patients with COVID-19 should be carefully considered....

whether patients with COVID-19 and hypertension who are taking an ACE inhibitor or angiotensin-receptor blocker should switch to another antihypertensive drug remains controversial, and further evidence is required."

https://www.nature.com/articles/s41569-020-0360-5;

https://www.thelancet.com/pdfs/journals/lanres/PIIS2213-2600(20)30116-8.pdf

\section{Weights}

Weights were used in all cases to make estimates relevant to the general population of over-50s in Ireland. In this instance, longitudinal weights which account for participant attrition between Wave 1 and Wave 5 were used. To calculate these weights, the underlying probability of being included in the computer assisted personal interview (CAPI) was multiplied by the reciprocal of the probability of participating in all 5 TILDA waves. This probability was calculated using a logistic regression with the following predictors: age, sex, education level, marital status, geographic location, smoking status, health insurance, medications, socio-economic stratum, self-rated health, disabilities, depression, employment status, cardiovascular conditions, diabetes, vision, cognitive status and whether one has wrist or hip fractures. 


\section{Frailty, Pre-Frailty and Home Circumstances and Community Health Service Supports among the Over-50s in Ireland}

\section{Author: Aisling O'Halloran}

\subsection{Introduction}

The following will give an overview of the numbers of people over 50 in Ireland classified by the phenotype frailty status as captured by Wave 5 of TILDA.

The phenotype frailty status is classified by the presence in an individual of five phenotypic criteria, namely exhaustion/fatigue, unintended weight loss, slow walking speed, muscle weakness and low levels of physical activity.

The presence of none, 1-2 and $\geq 3$ of these criteria indicates that an individual is nonfrail, pre-frail or frail respectively. Pre-frail individuals are at an intermediate stage in the development of frailty, and are at a higher level of adverse health outcomes than non-frail individuals. Frailty is a precursor state on the disability cascade. Individuals living with frailty are at increased risk of developing disabilities, adverse health outcomes, increased hospital admission, transition to long-term care and mortality.

The number of people living with phenotype pre-frailty and frailty will be reported. The numbers of people living alone by frailty status will also be provided. In the final section, the numbers of people accessing support services in the community, e.g. home help, personal care, meals-on-wheels and home care packages will be reported by frailty status and by the age groups 65-74 and 75+ at Wave 5 of the TILDA study.

All estimates are based on data from the most recent Wave 5 of TILDA (collected in 2018, $\mathrm{n}=5,206$ participants); total population estimates are based on figures collected from the most recent 2016 Census data (which reported a total of $1,446,460$ people over 50 living in Ireland). It should be noted that the TILDA sampling frame does not include people with dementia at baseline or people living in nursing homes, and as such this data may slightly underestimate prevalence for the total population in Ireland.

For estimates of phenotype frailty prevalence, all numbers are calculated based on the presence of the five pheontypic criteria among participants at Wave 5 (2018).

In all cases, population numbers have been rounded to the nearest 100 . 
Table 1.1. Enumerated Population CSO Census 2016 and TILDA Wave 52018 (Number) by Sex and Age Group

\begin{tabular}{|c|c|c|}
\hline & CSO 2016 & TILDA 2018 \\
\hline \multicolumn{3}{|l|}{ Male } \\
\hline $50+$ years & 697,605 & 2,286 \\
\hline $50-54$ years & 148,212 & 1 \\
\hline $55+$ years & 549,393 & 2,285 \\
\hline 55 - 59 years & 133,858 & 182 \\
\hline $60-64$ years & 118,698 & 503 \\
\hline 65 - 69 years & 104,961 & 464 \\
\hline $70-74$ years & 79,501 & 419 \\
\hline 75 - 79 years & 54,117 & 345 \\
\hline 80 - 84 years & 35,196 & 223 \\
\hline 85 years and over & 23,062 & 149 \\
\hline \multicolumn{3}{|l|}{ Female } \\
\hline $50+$ years & 748,855 & 2,920 \\
\hline 50 - 54 years & 151,723 & 58 \\
\hline $55+$ years & 597,132 & 2,862 \\
\hline $55-59$ years & 136,244 & 308 \\
\hline $60-64$ years & 120,158 & 644 \\
\hline 65 - 69 years & 106,275 & 564 \\
\hline 70 - 74 years & 82,771 & 532 \\
\hline 75 - 79 years & 61,350 & 353 \\
\hline $80-84$ years & 45,841 & 232 \\
\hline $85+$ years & 44,493 & 229 \\
\hline \multicolumn{3}{|l|}{ Total } \\
\hline $50+$ years & $1,446,460$ & 5,206 \\
\hline 50 - 54 years & 299,935 & 59 \\
\hline $55+$ years & $1,146,525$ & 5,147 \\
\hline 55 - 59 years & 270,102 & 490 \\
\hline 60 - 64 years & 238,856 & 1,147 \\
\hline $65-69$ years & 211,236 & 1,028 \\
\hline $70-74$ years & 162,272 & 951 \\
\hline 75 - 79 years & 115,467 & 698 \\
\hline 80 - 84 years & 81,037 & 455 \\
\hline $85+$ years & 67,555 & 378 \\
\hline
\end{tabular}

Table 1.1 Data from Wave 5 (2018) TILDA weighted to account for population. 


\section{$1.2 \quad$ Living with phenotype pre-frailty and frailty}

Figure 1.1 Phenotype Frailty by Age Group and Gender

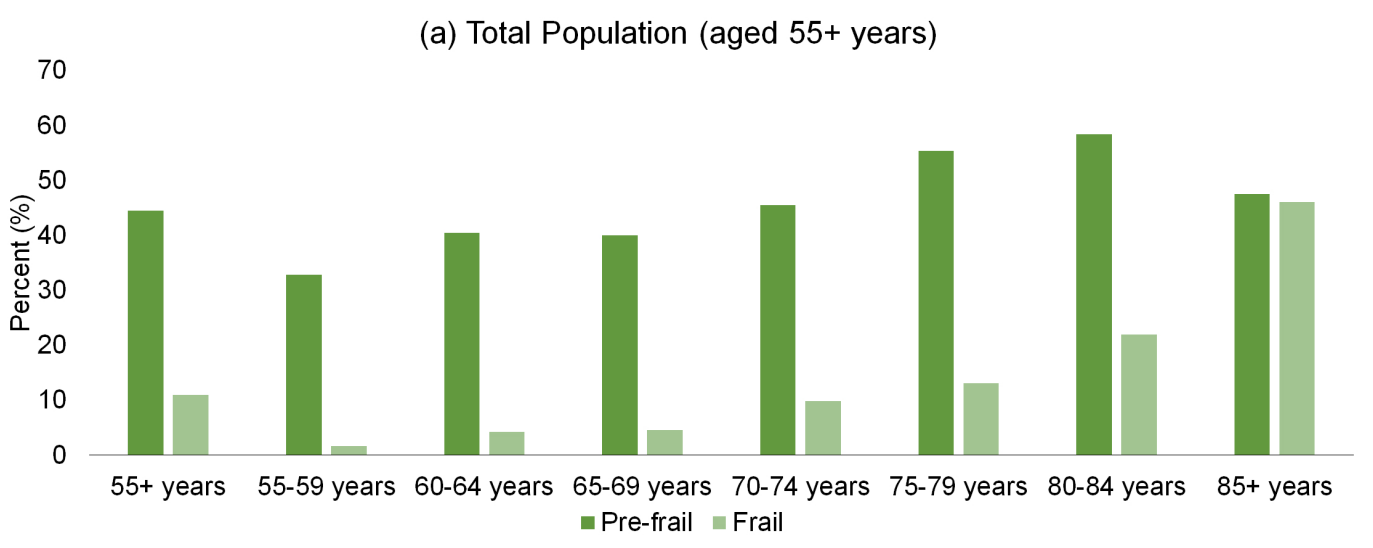

(b) Males (aged 55+ years)

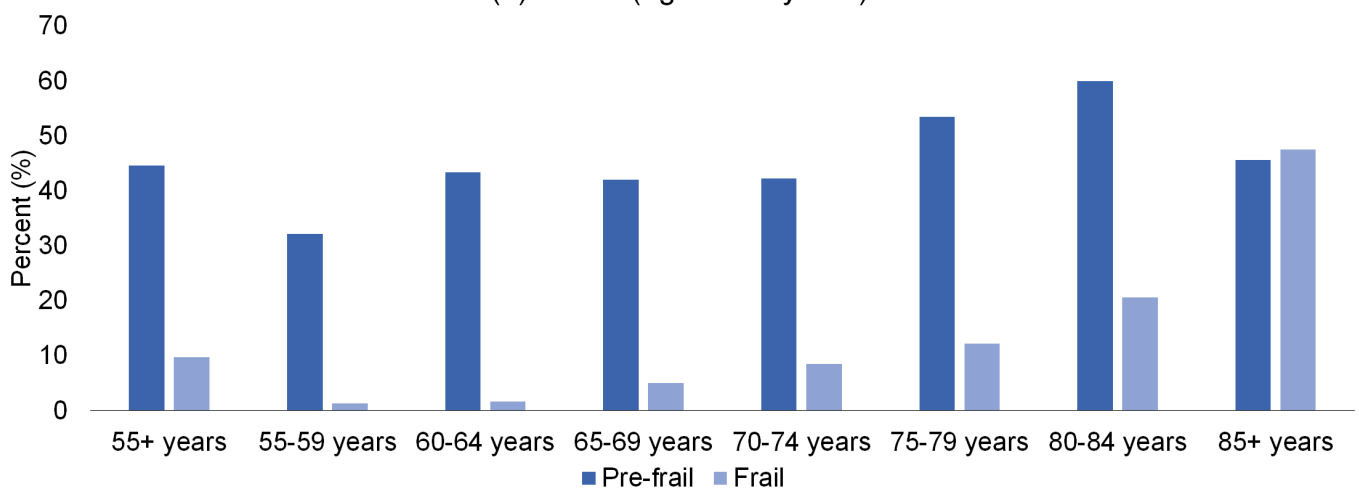

(c) Females (aged 55+ years)

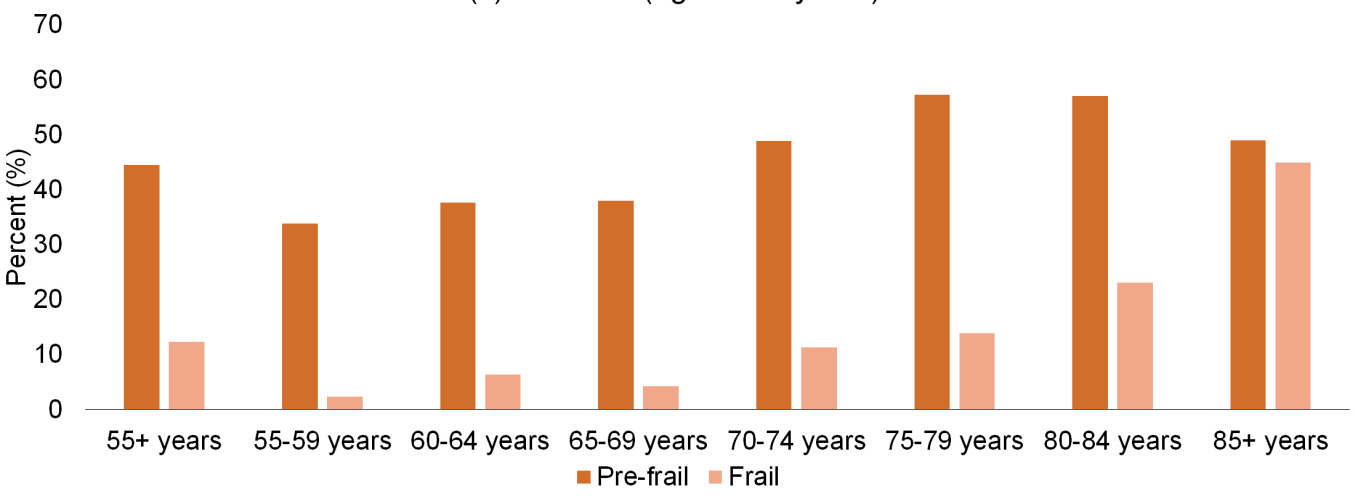

\section{(a) Frailty by Age Group for All participants aged 55+ years}

Total Pop \%: - Pre-frail: 44.5, Frail: 11.0; Pop Number: - Pre-frail: 510,204, Frail: 126,118

(b) Frailty by Age Group for Male participants aged 55+ years

Total Pop \%: - Pre-frail: 44.6, Frail: 9.7; Pop Number: - Pre-frail: 245,029, Frail: 53,291

(c) Frailty by Age Group for Female participants aged 55+ years

Total Pop \%: - Pre-frail: 44.5, Frail: 12.3; Pop Number: - Pre-frail: 265,724, Frail: 73,447 


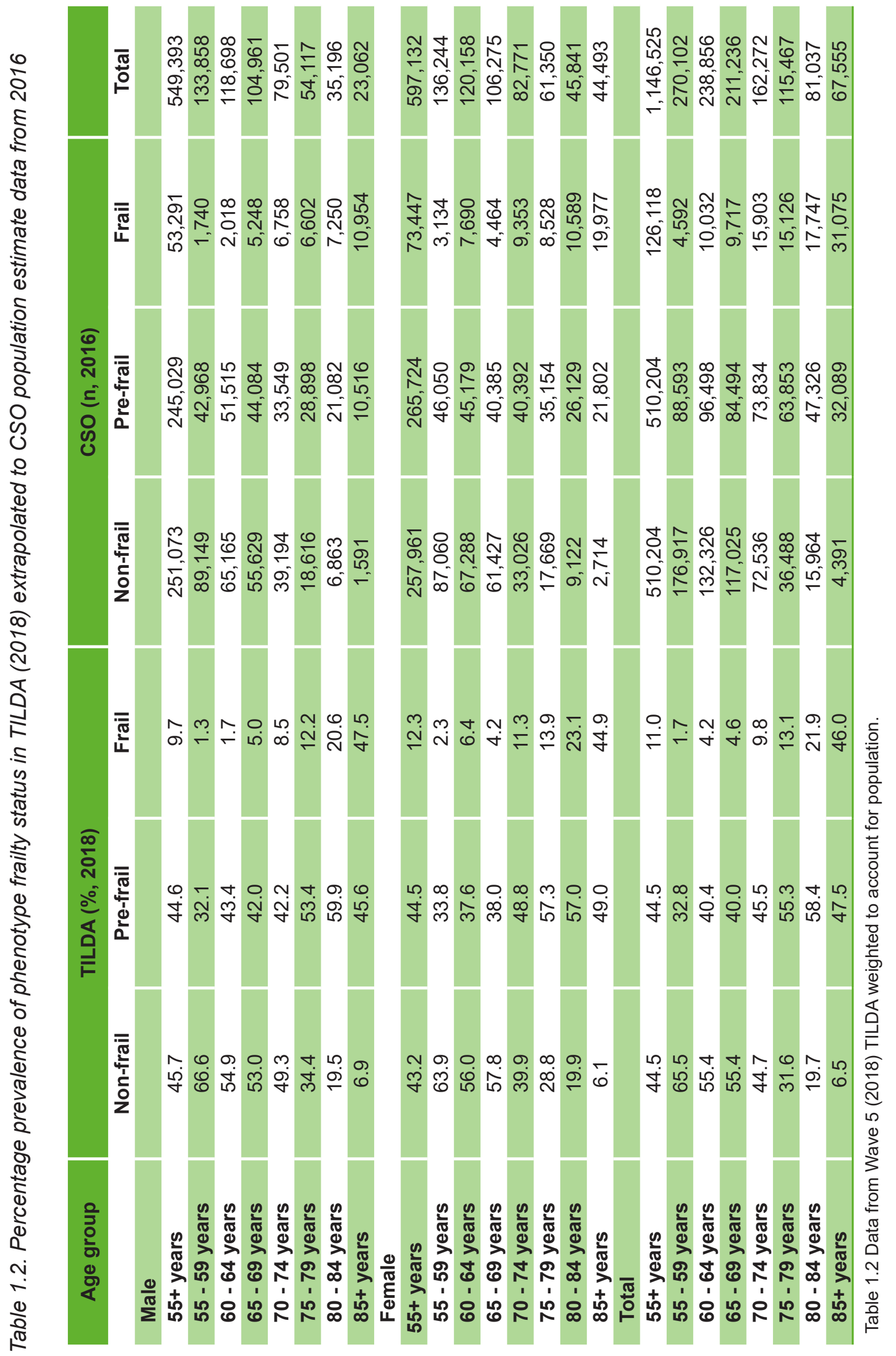




\subsection{Living alone by frailty status}

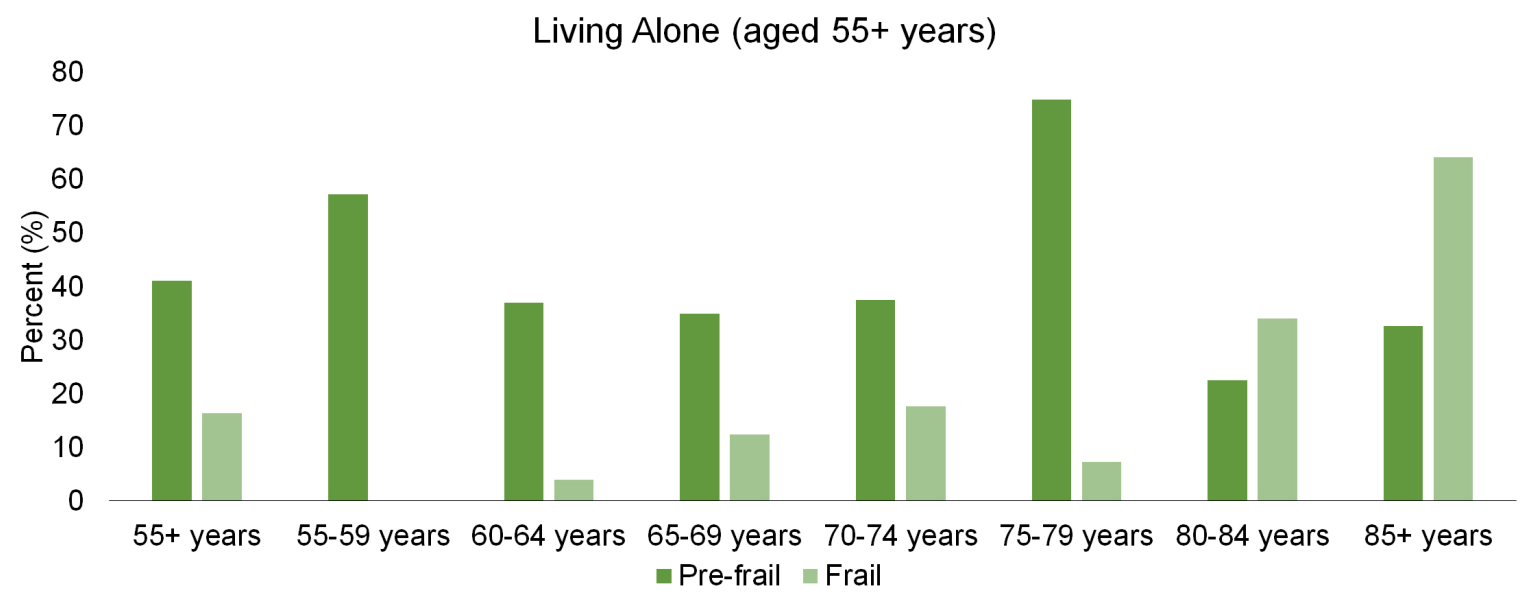

Figure 1.1 Prevalence of Phenotype Frailty in those Living Alone by Age Group

Of those living alone \%: - Pre-frail: 41.1, Frail: 16.4; Pop Number: - Pre-frail: 44,043, Frail: 17,574

Table 1.3. Percentage prevalence of living alone by frailty status in TILDA (2018) extrapolated to CSO population estimate data from 2016

\begin{tabular}{|l|c|c|c|c|c|c|}
\hline & \multicolumn{3}{c}{ TILDA (\%, 2018) } & \multicolumn{3}{c|}{ CSO (n, 2016) } \\
\hline & Non-frail & Pre-frail & Frail & Non-frail & Pre-frail & Frail \\
\hline Total & & & & & & \\
\hline $\mathbf{5 5 +}$ years & $\mathbf{4 2 . 5}$ & $\mathbf{4 1 . 1}$ & $\mathbf{1 6 . 4}$ & $\mathbf{4 5 , 5 4 3}$ & $\mathbf{4 4 , 0 4 3}$ & $\mathbf{1 7 , 5 7 4}$ \\
\hline 55 - 59 years & $\mathbf{4 2 . 7}$ & $\mathbf{5 7 . 3}$ & 0 & 7,727 & 10,369 & 0 \\
\hline 60 - 64 years & 59.1 & 37.0 & 3.9 & 13,975 & 8,749 & 922 \\
\hline $65-69$ years & 52.7 & 34.9 & 12.4 & 11,577 & 7,667 & 2,724 \\
\hline $70-74$ years & 44.8 & 37.5 & 17.7 & 6,470 & 5,416 & 2,556 \\
\hline $75-79$ years & 17.8 & 74.9 & 7.3 & 1,809 & 7,611 & 742 \\
\hline $80-84$ years & 43.5 & 22.5 & 34.0 & 3,878 & 2,006 & 3,031 \\
\hline $85+$ years & 3.0 & 32.7 & 64.2 & 298 & 3,247 & 6,375 \\
\hline
\end{tabular}

Table 1.3 Data from Wave 5 (2018) TILDA weighted to account for population. 


\subsection{Accessing support services in the community by frailty status and age group}

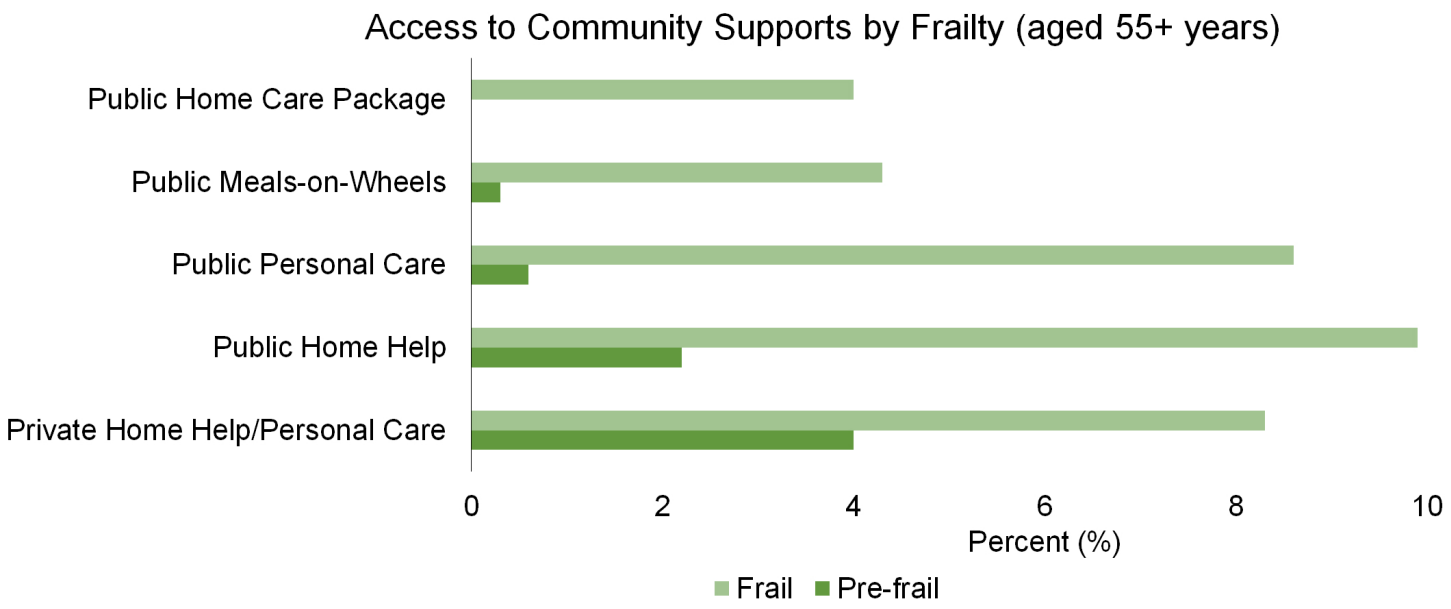

Figure 1.3. Access to Community Supports by Phenotype Frailty for participants aged 55+ years

Total Pop \%: - Pre-frail: 44.5, Frail: 11.0; Pop Number: - Pre-frail: 510,204, Frail: 126, 118

Table 1.4. Percentage access to community supports by frailty status in TILDA (2018) extrapolated to CSO population estimate data from 2016

\begin{tabular}{|l|c|c|c|c|}
\hline & \multicolumn{2}{|c|}{ TILDA (\%, 2018) } & \multicolumn{2}{c|}{ CSO (n, 2016) } \\
\hline & Pre-frail & Frail & Pre-frail & Frail \\
\hline Pop 55+ years & 44.5 & 11.0 & 510,204 & 126,118 \\
\hline Private Home Help/ Personal Care & 4.0 & 8.3 & 20,408 & 10,468 \\
\hline Public Home Help & 2.2 & 9.9 & 11,224 & 12,486 \\
\hline Public Personal Care & 0.6 & 8.6 & 3,061 & 10,846 \\
\hline Public Meals-on-Wheels & 0.3 & 4.3 & 1,531 & 5,423 \\
\hline Public Home Care Package & 0.0 & 4.0 & 0 & 5,045 \\
\hline
\end{tabular}

Table 1.4 Data from Wave 5 (2018) TILDA weighted to account for population. 
Table 1.5.1. Percentage paying for private home help/personal care in TILDA (2018) extrapolated to CSO population estimate data from 2016

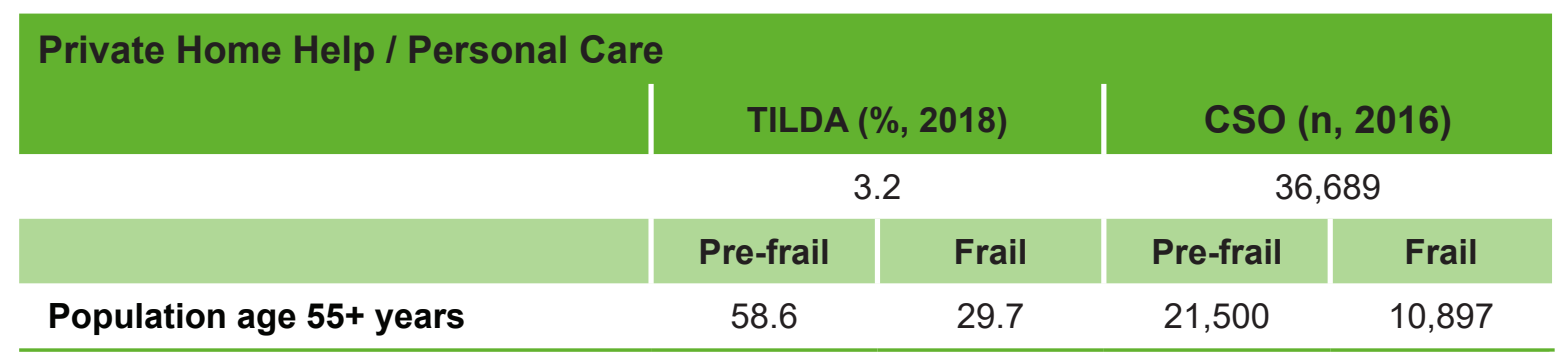

Of these: - $15.3 \%$ were aged $65-74$ years, equivalent to 5,613 individuals and $80.2 \%$ were aged 75 and over, equivalent to 29,425 individuals

Table 1.5.2. Percentage receiving public home help in TILDA (2018) extrapolated to CSO population estimate data from 2016

\begin{tabular}{|c|c|c|c|c|}
\hline \multicolumn{5}{|l|}{ Public Home Help } \\
\hline & \multicolumn{2}{|c|}{ TILDA $(\%, 2018)$} & \multicolumn{2}{|c|}{$\operatorname{cso}(n, 2016)$} \\
\hline & \multicolumn{2}{|c|}{3.4} & \multicolumn{2}{|c|}{38,982} \\
\hline & Pre-frail & Frail & Pre-frail & Frail \\
\hline Population age $55+$ years & 44.9 & 44.9 & 17,503 & 17,503 \\
\hline
\end{tabular}

Of these: - $10.1 \%$ were aged $65-74$ years, equivalent to 3,937 individuals and $88.4 \%$ were aged 75 and over, equivalent to 43,460 individuals

Table 1.5.3. Percentage receiving a public personal care attendant in TILDA (2018) extrapolated to CSO population estimate data from 2016

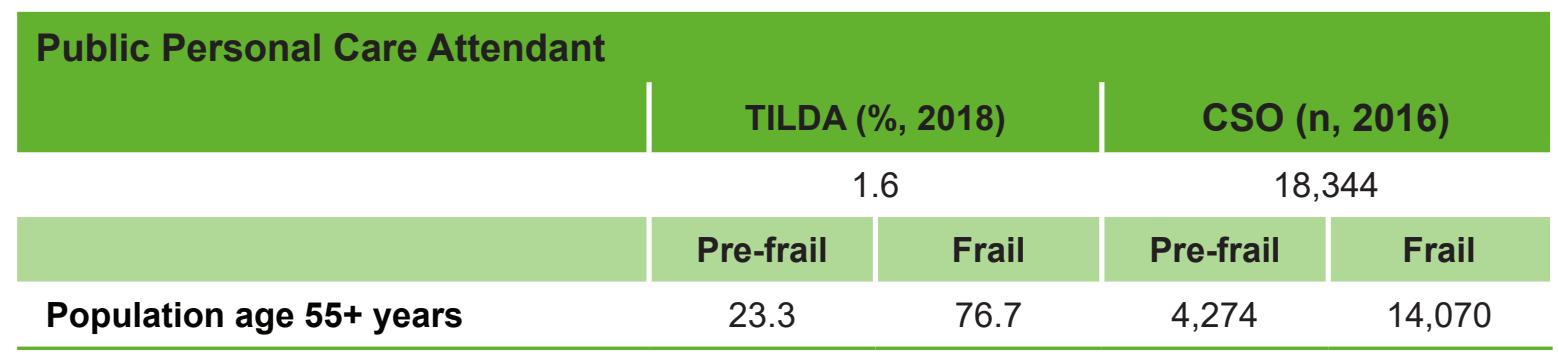

Of these: - $16.7 \%$ were aged $65-74$ years, equivalent to 3,068 individuals and $80.0 \%$ were aged 75 and over, equivalent to 14,675 individuals 
Table 1.5.4. Percentage receiving public meals-on-wheels in TILDA (2018) extrapolated to CSO population estimate data from 2016

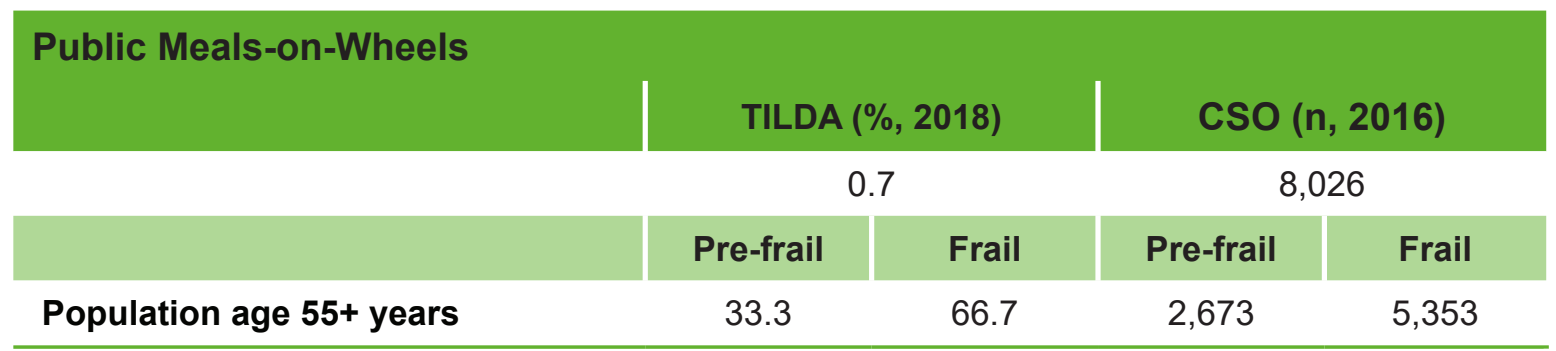

Of these: - $17.9 \%$ were aged $65-74$ years, equivalent to 1,437 individuals and $78.6 \%$ were aged 75 and over, equivalent to 6,308 individuals

Table 1.5.5. Percentage receiving a public home care package in TILDA (2018) extrapolated to CSO population estimate data from 2016

\begin{tabular}{l|c|c|c|c|}
\hline Public Home Care Package & \multicolumn{3}{c|}{ TILDA (\%, 2018) } & \multicolumn{3}{c|}{ CSO (n, 2016) } \\
\hline & \multicolumn{3}{|c|}{0.6} & \multicolumn{2}{c}{6,879} \\
& Pre-frail & Frail & Pre-frail & Frail \\
\hline Population age 55+ years & 3.6 & 96.4 & 248 & 6,631 \\
\hline
\end{tabular}

Of these: - $20.7 \%$ were aged $65-74$ years, equivalent to 1,424 individuals and $75.9 \%$ were aged 75 and over, equivalent to 5,221 individuals 
2. Cardiovascular and Chronic Diseases, Comorbidities and Medication Usage in the Over-50s in Ireland

\section{Author: Belinda Hernández}

\subsection{Introduction}

The following will give an overview of the numbers of people over 50 in Ireland with the following 16 cardiovascular or chronic conditions captured by TILDA:

- High Cholesterol

- Hypertension

- Arthritis (including osteoarthritis, or rheumatism)

- Osteoporosis, sometimes called thin or brittle bones

- Asthma

- Diabetes

- Cancer or a malignant tumour

- Thyroid Problems

- Chronic lung disease such as chronic bronchitis or emphysema

- Angina

- A heart attack (incl. myocardial infarction or coronary thrombosis)

- Varicose Ulcers (an ulcer due to varicose veins)

- Mini stroke/TIA

- Stroke

- Congestive heart failure

- Cirrhosis, or serious liver damage 
The number of people living with multiple co-occurring medical conditions, as well as the pairwise combinations of coexisting conditions (comorbidities), will also be reported. The final section of this report will give an overview of the medications being used at Wave 5 .

All estimates are based on data from the most recent Wave 5 of TILDA (collected in 2018, $\mathrm{n}=5,206$ participants); total population estimates are based on figures collected from the most recent 2016 census data (which reported a total of 1,446,460 people over 50 living in Ireland). It should be noted that the TILDA sampling frame does not include people with dementia at baseline or people living in nursing homes, and so this data may slightly underestimate prevalence for the total population in Ireland.

For estimates of diseases and comorbidity prevalence, all numbers are calculated based on participants having a history of the disease, not just disease incidence at wave 5 ; i.e., we counted disease as being present if the participant reported ever having any of the above medical conditions in any of the TILDA waves (2009-2018), not only if they reported it in 2018. To do this, we included data from all 5 waves of TILDA and counted disease as being present if a participant reported having the disease in any of the 5 waves and didn't later dispute having the disease at a later wave. The reason for this is that many participants confuse being cured of a disease and having a disease under control (even though they are asked if they have ever been diagnosed with the conditions above many will report no as their condition is under control even though they previously reported having the condition). If they report a condition at a given wave, they are asked to confirm it at the next wave, and are given the opportunity to dispute the diagnosis. In all cases our estimates have corrected for disputed/false diagnoses.

In all cases population numbers have been rounded to the nearest 100 . 


\subsection{Population estimates of Cardiovasular and Chronic Diseases}

Figure 2.1 Disease prevalence in the population of over-50s in Ireland

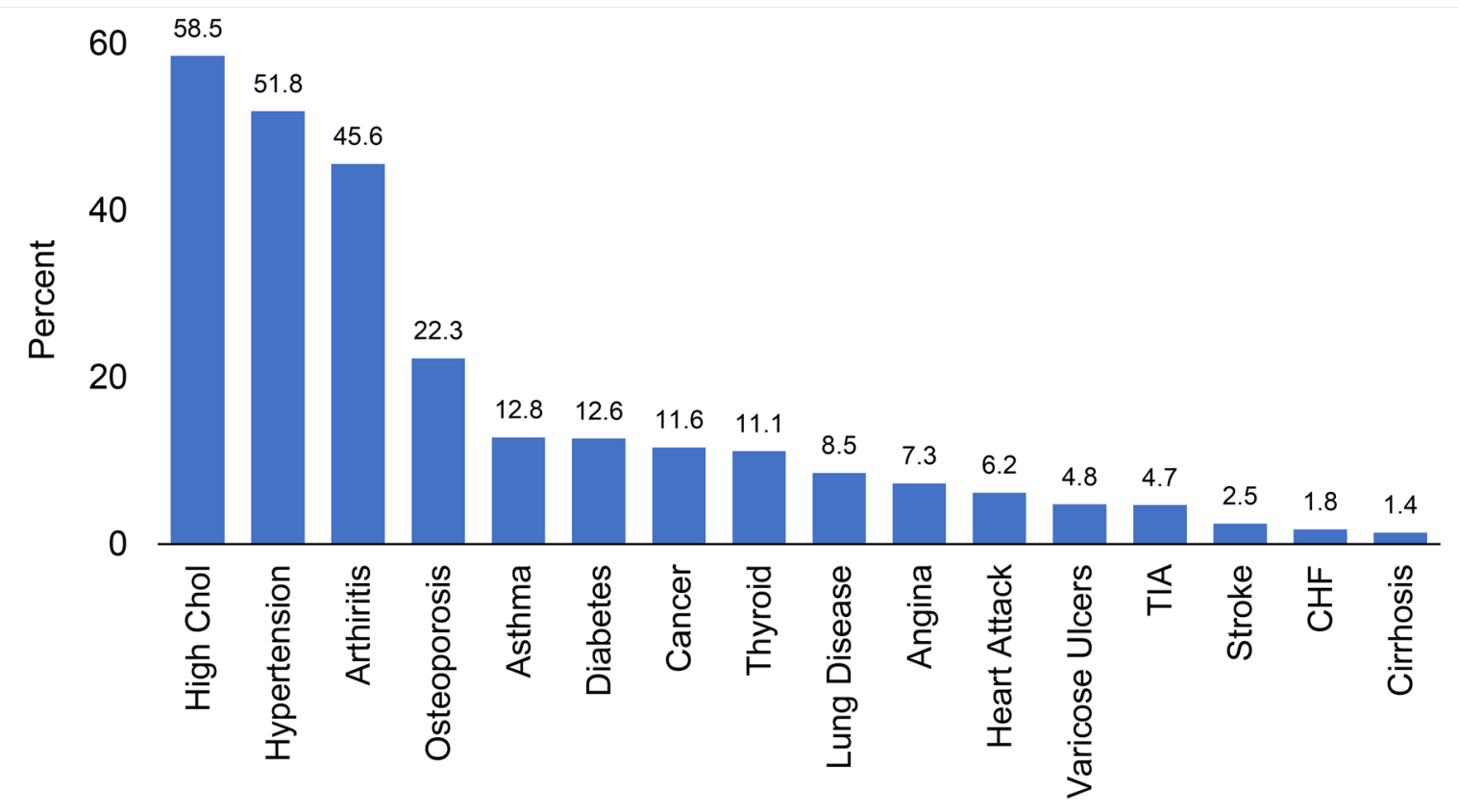


Depicted in Table 2.1 is the percentage in the population with each of the 16 conditions mentioned.

Table 2.1. Disease prevalence in TILDA and the population of over-50s in Ireland

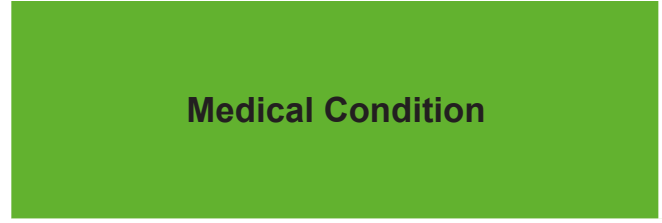

Asthma

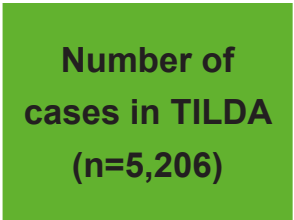

657

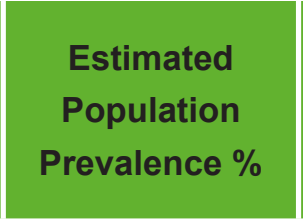

12.79

8.53

58.5
Estimated Number in

Population $(n=1,446,460)$

185,002

\begin{tabular}{|c|c|c|c|}
\hline $\begin{array}{l}\text { Chronic lung disease such as chronic } \\
\text { bronchitis or emphysema }\end{array}$ & 402 & 8.53 & 123,383 \\
\hline High Cholesterol & 3,037 & 58.5 & 846,179 \\
\hline Hypertension & 2,589 & 51.84 & 749,845 \\
\hline $\begin{array}{l}\text { Arthritis (including osteoarthritis, or } \\
\text { rheumatism) }\end{array}$ & 2,256 & 45.55 & 658,863 \\
\hline $\begin{array}{l}\text { Osteoporosis, sometimes called thin or } \\
\text { brittle bones }\end{array}$ & 1,148 & 22.27 & 322,127 \\
\hline Diabetes & 612 & 12.64 & 182,833 \\
\hline Cancer or a malignant tumour & 612 & 11.58 & 167,500 \\
\hline Thyroid Problems & 592 & 11.11 & 160,702 \\
\hline Angina & 337 & 7.27 & 105,158 \\
\hline $\begin{array}{l}\text { A heart attack (incl. myocardial infarction } \\
\text { or coronary thrombosis) }\end{array}$ & 295 & 6.16 & 89,102 \\
\hline $\begin{array}{l}\text { Varicose Ulcers (an ulcer due to varicose } \\
\text { veins) }\end{array}$ & 226 & 4.75 & 68,707 \\
\hline Mini stroke/TIA & 242 & 4.66 & 67,405 \\
\hline A stroke (cerebral vascular disease) & 143 & 2.45 & 35,438 \\
\hline Congestive heart failure & 83 & 1.75 & 25,313 \\
\hline Cirrhosis, or serious liver damage & 59 & 1.40 & 20,250 \\
\hline
\end{tabular}

Table 2.1 shows the actual numbers of cases in TILDA and the estimated number of people in the population with each of these diseases. NOTE: The population prevalence is weighted to the population of over-50s in Ireland and so will not correspond to the \% of cases in TILDA, i.e. for high cholesterol 3037/5026*100 does not equal $58.5 \%$ this is because we have used weights to make our estimates relevant to the population of over-50s in Ireland and not just to TILDA 


\subsection{Disease and age breakdown}

\subsubsection{Chronic Lung Disease}

Figures $2.2-2.17$ inclusive show the percentage age distribution for each disease type in the population of over-50s in Ireland. The corresponding breakdown by age group of the actual numbers of cases in TILDA and the estimated number of people in the population with each disease type are presented in Tables 2.2 -2.17 inclusive.

Figure 2.2. Percentage prevalence of Chronic Lung Disease by Age Group

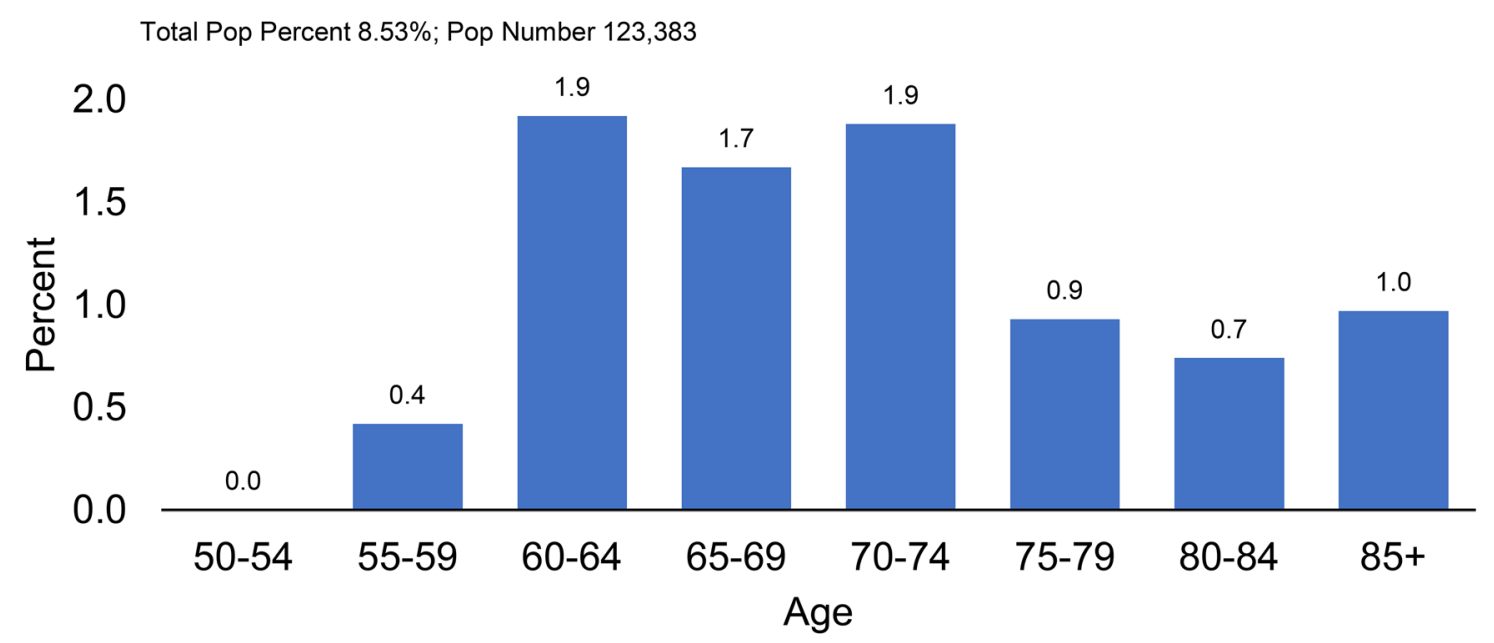

Table 2.2. Prevalence of Chronic Lung Disease in TILDA and the population of over-50s in Ireland by Age Group

\begin{tabular}{|c|c|c|c|c|c|c|c|c|c|}
\hline $\begin{array}{l}\text { Chronic lung } \\
\text { disease such as } \\
\text { chronic bronchitis or } \\
\text { emphysema by Age }\end{array}$ & $50-54$ & $55-59$ & $60-64$ & $65-69$ & $70-74$ & $75-79$ & $80-84$ & $85+$ & TOTAL \\
\hline $\begin{array}{l}\text { Number Cases in } \\
\text { TILDA }\end{array}$ & 4 & 24 & 77 & 78 & 85 & 52 & 40 & 42 & 402 \\
\hline $\begin{array}{l}\text { Estimated Prevalence } \\
\text { in Population }\end{array}$ & $0.00 \%$ & $0.42 \%$ & $1.92 \%$ & $1.67 \%$ & $1.88 \%$ & $0.93 \%$ & $0.74 \%$ & $0.97 \%$ & $8.53 \%$ \\
\hline $\begin{array}{l}\text { Estimated Number of } \\
\text { Cases in Population }\end{array}$ & 0 & 6,075 & 27,772 & 24,156 & 27,193 & 13,452 & 10,704 & 14,031 & 123,383 \\
\hline
\end{tabular}

Table 2.2 shows the actual numbers of cases in TILDA and the estimated number of people in the population with chronic lung disease. NOTE: The population prevalence is weighted to the population of over-50s in Ireland and so will not correspond to the \% of cases in TILDA. 


\subsubsection{Asthma}

Figure 2.3. Percentage prevalence of Asthma by Age Group

Total Pop Percent 12.79\%; Pop Number 185,002

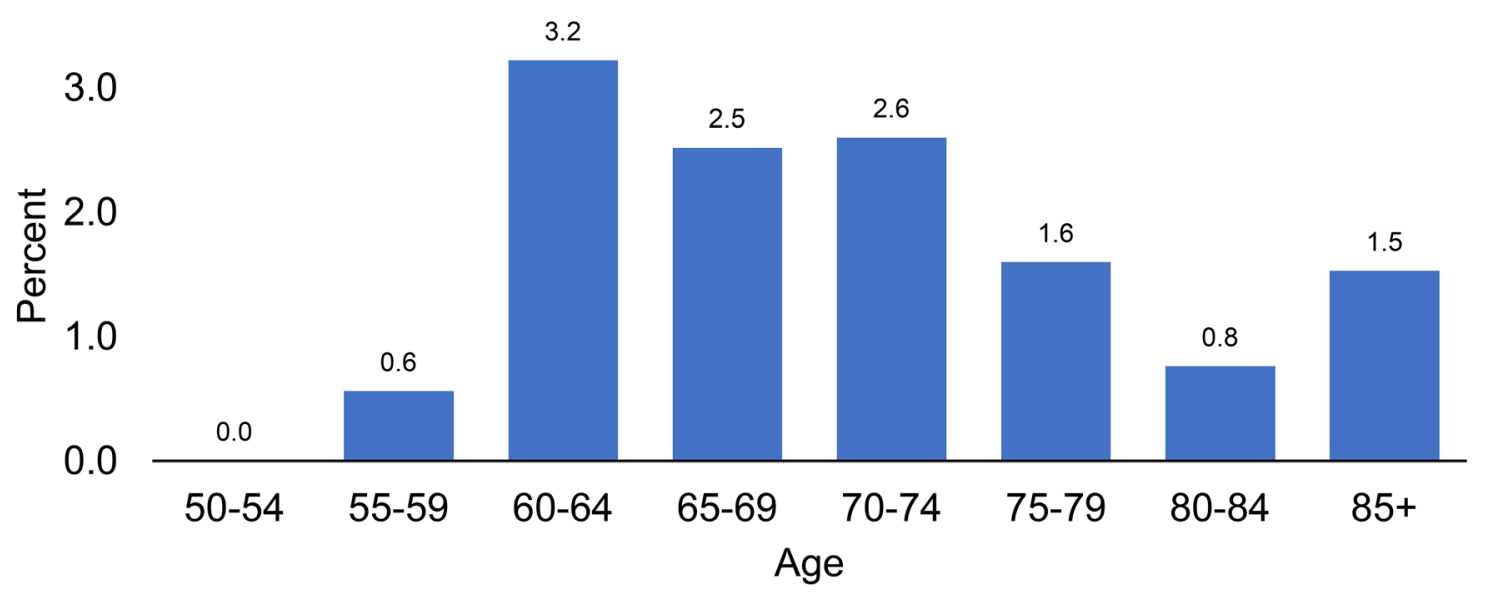

Table 2.3. Prevalence of Asthma in TILDA and the population of over-50s in Ireland by Age Group

\begin{tabular}{|l|c|c|c|c|c|c|c|c|c|}
\hline $\begin{array}{l}\text { Asthma by Age } \\
\text { Number Cases in }\end{array}$ & $\mathbf{5 0 - 5 4}$ & $\mathbf{5 5 - 5 9}$ & $\mathbf{6 0 - 6 4}$ & $\mathbf{6 5 - 6 9}$ & $\mathbf{7 0 - 7 4}$ & $\mathbf{7 5 - 7 9}$ & $\mathbf{8 0 - 8 4}$ & $\mathbf{8 5 +}$ & TOTAL \\
\hline $\begin{array}{l}\text { NILDA } \\
\text { TILA }\end{array}$ & 42 & 152 & 132 & 130 & 86 & 46 & 55 & 657 \\
\hline $\begin{array}{l}\text { Estimated Prevalence } \\
\text { in Population }\end{array}$ & $0.00 \%$ & $0.56 \%$ & $3.22 \%$ & $2.52 \%$ & $2.60 \%$ & $1.60 \%$ & $0.76 \%$ & $1.53 \%$ & $12.79 \%$ \\
\hline $\begin{array}{l}\text { Estimated Number of } \\
\text { Cases in Population }\end{array}$ & 0 & 8,100 & 46,576 & 36,451 & 37,608 & 23,143 & 10,993 & 22,131 & 185,002 \\
\hline
\end{tabular}

Table 2.3 shows the actual numbers of cases in TILDA and the estimated number of people in the population with asthma. NOTE: The population prevalence is weighted to the population of over-50s in Ireland and so will not correspond to the $\%$ of cases in TILDA. 


\subsubsection{Hypertension}

Figure 2.4. Percentage prevalence of Hypertension by Age Group

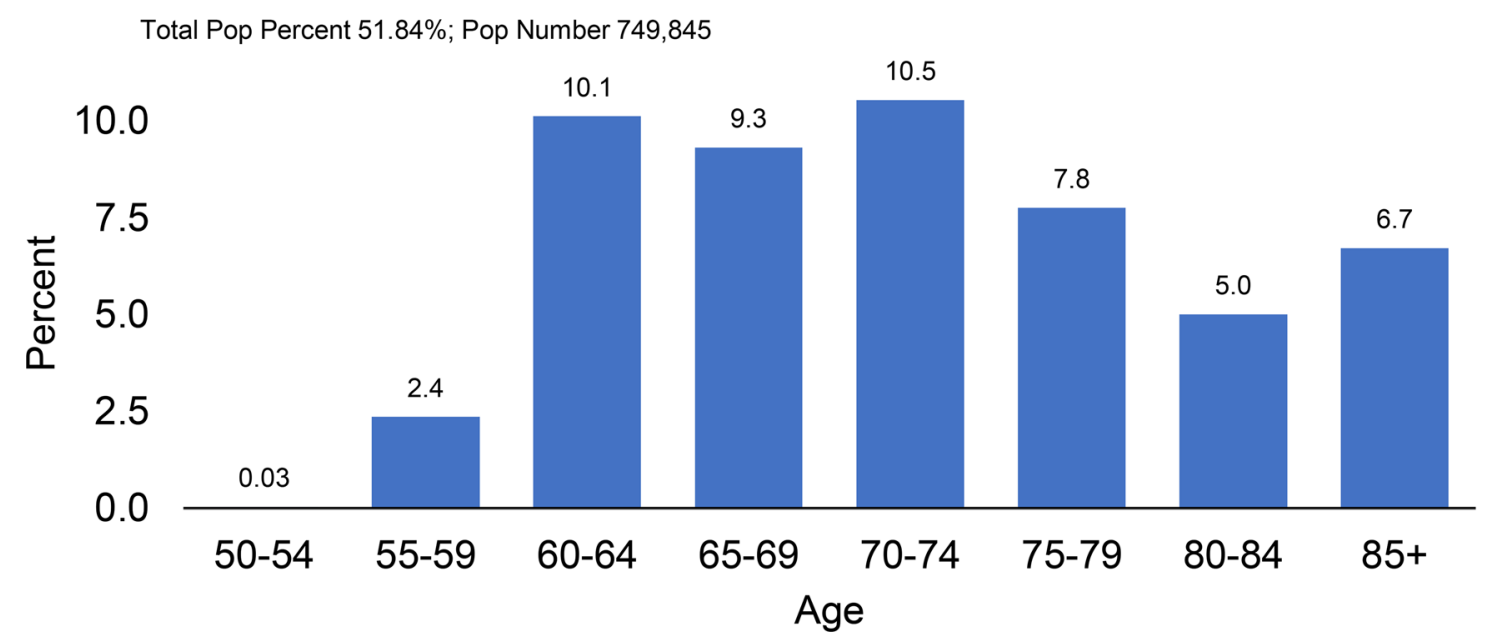

Table 2.4. Prevalence of Hypertension in TILDA and the population of over-50s in Ireland by Age Group

\begin{tabular}{|l|c|c|c|c|c|c|c|c|c|}
\hline Hypertension by Age & $\mathbf{5 0 - 5 4}$ & $\mathbf{5 5 - 5 9}$ & $\mathbf{6 0 - 6 4}$ & $\mathbf{6 5 - 6 9}$ & $\mathbf{7 0 - 7 4}$ & $\mathbf{7 5 - 7 9}$ & $\mathbf{8 0 - 8 4}$ & $\mathbf{8 5 +}$ & TOTAL \\
\hline $\begin{array}{l}\text { Number Cases in } \\
\text { TILDA }\end{array}$ & 20 & 156 & 459 & 463 & 520 & 428 & 282 & 2,611 \\
\hline $\begin{array}{l}\text { Estimated Prevalence } \\
\text { in Population }\end{array}$ & $0.03 \%$ & $2.35 \%$ & $10.12 \%$ & $9.31 \%$ & $10.54 \%$ & $7.76 \%$ & $5.01 \%$ & $6.72 \%$ & 51.84 \\
\hline $\begin{array}{l}\text { Estimated Number of } \\
\text { Cases in Population }\end{array}$ & 434 & 33,992 & 146,382 & 134,665 & 152,457 & 112,245 & 72,468 & 97,202 & 749,845 \\
\hline
\end{tabular}

Table 2.4 shows the actual numbers of cases in TILDA and the estimated number of people in the population with hypertension. NOTE: The population prevalence is weighted to the population of over-50s in Ireland and so will not correspond to the $\%$ of cases in TILDA 


\subsubsection{Heart Attack}

Figure 2.5. Percentage prevalence of Heart Attack by Age Group

Total Pop Percent 6.16\%; Pop Number 89,102

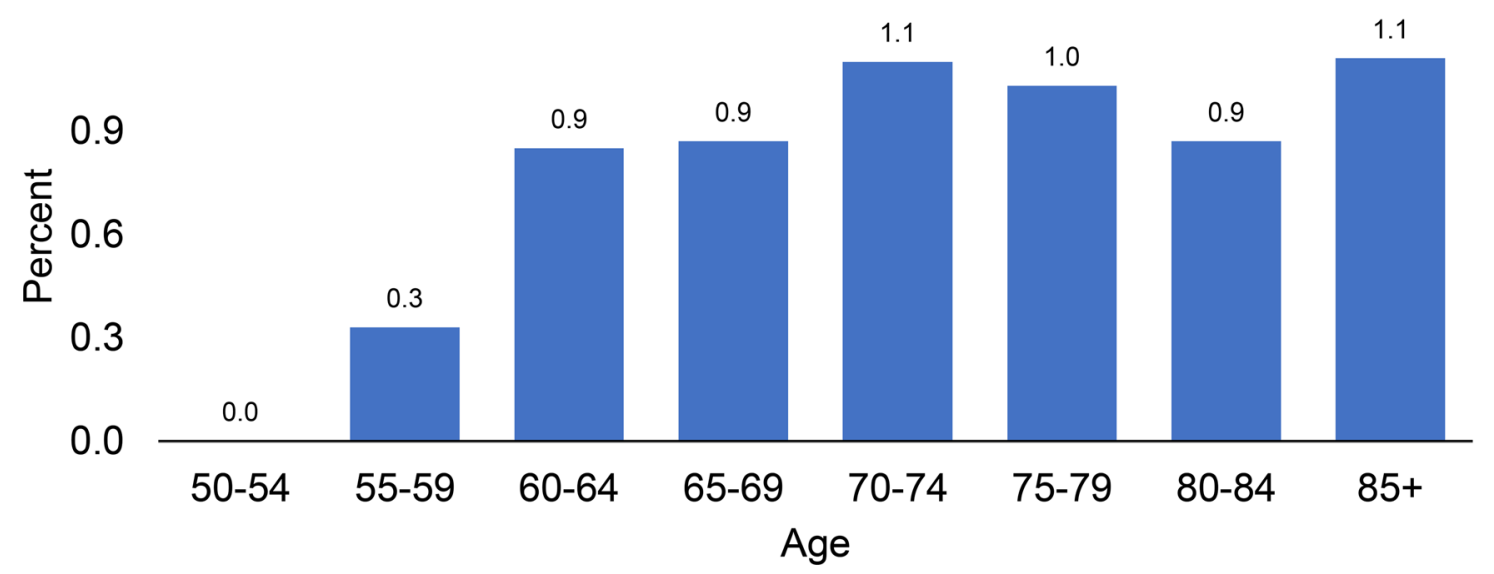

Table 2.5. Prevalence of Hypertension in TILDA and the population of over-50s in Ireland by Age Group

\begin{tabular}{|l|c|c|c|c|c|c|c|c|c|}
\hline Heart Attack by Age & $\mathbf{5 0 - 5 4}$ & $\mathbf{5 5 - 5 9}$ & $\mathbf{6 0 - 6 4}$ & $\mathbf{6 5 - 6 9}$ & $\mathbf{7 0 - 7 4}$ & $\mathbf{7 5 - 7 9}$ & $\mathbf{8 0 - 8 4}$ & $\mathbf{8 5 +}$ & TOTAL \\
\hline $\begin{array}{l}\text { Number Cases in } \\
\text { TILDA }\end{array}$ & 0 & 13 & 35 & 41 & 56 & 55 & 56 & 39 & 295 \\
\hline $\begin{array}{l}\text { Estimated Prevalence } \\
\text { in Population }\end{array}$ & $0.00 \%$ & $0.33 \%$ & $0.85 \%$ & $0.87 \%$ & $1.10 \%$ & $1.03 \%$ & $0.87 \%$ & $1.11 \%$ & $6.16 \%$ \\
\hline $\begin{array}{l}\text { Estimated Number of } \\
\text { Cases in Population }\end{array}$ & 0 & 4,773 & 12,295 & 12,584 & 15,911 & 14,899 & 12,584 & 16,056 & 89,102 \\
\hline
\end{tabular}

Table 2.5 shows the actual numbers of cases in TILDA and the estimated number of people in the population with heart attack. NOTE: The population prevalence is weighted to the population of over-50s in Ireland and so will not correspond to the $\%$ of cases in TILDA. 


\subsubsection{Angina}

Figure 2.6. Percentage prevalence of Angina by Age Group Total Pop Percent $7.27 \%$; Pop Number 105.158

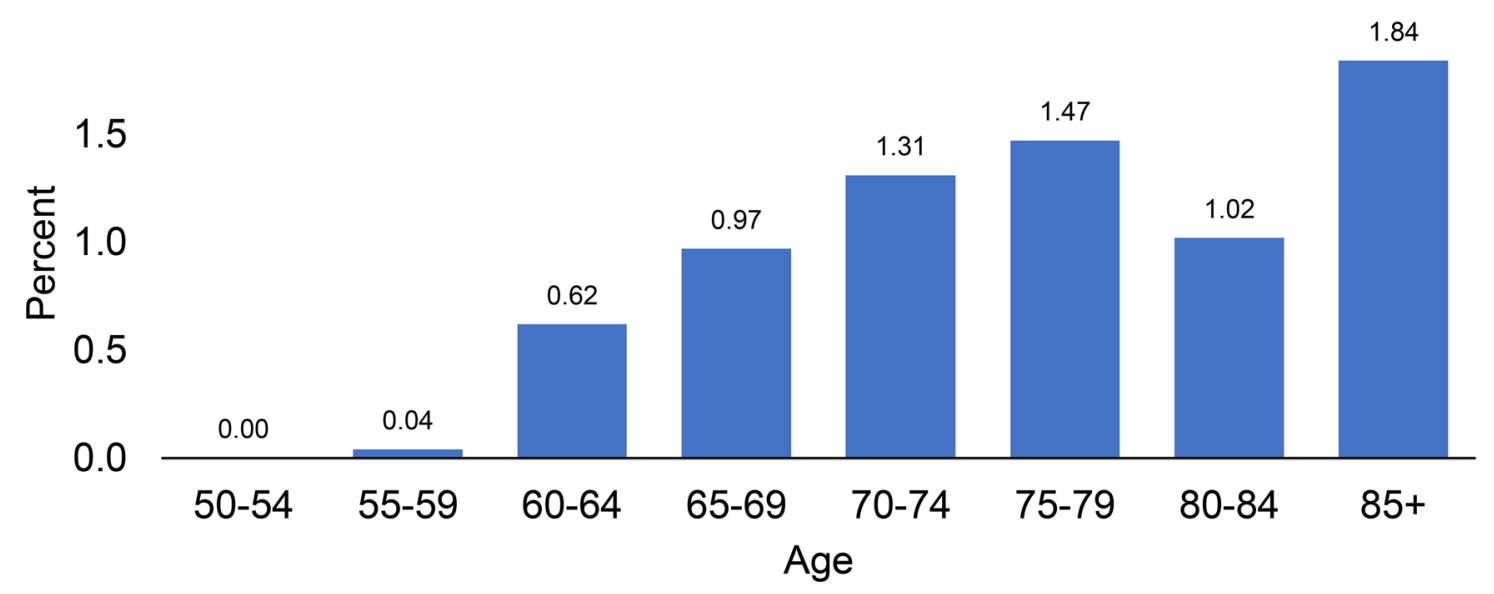

Table 2.6. Prevalence of Angina in TILDA and the population of over-50s in Ireland by Age Group

\begin{tabular}{|l|c|c|c|c|c|c|c|c|c|}
\hline Angina by Age & $\mathbf{5 0 - 5 4}$ & $\mathbf{5 5 - 5 9}$ & $\mathbf{6 0 - 6 4}$ & $\mathbf{6 5 - 6 9}$ & $\mathbf{7 0 - 7 4}$ & $\mathbf{7 5 - 7 9}$ & $\mathbf{8 0 - 8 4}$ & $\mathbf{8 5 +}$ & TOTAL \\
\hline $\begin{array}{l}\text { Number Cases in } \\
\text { TILDA }\end{array}$ & 1 & 4 & 24 & 45 & 64 & 74 & 62 & 63 & 337 \\
\hline $\begin{array}{l}\text { Estimated Prevalence } \\
\text { in Population }\end{array}$ & $0.00 \%$ & $0.04 \%$ & $0.62 \%$ & $0.97 \%$ & $1.31 \%$ & $1.47 \%$ & $1.02 \%$ & $1.84 \%$ & $7.27 \%$ \\
\hline $\begin{array}{l}\text { Estimated Number of } \\
\text { Cases in Population }\end{array}$ & 0 & 579 & 8,968 & 14,031 & 18,949 & 21,263 & 14,754 & 26,615 & 105,158 \\
\hline
\end{tabular}

Table 2.6 shows the actual numbers of cases in TILDA and the estimated number of people in the population with angina. NOTE: The population prevalence is weighted to the population of over-50s in Ireland and so will not correspond to the $\%$ of cases in TILDA 


\subsubsection{Congestive Heart Failure}

Figure 2.7. Percentage prevalence of Congestive Heart Failure by Age Group

Total Pop Percent 1.75\%; Pop Number 25.313

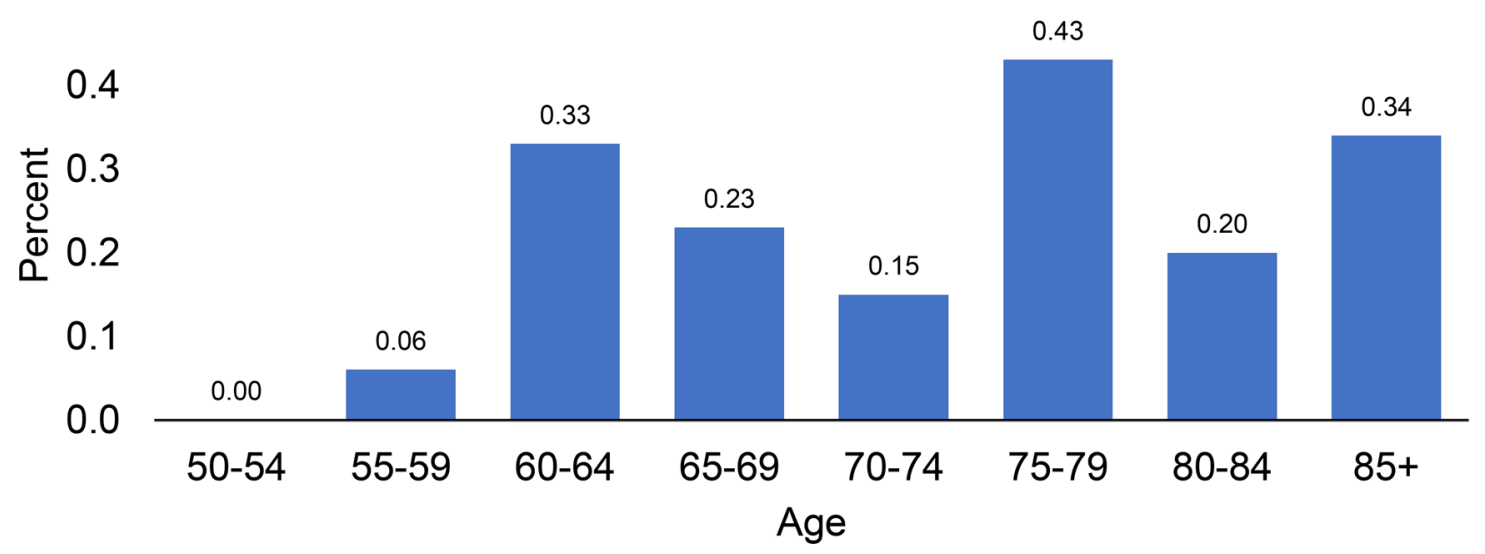

Table 2.7. Prevalence of Congestive Heart Failure in TILDA and the population of over-50s in Ireland by Age Group

\begin{tabular}{|l|c|c|c|c|c|c|c|c|c|}
\hline $\begin{array}{l}\text { Congestive Heart } \\
\text { Failure by Age }\end{array}$ & $\mathbf{5 0 - 5 4}$ & $\mathbf{5 5 - 5 9}$ & $\mathbf{6 0 - 6 4}$ & $\mathbf{6 5 - 6 9}$ & $\mathbf{7 0 - 7 4}$ & $\mathbf{7 5 - 7 9}$ & $\mathbf{8 0 - 8 4}$ & $\mathbf{8 5 +}$ & TOTAL \\
\hline $\begin{array}{l}\text { Number Cases in } \\
\text { TILDA }\end{array}$ & 0 & 3 & 10 & 12 & 13 & 20 & 11 & 14 & 83 \\
\hline $\begin{array}{l}\text { Estimated Prevalence } \\
\text { in Population }\end{array}$ & $0.00 \%$ & $0.06 \%$ & $0.33 \%$ & $0.23 \%$ & $0.15 \%$ & $0.43 \%$ & $0.20 \%$ & $0.34 \%$ & $1.75 \%$ \\
\hline $\begin{array}{l}\text { Estimated Number of } \\
\text { Cases in Population }\end{array}$ & 0 & 853 & 4,773 & 3,327 & 2,170 & 6,220 & 2,893 & 4,918 & 25,313 \\
\hline
\end{tabular}

Table 2.7 shows the actual numbers of cases in TILDA and the estimated number of people in the population with congestive heart failure. NOTE: The population prevalence is weighted to the population of over-50s in Ireland and so will not correspond to the $\%$ of cases in TILDA 


\subsubsection{Diabetes}

Figure 2.8. Percentage prevalence of Diabetes by Age Group

Total Pop Percent 12.64\%; Pop Number 182,833

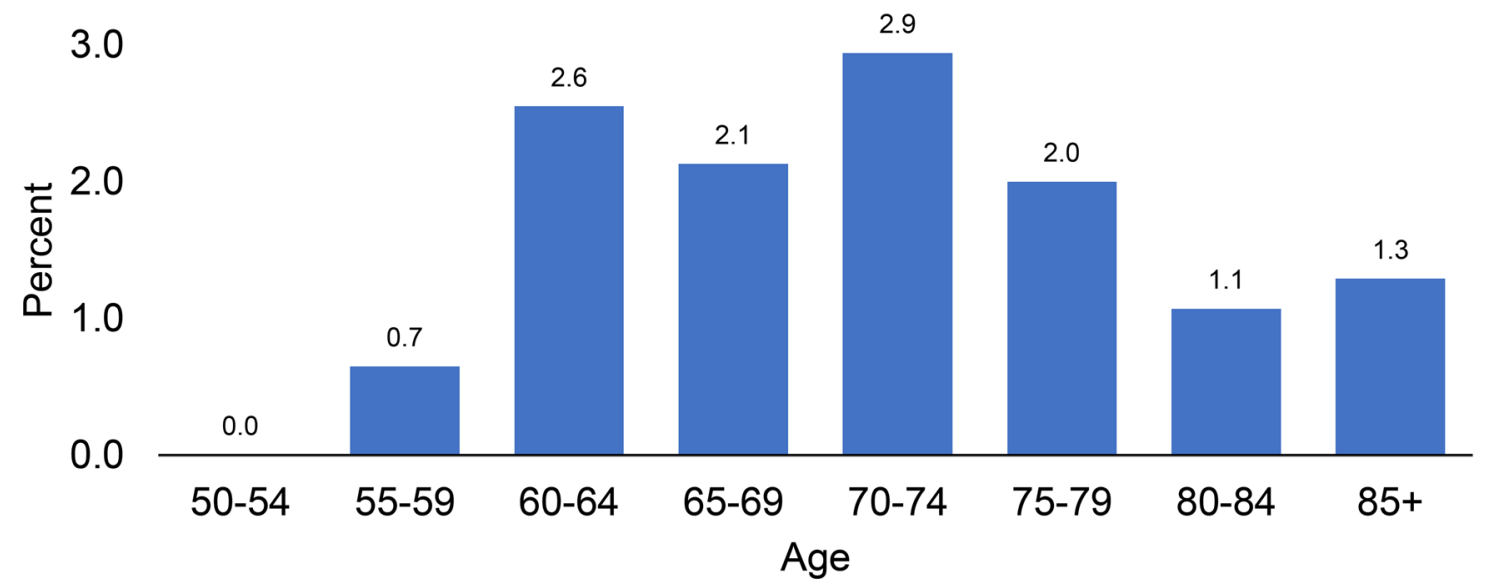

Table 2.8. Prevalence of Diabetes in TILDA and the population of over-50s in Ireland by Age Group

\begin{tabular}{|l|c|c|c|c|c|c|c|c|c|}
\hline Diabetes by Age & $\mathbf{5 0 - 5 4}$ & $\mathbf{5 5 - 5 9}$ & $\mathbf{6 0 - 6 4}$ & $\mathbf{6 5 - 6 9}$ & $\mathbf{7 0 - 7 4}$ & $\mathbf{7 5 - 7 9}$ & $\mathbf{8 0 - 8 4}$ & $\mathbf{8 5 +}$ & TOTAL \\
\hline $\begin{array}{l}\text { Number Cases in } \\
\text { TILDA }\end{array}$ & 4 & 32 & 108 & 102 & 134 & 117 & 64 & 51 & 612 \\
\hline $\begin{array}{l}\text { Estimated Prevalence } \\
\text { in Population }\end{array}$ & $0.00 \%$ & $0.65 \%$ & $2.55 \%$ & $2.13 \%$ & $2.94 \%$ & $2.00 \%$ & $1.07 \%$ & $1.29 \%$ & $12.64 \%$ \\
\hline $\begin{array}{l}\text { Estimated Number of } \\
\text { Cases in Population }\end{array}$ & 0 & 9,402 & 36,885 & 30,810 & 42,526 & 28,929 & 15,477 & 18,659 & 182,833 \\
\hline
\end{tabular}

Table 2.8 shows the actual numbers of cases in TILDA and the estimated number of people in the population with diabetes. NOTE: The population prevalence is weighted to the population of over-50s in Ireland and so will not correspond to the \% of cases in TILDA 


\subsubsection{Stroke}

Figure 2.9. Percentage prevalence of Stroke by Age Group

Total Pop Percent 2.45\%; Pop Number 35,438

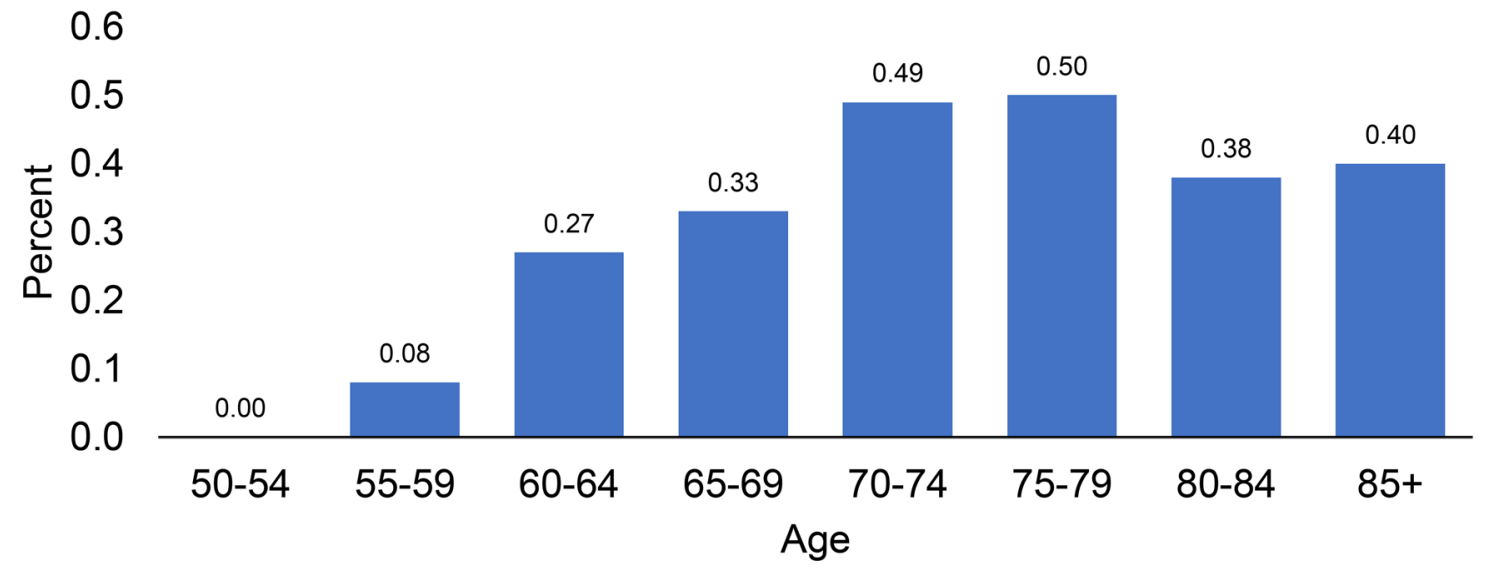

Table 2.9. Prevalence of Stroke in TILDA and the population of over-50s in Ireland by Age Group

\begin{tabular}{|c|c|c|c|c|c|c|c|c|c|}
\hline $\begin{array}{l}\text { Stroke (cerebral } \\
\text { vascular disease) } \\
\text { by Age }\end{array}$ & $50-54$ & $55-59$ & $60-64$ & $65-69$ & $70-74$ & $75-79$ & $80-84$ & $85+$ & TOTAL \\
\hline $\begin{array}{l}\text { Number Cases in } \\
\text { TILDA }\end{array}$ & 0 & 5 & 12 & 18 & 27 & 33 & 26 & 22 & 143 \\
\hline $\begin{array}{l}\text { Estimated Prevalence } \\
\text { in Population }\end{array}$ & $0.00 \%$ & $0.08 \%$ & $0.27 \%$ & $0.33 \%$ & $0.49 \%$ & $0.50 \%$ & $0.38 \%$ & $0.40 \%$ & $2.45 \%$ \\
\hline $\begin{array}{l}\text { Estimated Number of } \\
\text { Cases in Population }\end{array}$ & 0 & 1,157 & 3,905 & 4,773 & 7,088 & 7,232 & 5,497 & 5,786 & 35,438 \\
\hline
\end{tabular}

Table 2.9 shows the actual numbers of cases in TILDA and the estimated number of people in the population with stroke. NOTE: The population prevalence is weighted to the population of over-50s in Ireland and so will not correspond to the $\%$ of cases in TILDA. 


\subsubsection{Ministroke/TIA}

Figure 2.10. Percentage prevalence of Ministroke/TIA by Age Group

Total Pop Percent 4.66\%; Pop Number 67,405

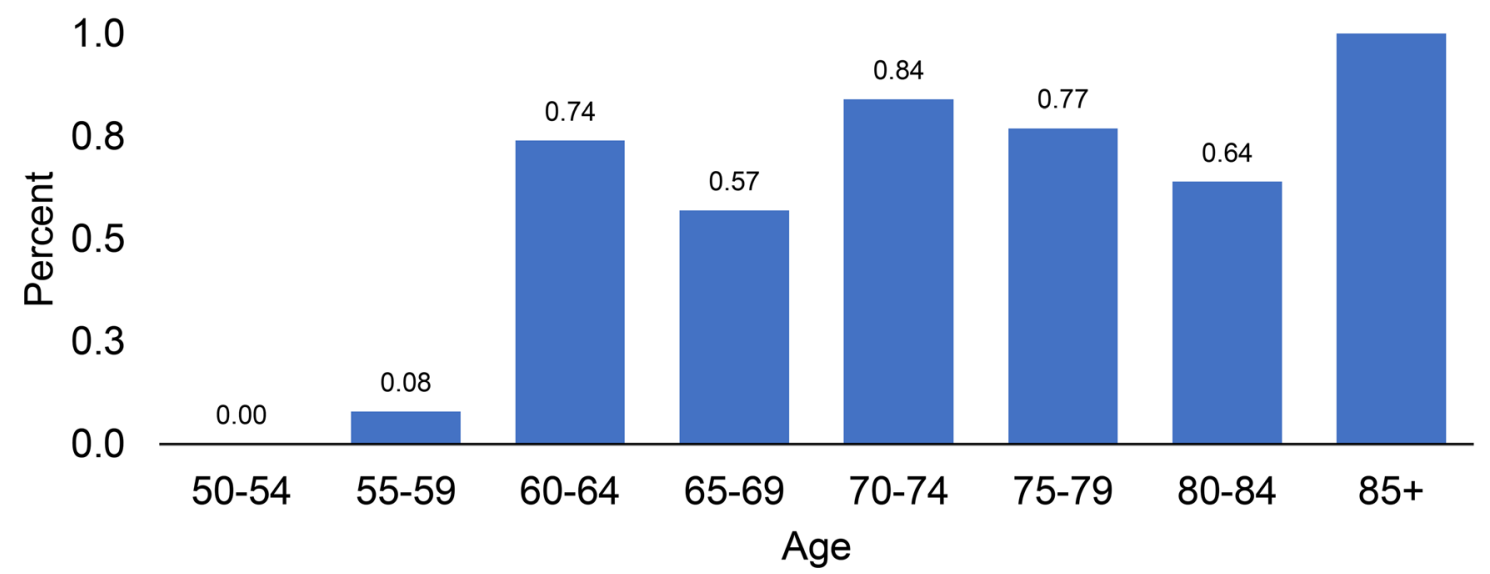

Table 2.10. Prevalence of Ministroke/TIA in TILDA and the population of over-50s in Ireland by Age Group

\begin{tabular}{|l|c|c|c|c|c|c|c|c|c|}
\hline Stroke by Age & $\mathbf{5 0 - 5 4}$ & $\mathbf{5 5 - 5 9}$ & $\mathbf{6 0 - 6 4}$ & $\mathbf{6 5 - 6 9}$ & $\mathbf{7 0 - 7 4}$ & $\mathbf{7 5 - 7 9}$ & $\mathbf{8 0 - 8 4}$ & $\mathbf{8 5 +}$ & TOTAL \\
\hline $\begin{array}{l}\text { Number Cases in } \\
\text { TILDA }\end{array}$ & 0 & 7 & 29 & 29 & 42 & 49 & 39 & 47 & 242 \\
\hline $\begin{array}{l}\text { Estimated Prevalence } \\
\text { in Population }\end{array}$ & $0.00 \%$ & $0.08 \%$ & $0.74 \%$ & $0.57 \%$ & $0.84 \%$ & $0.77 \%$ & $0.64 \%$ & $1.02 \%$ & $4.66 \%$ \\
\hline $\begin{array}{l}\text { Estimated Number of } \\
\text { Cases in Population }\end{array}$ & 0 & 1,157 & 10,704 & 8,245 & 12,150 & 11,138 & 9,257 & 14,754 & 67,405 \\
\hline
\end{tabular}

Table 2.10 shows the actual numbers of cases in TILDA and the estimated number of people in the population with mini stroke/TIA. NOTE: The population prevalence is weighted to the population of over-50s in Ireland and so will not correspond to the \% of cases in TILDA 


\subsubsection{High Cholesterol}

Figure 2.11. Percentage prevalence of High Cholesterol by Age Group Total Pop Percent 58.5\%; Pop Number 846,179

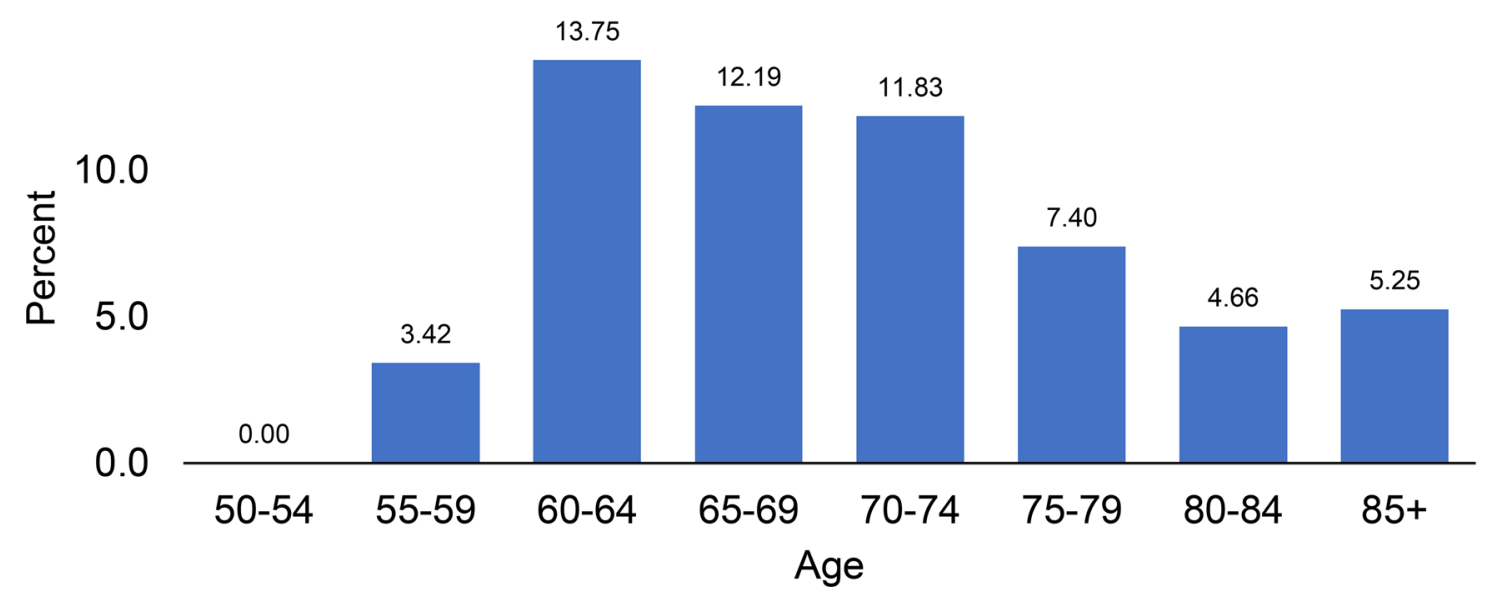

Table 2.11. Prevalence of High Cholesterol in TILDA and the population of over-50s in Ireland by Age Group

\begin{tabular}{|l|c|c|c|c|c|c|c|c|c|}
\hline $\begin{array}{l}\text { High Cholesterol } \\
\text { by Age }\end{array}$ & $\mathbf{5 0 - 5 4}$ & $\mathbf{5 5 - 5 9}$ & $\mathbf{6 0 - 6 4}$ & $\mathbf{6 5 - 6 9}$ & $\mathbf{7 0 - 7 4}$ & $\mathbf{7 5 - 7 9}$ & $\mathbf{8 0 - 8 4}$ & $\mathbf{8 5 +}$ & TOTAL \\
\hline $\begin{array}{l}\text { Number Cases in } \\
\text { TILDA }\end{array}$ & 29 & 241 & 642 & 619 & 607 & 419 & 273 & 207 & 3,037 \\
\hline $\begin{array}{l}\text { Estimated } \\
\begin{array}{l}\text { Prevalence in } \\
\text { Population }\end{array}\end{array}$ & $0.00 \%$ & $3.42 \%$ & $13.75 \%$ & $12.19 \%$ & $11.83 \%$ & $7.40 \%$ & $4.66 \%$ & $5.25 \%$ & $58.50 \%$ \\
\hline $\begin{array}{l}\text { Estimated Number } \\
\text { of Cases in } \\
\text { Population }\end{array}$ & 0 & 49,469 & 198,888 & 176,323 & 171,116 & 107,038 & 67,405 & 75,939 & 846,179 \\
\hline
\end{tabular}

Table 2.11 shows the actual numbers of cases in TILDA and the estimated number of people in the population with high cholesterol. NOTE: The population prevalence is weighted to the population of over-50s in Ireland and so will not correspond to the $\%$ of cases in TILDA 


\subsubsection{Arthritis}

Figure 2.12. Percentage prevalence of Arthritis by Age Group

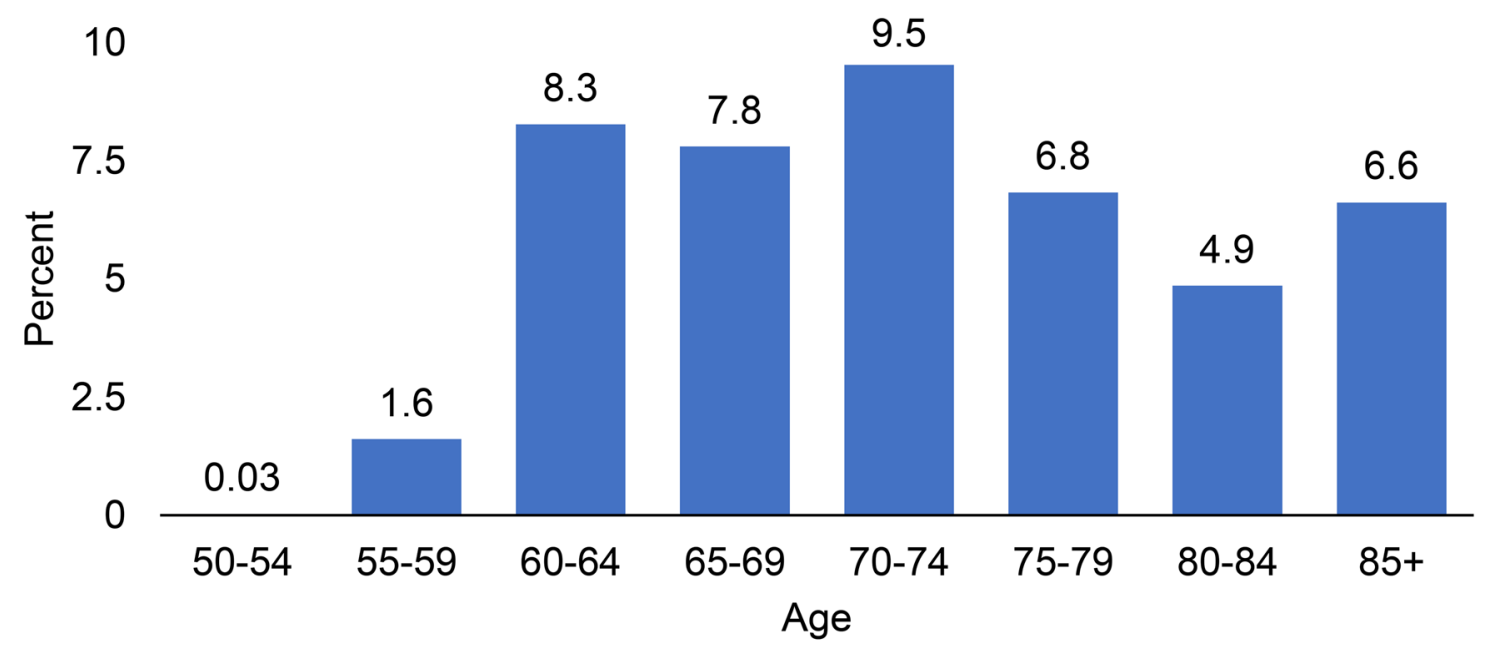

Table 2.12. Prevalence of Arthritis in TILDA and the population of over-50s in Ireland by Age Group

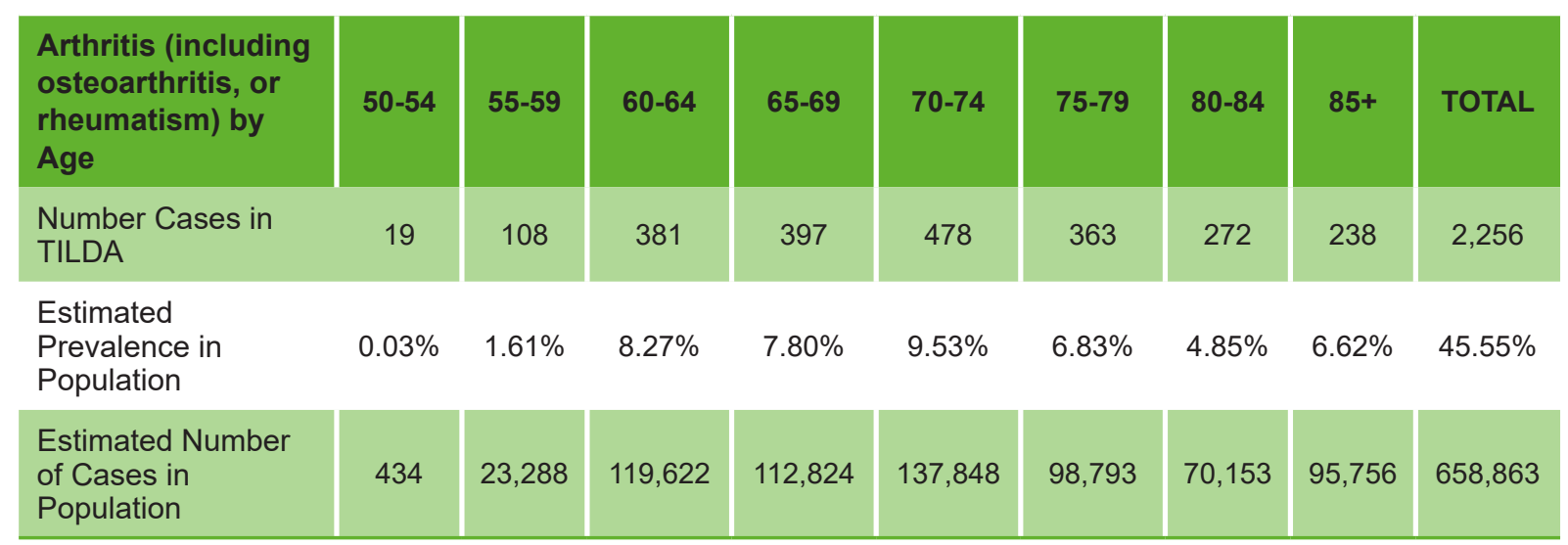

Table 2.12 shows the actual numbers of cases in TILDA and the estimated number of people in the population with arthritis. NOTE: The population prevalence is weighted to the population of over-50s in Ireland and so will not correspond to the $\%$ of cases in TILDA 


\subsubsection{Osteoporosis}

Figure 2.13. Percentage prevalence of Osteoporosis by Age Group Total Pop Percent 22.27\%; Pop Number 322,127

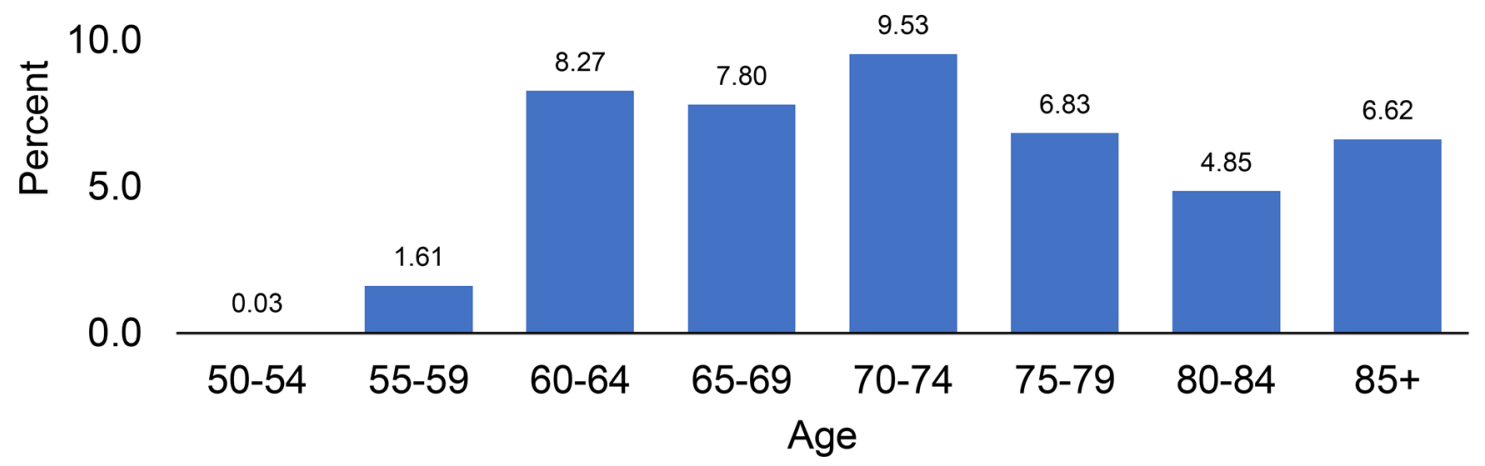

Table 2.13. Prevalence of Osteoporosis in TILDA and the population of over-50s in Ireland by Age Group

\begin{tabular}{|l|c|c|c|c|c|c|c|c|c|}
\hline $\begin{array}{l}\text { Osteoporosis by } \\
\text { Age }\end{array}$ & $\mathbf{5 0 - 5 4}$ & $\mathbf{5 5 - 5 9}$ & $\mathbf{6 0 - 6 4}$ & $\mathbf{6 5 - 6 9}$ & $\mathbf{7 0 - 7 4}$ & $\mathbf{7 5 - 7 9}$ & $\mathbf{8 0 - 8 4}$ & $\mathbf{8 5 +}$ & TOTAL \\
\hline $\begin{array}{l}\text { Number Cases in } \\
\text { TILDA }\end{array}$ & 3 & 58 & 193 & 222 & 237 & 196 & 118 & 121 & 1,148 \\
\hline $\begin{array}{l}\text { Estimated Prevalence } \\
\text { in Population }\end{array}$ & $0.03 \%$ & $0.64 \%$ & $3.94 \%$ & $4.20 \%$ & $4.37 \%$ & $3.51 \%$ & $2.22 \%$ & $3.36 \%$ & $22.27 \%$ \\
\hline $\begin{array}{l}\text { Estimated Number of } \\
\text { Cases in Population }\end{array}$ & 434 & 9,257 & 56,991 & 60,751 & 63,210 & 50,771 & 32,111 & 48,601 & 322,127 \\
\hline
\end{tabular}

Table 2.13 shows the actual numbers of cases in TILDA and the estimated number of people in the population with osteoporosis. NOTE: The population prevalence is weighted to the population of over-50s in Ireland and so will not correspond to the $\%$ of cases in TILDA. 


\subsubsection{Cancer or Malignant Tumour}

Figure 2.14. Percentage prevalence of Cancer or Malignant Tumour by Age Group Total Pop Percent 11.58\%; Pop Number 167,500

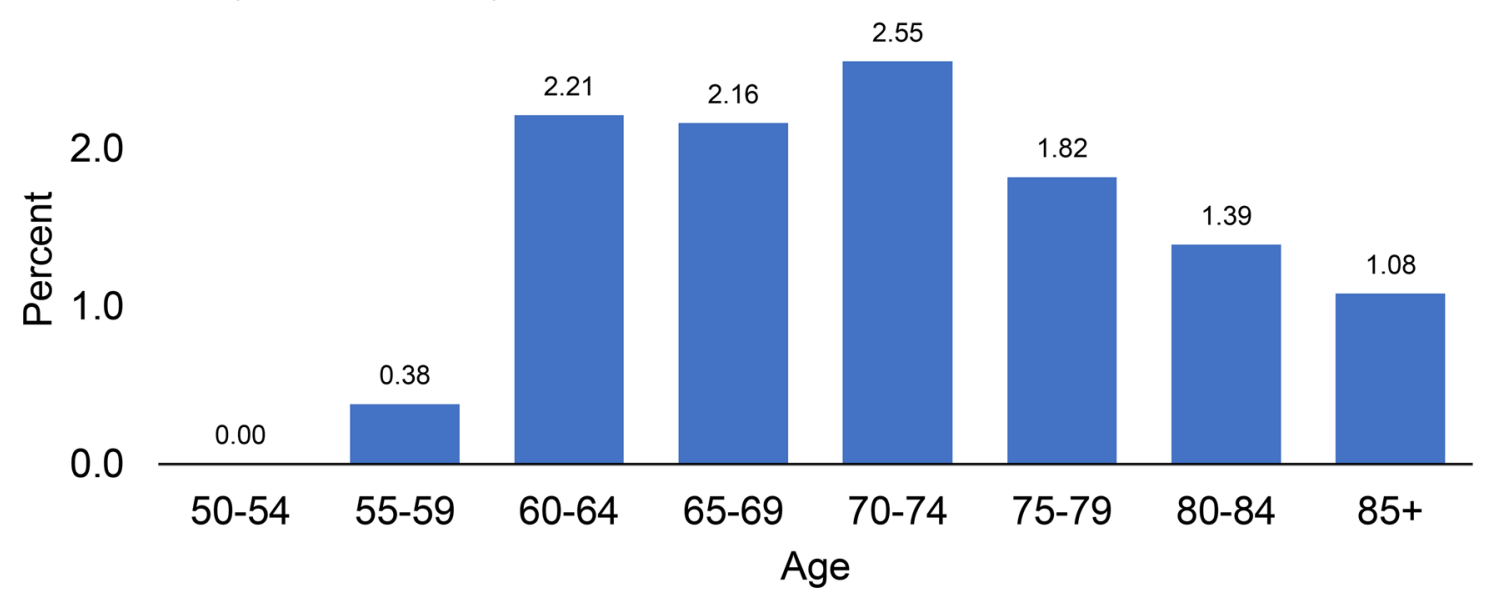

Table 2.14. Prevalence of Cancer or Malignant Tumour in TILDA and the population of over-50s in Ireland by Age Group

\begin{tabular}{|l|c|c|c|c|c|c|c|c|c|}
\hline $\begin{array}{l}\text { Cancer or Malignant } \\
\text { Tumour by Age }\end{array}$ & $\mathbf{5 0 - 5 4}$ & $\mathbf{5 5 - 5 9}$ & $\mathbf{6 0 - 6 4}$ & $\mathbf{6 5 - 6 9}$ & $\mathbf{7 0 - 7 4}$ & $\mathbf{7 5 - 7 9}$ & $\mathbf{8 0 - 8 4}$ & $\mathbf{8 5 +}$ & TOTAL \\
\hline $\begin{array}{l}\text { Number Cases in } \\
\text { TILDA }\end{array}$ & 2 & 33 & 105 & 109 & 134 & 107 & 81 & 41 & 612 \\
\hline $\begin{array}{l}\text { Estimated Prevalence } \\
\text { in Population }\end{array}$ & $0.0 \%$ & $0.38 \%$ & $2.21 \%$ & $2.16 \%$ & $2.55 \%$ & $1.82 \%$ & $1.39 \%$ & $1.08 \%$ & $11.58 \%$ \\
\hline $\begin{array}{l}\text { Estimated Number of } \\
\text { Cases in Population }\end{array}$ & 0 & 5,497 & 31,967 & 31,244 & 36,885 & 26,326 & 20,106 & 15,622 & 167,500 \\
\hline
\end{tabular}

Table 2.14 shows the actual numbers of cases in TILDA and the estimated number of people in the population with cancer or malignant tumour. NOTE: The population prevalence is weighted to the population of over-50s in Ireland and so will not correspond to the \% of cases in TILDA. 


\subsubsection{Varicose Ulcers}

Figure 2.15. Percentage prevalence of Varicose Ulcers by Age Group Total Pop Percent 4.75\%; Pop Number 68,707

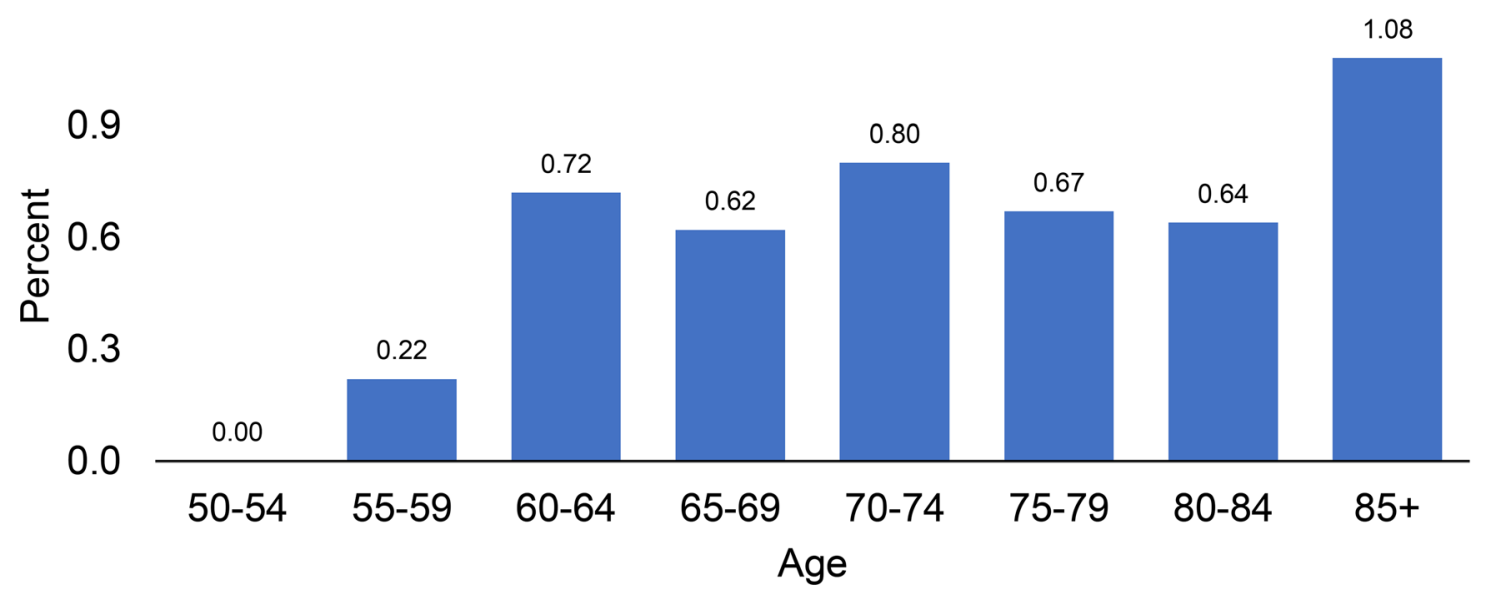

Table 2.15. Prevalence of Varicose Ulcers in TILDA and the population of over-50s in Ireland by Age Group

\begin{tabular}{l|c|c|c|c|c|c|c|c|c|}
\hline $\begin{array}{l}\text { Varicose Ulcers by } \\
\text { Age }\end{array}$ & $\mathbf{5 0 - 5 4}$ & $\mathbf{5 5 - 5 9}$ & $\mathbf{6 0 - 6 4}$ & $\mathbf{6 5 - 6 9}$ & $\mathbf{7 0 - 7 4}$ & $\mathbf{7 5 - 7 9}$ & $\mathbf{8 0 - 8 4}$ & $\mathbf{8 5 +}$ & TOTAL \\
\hline $\begin{array}{l}\text { Number Cases in } \\
\text { TILDA }\end{array}$ & 1 & 12 & 30 & 33 & 36 & 40 & 37 & 37 & 226 \\
\hline $\begin{array}{l}\text { Estimated Prevalence } \\
\text { in Population }\end{array}$ & $0.00 \%$ & $0.22 \%$ & $0.72 \%$ & $0.62 \%$ & $0.80 \%$ & $0.67 \%$ & $0.64 \%$ & $1.08 \%$ & $4.75 \%$ \\
\hline $\begin{array}{l}\text { Estimated Number of } \\
\text { Cases in Population }\end{array}$ & 0 & 3,182 & 10,415 & 8,968 & 11,572 & 9,691 & 9,257 & 15,622 & 68,707 \\
\hline
\end{tabular}

Table 2.15 shows the actual numbers of cases in TILDA and the estimated number of people in the population with varicose ulcers. NOTE: The population prevalence is weighted to the population of over-50s in Ireland and so will not correspond to the \% of cases in TILDA. 


\subsubsection{Cirrhosis, or serious Liver Damage}

Figure 2.16. Percentage prevalence of Cirrhosis, or serious liver damage by Age Group Total Pop Percent 1.4\%; Pop Number 20,250

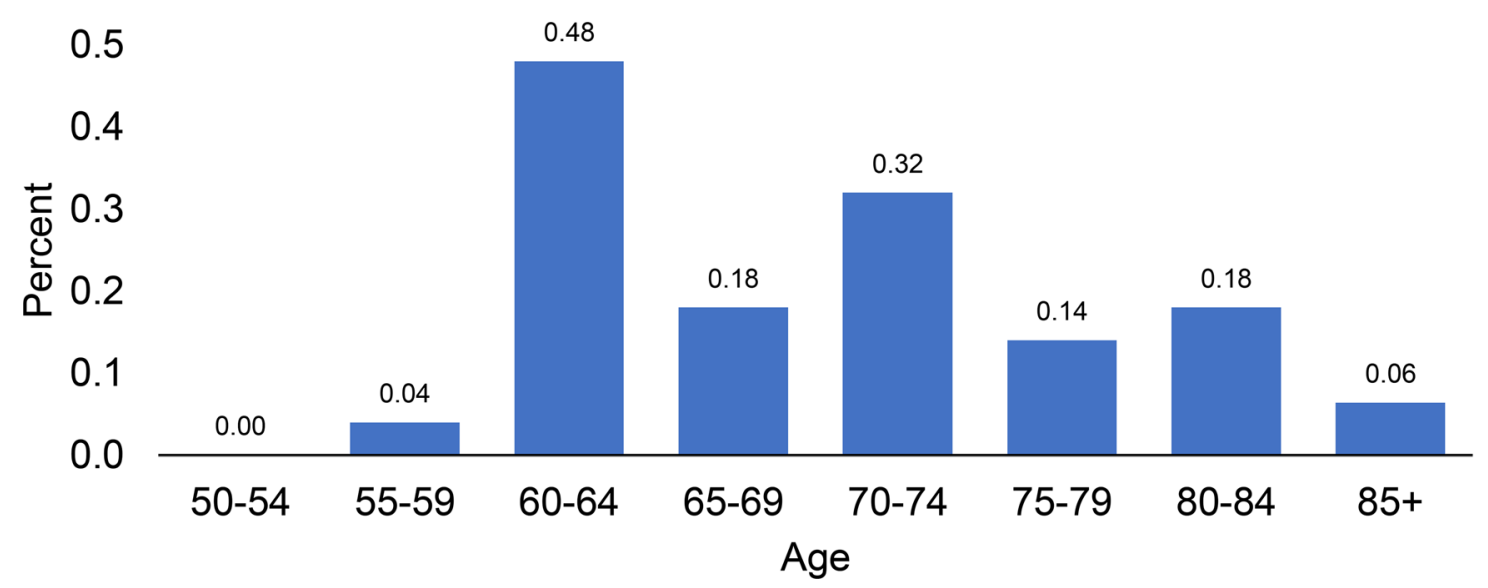

Table 2.16. Prevalence of Cirrhosis, or serious liver damage in TILDA and the population of over-50s in Ireland by Age Group

\begin{tabular}{l|c|c|c|c|c|c|c|c|c|}
\hline $\begin{array}{l}\text { Varicose Ulcers by } \\
\text { Age }\end{array}$ & $\mathbf{5 0 - 5 4}$ & $\mathbf{5 5 - 5 9}$ & $\mathbf{6 0 - 6 4}$ & $\mathbf{6 5 - 6 9}$ & $\mathbf{7 0 - 7 4}$ & $\mathbf{7 5 - 7 9}$ & $\mathbf{8 0 - 8 4}$ & $\mathbf{8 5 +}$ & TOTAL \\
\hline $\begin{array}{l}\text { Number Cases in } \\
\text { TILDA }\end{array}$ & 0 & 4 & 15 & 10 & 13 & 8 & 8 & 1 & 59 \\
\hline $\begin{array}{l}\text { Estimated Prevalence } \\
\text { in Population }\end{array}$ & $0.00 \%$ & $0.04 \%$ & $0.48 \%$ & $0.18 \%$ & $0.32 \%$ & $0.14 \%$ & $0.18 \%$ & $0.064 \%$ & $1.40 \%$ \\
\hline $\begin{array}{l}\text { Estimated Number of } \\
\text { Cases in Population }\end{array}$ & 0 & 579 & 6,943 & 2,604 & 4,629 & 2,025 & 2,604 & 868 & 20,250 \\
\hline
\end{tabular}

Table 2.16 shows the actual numbers of cases in TILDA and the estimated number of people in the population with cirrhosis, or serious liver damage. NOTE: The population prevalence is weighted to the population of over-50s in Ireland and so will not correspond to the \% of cases in TILDA. 


\subsubsection{Thyroid Problems}

Figure 2.17. Percentage prevalence of Thyroid Problems by Age Group Total Pop Percent 11.11\%; Pop Number 160,702

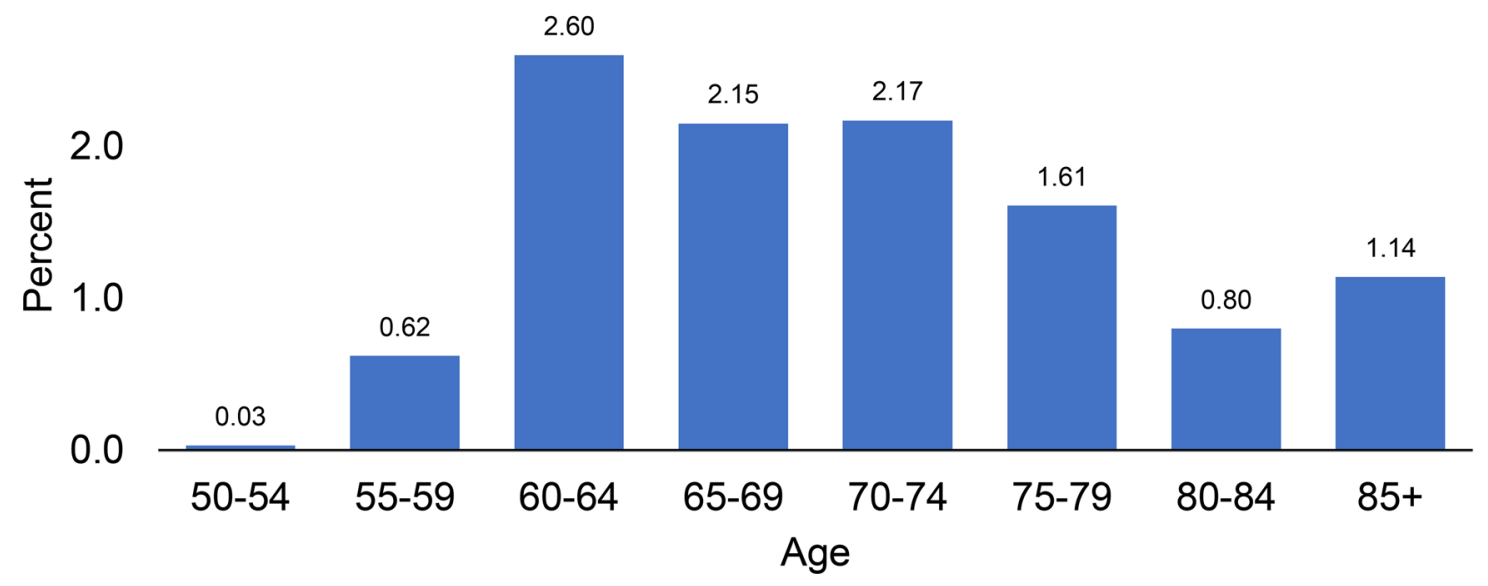

Table 2.17. Prevalence of Thyroid Problems in TILDA and the population of over-50s in Ireland by Age Group

\begin{tabular}{|c|c|c|c|c|c|c|c|c|c|}
\hline $\begin{array}{l}\text { Varicose Ulcers by } \\
\text { Age }\end{array}$ & $50-54$ & $55-59$ & $60-64$ & $65-69$ & $70-74$ & 75-79 & $80-84$ & $85+$ & TOTAL \\
\hline $\begin{array}{l}\text { Number Cases in } \\
\text { TILDA }\end{array}$ & 6 & 52 & 135 & 111 & 112 & 86 & 47 & 43 & 592 \\
\hline $\begin{array}{l}\text { Estimated Prevalence } \\
\text { in Population }\end{array}$ & $0.03 \%$ & $0.62 \%$ & $2.60 \%$ & $2.15 \%$ & $2.17 \%$ & $1.61 \%$ & $0.80 \%$ & $1.14 \%$ & $11.11 \%$ \\
\hline $\begin{array}{l}\text { Estimated Number of } \\
\text { Cases in Population }\end{array}$ & 434 & 8,968 & 37,608 & 31,099 & 31,388 & 23,288 & 11,572 & 16,490 & 160,702 \\
\hline
\end{tabular}

Table 2.17 shows the actual numbers of cases in TILDA and the estimated number of people in the population with thyroid problems. NOTE: The population prevalence is weighted to the population of over-50s in Ireland and so will not correspond to the $\%$ of cases in TILDA. 


\subsection{Comorbidities}

Figure 2.18 shows the percent in the over-50s population in Ireland (to the nearest 100) with co-occurring medical conditions. For example, $7.86 \%$ of the population $(113,692$ people; Table 2.18) are estimated to have none of the 16 reported medical conditions, whereas $18.46 \%$ (267,017 people; Table 2.18$)$ have only one condition. $24.79 \%(358,577$ people; Table 2.18 ) have exactly two of the 16 listed medical conditions etc.

Figure 2.18 Percentage prevalence of coexisting comorbidities in the over-50's population

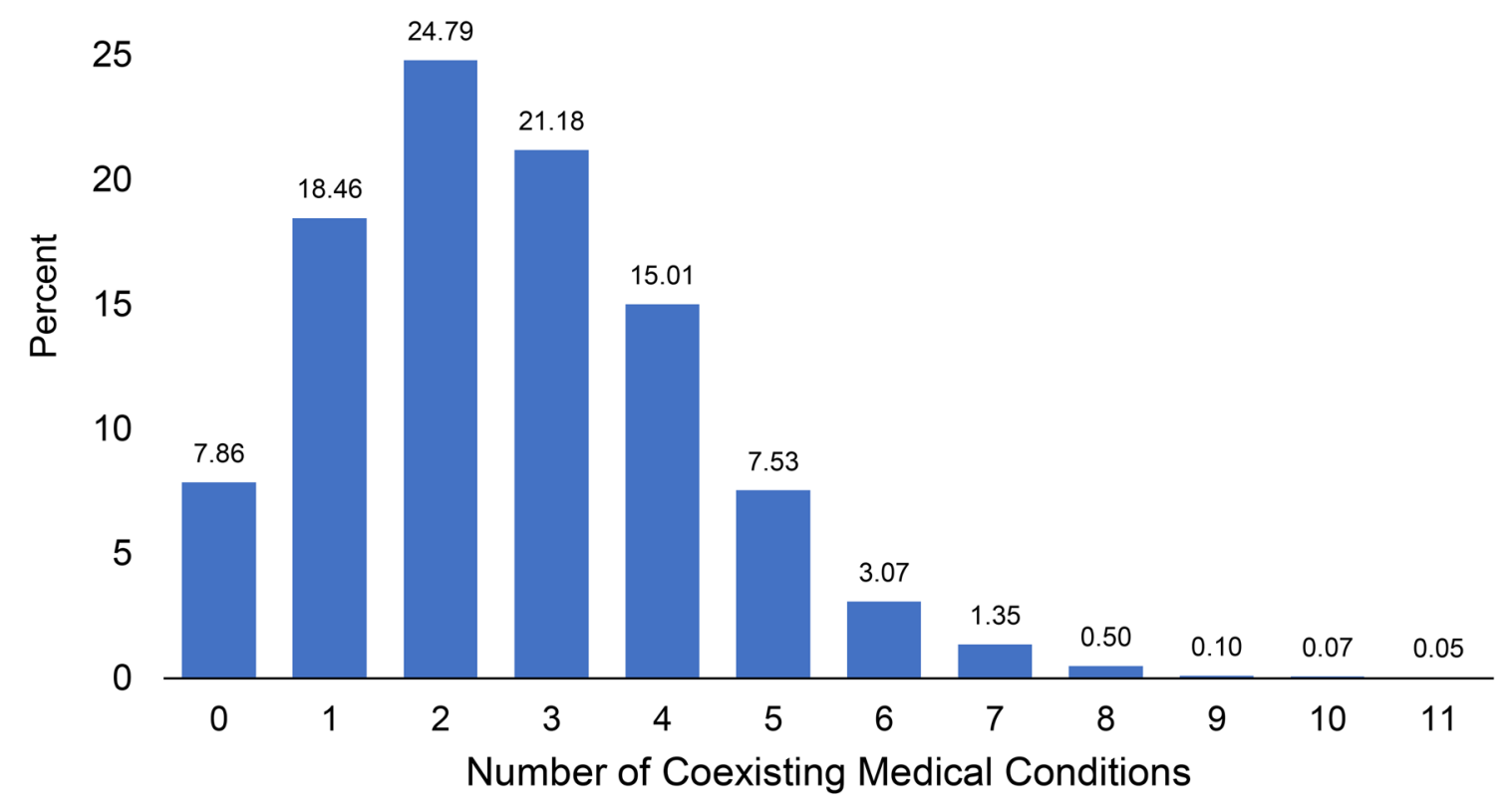


Table 2.18. Prevalence of coexisting comorbidities in TILDA and the population of over-50s in Ireland

\begin{tabular}{|l|c|c|c|}
\hline Medical Condition & Number in & $\begin{array}{c}\text { Population } \\
\text { PILDA }\end{array}$ & $\begin{array}{c}\text { Estimated } \\
\text { Number in } \\
\text { Population }\end{array}$ \\
\hline 0 & 475 & $7.86 \%$ & 113,692 \\
\hline 1 & 1,009 & $18.46 \%$ & 267,017 \\
\hline 2 & 1,290 & $24.79 \%$ & 358,577 \\
\hline 3 & 1,061 & $21.18 \%$ & 306,360 \\
\hline 4 & 742 & $15.01 \%$ & 217,114 \\
\hline 5 & 378 & $7.53 \%$ & 108,918 \\
\hline 6 & 151 & $3.07 \%$ & 44,406 \\
\hline 7 & 62 & $1.35 \%$ & 19,527 \\
\hline 8 & 29 & $0.50 \%$ & 7,232 \\
\hline 9 & 4 & $0.10 \%$ & 1,403 \\
\hline 10 & 3 & $0.07 \%$ & 984 \\
\hline
\end{tabular}

Table 2.18 shows the actual numbers of cases in TILDA and the estimated number of people in the population with coexisting comorbidities. NOTE: The population prevalence is weighted to the population of over-50s in Ireland and so will not correspond to the \% of cases in TILDA.

Table 2.19 shows the most common combinations of comorbidities in the population of over-50s in Ireland (to nearest 100). As there are so many different combinations, this table has been limited to the 39 comorbidities occurring in more than $2 \%$ of the population. So $33.1 \%$ of over-50s in Ireland or 478,778 people are estimated to have both hypertension and high cholesterol etc.

As we are only looking at occurrence of two conditions here, there may be double counting across comorbidities i.e. some of the $28.2 \%$ who have hypertension and arthritis may also be part of the $33.1 \%$ who have hypertension and high cholesterol. Therefore, there may be another set of people within these figures who have hypertension, high cholesterol and arthritis together.

If required, more detailed information is available on request for combinations of $3,4,5+$ cooccurring diseases. 
Table 2.19. Prevalence of common comorbidities in TILDA and the population of over-50s in Ireland

\begin{tabular}{|c|c|c|c|c|}
\hline Condition1 & Condition2 & $\begin{array}{c}\text { Number in } \\
\text { TILDA }\end{array}$ & $\begin{array}{l}\text { Population } \\
\text { Prevalence }\end{array}$ & $\begin{array}{l}\text { Estimated } \\
\text { Number in } \\
\text { Population }\end{array}$ \\
\hline Chronic lung disease & Asthma & 154 & $3.0 \%$ & 43,683 \\
\hline Asthma & Arthritis & 358 & $7.5 \%$ & 108,774 \\
\hline Asthma & High Cholesterol & 390 & $7.4 \%$ & 106,749 \\
\hline Asthma & Hypertension & 355 & $7.0 \%$ & 100,529 \\
\hline Chronic lung disease & High Cholesterol & 249 & $5.3 \%$ & 76,662 \\
\hline Chronic lung disease & Arthritis & 237 & $5.0 \%$ & 71,744 \\
\hline Asthma & Osteoporosis & 194 & $4.0 \%$ & 57,858 \\
\hline Chronic lung disease & Hypertension & 239 & $4.9 \%$ & 71,455 \\
\hline Angina & High Cholesterol & 254 & $5.4 \%$ & 77,530 \\
\hline High Cholesterol & Arthritis & 1,429 & $28.2 \%$ & 408,480 \\
\hline Hypertension & Arthritis & 1,263 & $26.1 \%$ & 377,960 \\
\hline High Cholesterol & Osteoporosis & 731 & $14.1 \%$ & 203,228 \\
\hline Arthritis & Osteoporosis & 641 & $12.8 \%$ & 185,436 \\
\hline Hypertension & Osteoporosis & 563 & $11.2 \%$ & 162,293 \\
\hline Hypertension & Diabetes & 449 & $9.5 \%$ & 136,690 \\
\hline Diabetes & High Cholesterol & 408 & $8.4 \%$ & 121,792 \\
\hline High Cholesterol & Thyroid Problems & 408 & $7.4 \%$ & 107,617 \\
\hline High Cholesterol & Cancer & 375 & $7.0 \%$ & 100,674 \\
\hline Hypertension & Cancer & 335 & $6.6 \%$ & 95,900 \\
\hline Diabetes & Arthritis & 313 & $6.6 \%$ & 95,756 \\
\hline Hypertension & Thyroid Problems & 315 & $6.3 \%$ & 91,272 \\
\hline Arthritis & Thyroid Problems & 309 & $6.0 \%$ & 87,077 \\
\hline Arthritis & Cancer & 280 & $5.6 \%$ & 81,580 \\
\hline Hypertension & Angina & 246 & $5.4 \%$ & 78,253 \\
\hline Angina & Arthritis & 205 & $4.5 \%$ & 65,235 \\
\hline Heart Attack & High Cholesterol & 216 & $4.5 \%$ & 64,657 \\
\hline Hypertension & Heart Attack & 196 & $4.1 \%$ & 59,016 \\
\hline Heart Attack & Arthritis & 157 & $3.4 \%$ & 48,601 \\
\hline Osteoporosis & Thyroid Problems & 182 & $3.3 \%$ & 48,312 \\
\hline
\end{tabular}




\begin{tabular}{|l|l|l|l|l|}
\hline \multicolumn{1}{|c|}{ Condition1 } & \multicolumn{1}{c|}{ Condition2 } & $\begin{array}{c}\text { Number in } \\
\text { TILDA }\end{array}$ & $\begin{array}{c}\text { Population } \\
\text { Prevalence }\end{array}$ & $\begin{array}{c}\text { Estimated } \\
\text { Number in } \\
\text { Population }\end{array}$ \\
\hline Arthritis & Varicose Ulcer & 141 & $3.1 \%$ & 45,419 \\
\hline Hypertension & Mini stroke/TIA & 168 & $3.1 \%$ & 44,696 \\
\hline Osteoporosis & Cancer & 150 & $3.0 \%$ & 42,815 \\
\hline Mini stroke/TIA & High Cholesterol & 150 & $2.9 \%$ & 41,513 \\
\hline Hypertension & Varicose Ulcer & 133 & $2.8 \%$ & 41,079 \\
\hline Chronic lung disease & Osteoporosis & 128 & $2.8 \%$ & 40,356 \\
\hline Mini stroke/TIA & Arthritis & 139 & $2.8 \%$ & 39,778 \\
\hline High Cholesterol & Varicose Ulcer & 132 & $2.7 \%$ & 38,765 \\
\hline Angina & Heart Attack & 111 & $2.3 \%$ & 32,690 \\
\hline
\end{tabular}

Table 2.19 shows the actual numbers of cases in TILDA and the estimated number of people in the population with the most common coexisting comorbidities. NOTE: The population prevalence is weighted to the population of over-50s in Ireland and so will not correspond to the $\%$ of cases in TILDA.

Figure 2.19 shows the percentage of each age group by number of medical conditions in the population of over-50s in Ireland. It depicts the percent of each age bracket with a given number of diseases. For example, $18.51 \%$ of those aged $55-59$ have none of the 16 medical conditions, $29.13 \%$ of those aged $55-59$ have 1 medical condition etc. The corresponding numbers of morbidities for each age bracket are presented in Table 2.20. 


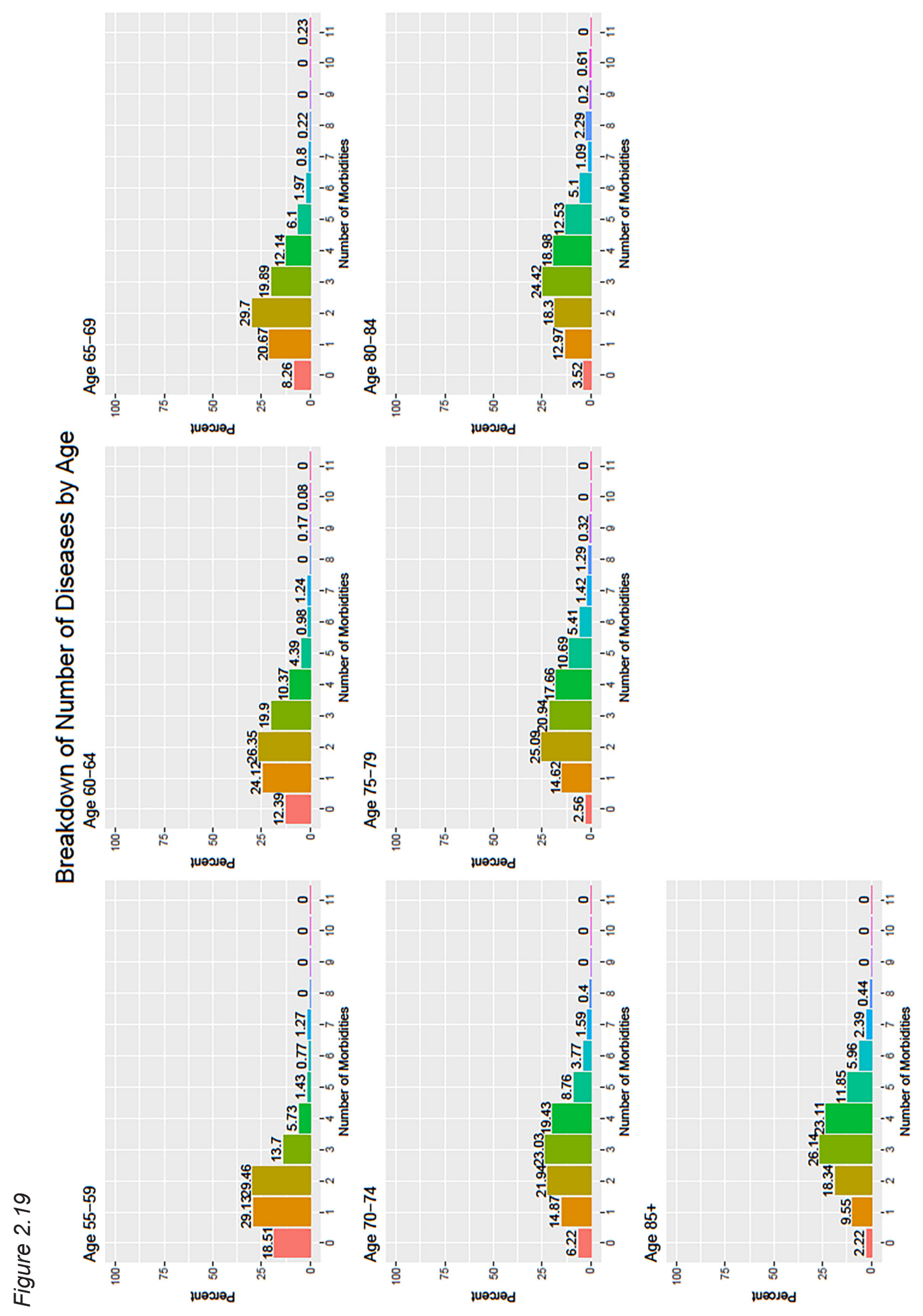


Table 2.20. The numbers of morbidities in the population of over-50s for each age bracket

\begin{tabular}{|l|c|c|c|c|c|c|c|c|}
\hline $\begin{array}{l}\text { Number of } \\
\text { Morbidities }\end{array}$ & $55-59$ & $60-64$ & $65-69$ & $70-74$ & $75-79$ & $80-84$ & $85+$ & TOTAL \\
\hline 0 & 17,791 & 43,394 & 23,722 & 16,779 & 4,629 & 4,050 & 3,327 & 113,692 \\
\hline 1 & 28,061 & 84,618 & 59,450 & 40,067 & 26,470 & 14,609 & 14,031 & 267,450 \\
\hline 2 & 28,351 & 92,429 & 85,486 & 59,160 & 45,419 & 20,684 & 27,049 & 358,577 \\
\hline 3 & 13,163 & 69,719 & 57,280 & 62,198 & 37,897 & 27,627 & 38,476 & 306,360 \\
\hline 4 & 5,497 & 36,306 & 35,004 & 52,506 & 31,967 & 21,408 & 33,992 & 217,114 \\
\hline 5 & 1,374 & 15,332 & 17,502 & 23,577 & 19,383 & 14,175 & 17,502 & 108,918 \\
\hline 6 & 738 & 3,472 & 5,641 & 10,125 & 9,836 & 5,786 & 8,823 & 44,406 \\
\hline 7 & 1,215 & 4,339 & 2,314 & 4,339 & 2,604 & 1,229 & 3,472 & 19,527 \\
\hline 8 & 0 & 0 & 636 & 1,085 & 2,314 & 2,604 & 651 & 7,232 \\
\hline 9 & 0 & 593 & 0 & 0 & 579 & 217 & 0 & 1,403 \\
\hline 10 & 0 & 289 & 0 & 0 & 0 & 0 & 694 & 0 \\
\hline
\end{tabular}

Table 2.20 Weights were too small in 50-54 age group to allow for comorbidity analysis. 


\subsection{Medications Data}

This section presents the breakdown of numbers of over-50s in Ireland at Wave 5 (2018) using the following medications (identified using WHO Anatomical Therapeutic Chemical (ATC) codes https://www.whocc.no/atc_ddd_index/):

- Any blood glucose lowering drug ${ }^{1}$

- Thiazolidinediones

- Antihypertensives ${ }^{2}$

- ACE Inhibitors

- Angiotensin II Antagonists ${ }^{3}$

- Oral Ibuprofen

These estimates are based on participants' reporting of medications that they take at the time of Wave 5 data collection on a regular basis, like every day or every week. They are asked to report not just prescription medications, but also over-the-counter medications and supplements. The data may underestimate exposure to medications used intermittently, such as ibuprofen in this case, where a participant may only have reported this if they use it regularly.

1 This includes insulin and its analogues, and other oral and non-oral blood glucose lowering drugs. This corresponds to ATC code A10.

2 This includes diuretics, beta blockers, calcium channel blockers, ACE inhibitors, Angiotensin II Antagonists, other Renin-Angiotensin System agents, and other antihypertensives. This corresponds to ATC codes C02, C03, C0, C08, and C09.

3 This includes both single ingredient and fixed-dose combination medications. 


\subsubsection{Blood Glucose Lowering Drug}

Figure 2.20. Percentage prevalence of Blood Glucose Lowering Drugs by Age Group Total Pop Percent 9.16\%; Pop Number 132,496

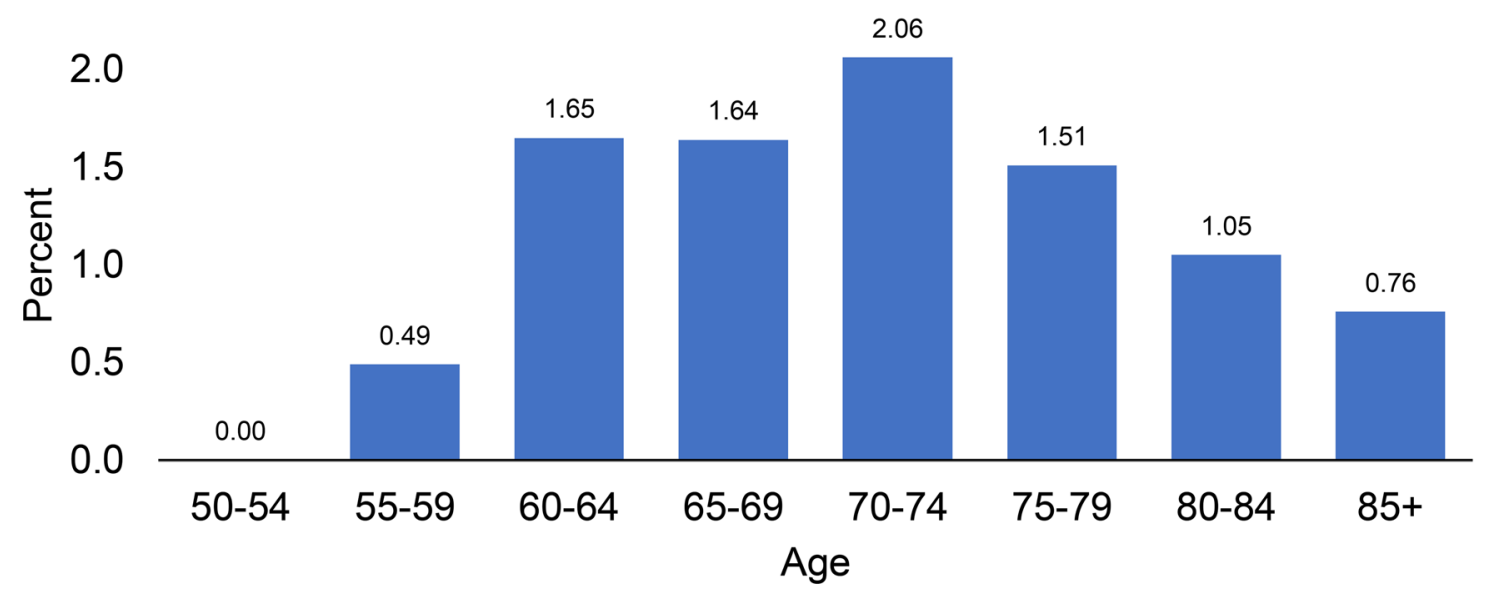

Table 2.21. Prevalence of Blood Glucose Lowering Drug usage in TILDA and the population of over-50s in Ireland by Age Group

\begin{tabular}{|c|c|c|c|c|c|c|c|c|c|}
\hline $\begin{array}{l}\text { Blood Glucose } \\
\text { Lowering Drug by } \\
\text { Age }\end{array}$ & $50-54$ & $55-59$ & $60-64$ & $65-69$ & $70-74$ & $75-79$ & $80-84$ & $85+$ & TOTAL \\
\hline $\begin{array}{l}\text { Number Cases in } \\
\text { TILDA }\end{array}$ & 3 & 26 & 70 & 80 & 96 & 84 & 60 & 29 & 448 \\
\hline $\begin{array}{l}\text { Estimated Prevalence } \\
\text { in Population }\end{array}$ & 0 & $0.49 \%$ & $1.65 \%$ & $1.64 \%$ & $2.06 \%$ & $1.51 \%$ & $1.05 \%$ & $0.76 \%$ & $9.16 \%$ \\
\hline $\begin{array}{l}\text { Estimated Number of } \\
\text { Cases in Population }\end{array}$ & 0 & 7,088 & 23,867 & 23,722 & 29,797 & 21,842 & 15,188 & 10,993 & 132,496 \\
\hline
\end{tabular}

Table 2.21 shows the actual numbers of cases in TILDA and the estimated number of people in the population using blood glucose lowering drugs. NOTE: The population prevalence is weighted to the population of over-50s in Ireland and so will not correspond to the \% of cases in TILDA. 


\subsubsection{Thiazolidinedione}

Figure 2.21. Percentage prevalence of any Thiazolidinedione by Age Group

Total Pop Percent 0.2\%; Pop Number 2,893

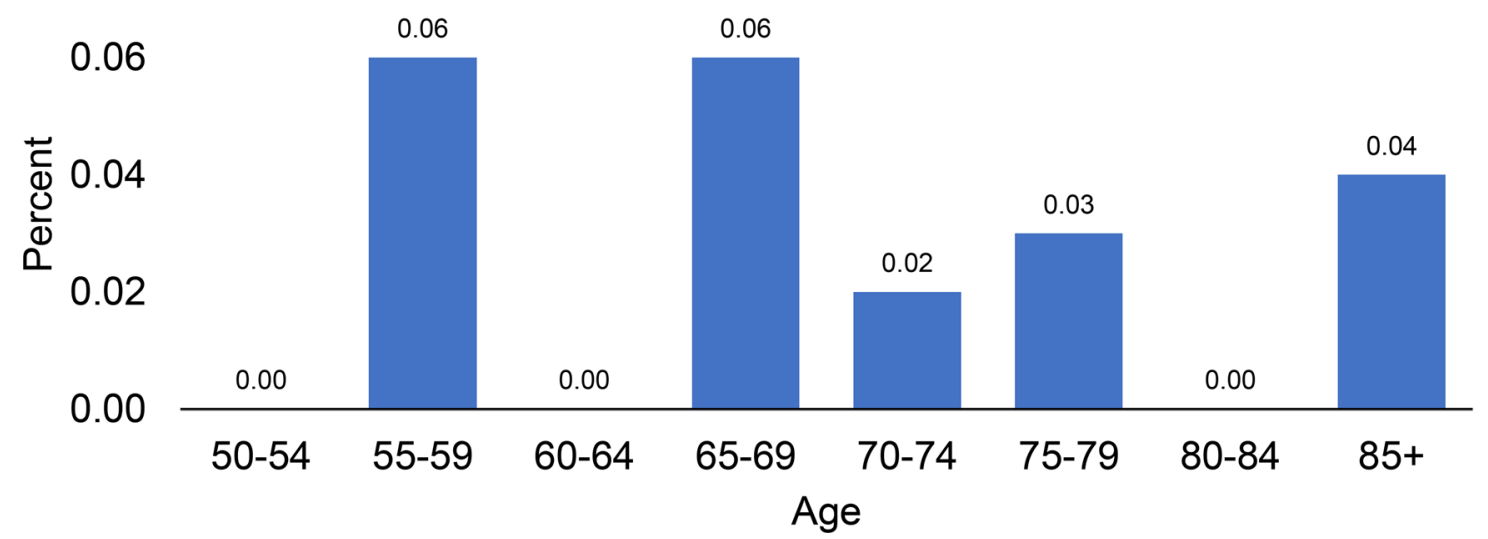

Table 2.22. Prevalence of any Thiazolidinedione usage in TILDA and the population of over-50s in Ireland by Age Group

\begin{tabular}{|l|c|c|c|c|c|c|c|c|c|}
\hline $\begin{array}{l}\text { Thiazolidinedione } \\
\text { by Age }\end{array}$ & $\mathbf{5 0 - 5 4}$ & $\mathbf{5 5 - 5 9}$ & $\mathbf{6 0 - 6 4}$ & $\mathbf{6 5 - 6 9}$ & $\mathbf{7 0 - 7 4}$ & $\mathbf{7 5 - 7 9}$ & $\mathbf{8 0 - 8 4}$ & $\mathbf{8 5 +}$ & TOTAL \\
\hline $\begin{array}{l}\text { Number Cases in } \\
\text { TILDA }\end{array}$ & 0 & 1 & 0 & 3 & 1 & 3 & 0 & 1 & 9 \\
\hline $\begin{array}{l}\text { Estimated Prevalence } \\
\text { in Population }\end{array}$ & $0.00 \%$ & $0.06 \%$ & $0.00 \%$ & $0.06 \%$ & $0.02 \%$ & $0.03 \%$ & $0.00 \%$ & $0.04 \%$ & $0.20 \%$ \\
\hline $\begin{array}{l}\text { Estimated Number of } \\
\text { Cases in Population }\end{array}$ & 0 & 882 & 0 & 839 & 275 & 376 & 0 & 550 & 2,893 \\
\hline
\end{tabular}

Table 2.22 shows the actual numbers of cases in TILDA and the estimated number of people in the population using any thiazolidinedione. NOTE: The population prevalence is weighted to the population of over-50s in Ireland and so will not correspond to the \% of cases in TILDA. 


\subsubsection{Antihypertensives}

Figure 2.22. Percentage prevalence of any Antihypertensives by Age Group Total Pop Percent 0.2\%; Pop Number 2,893

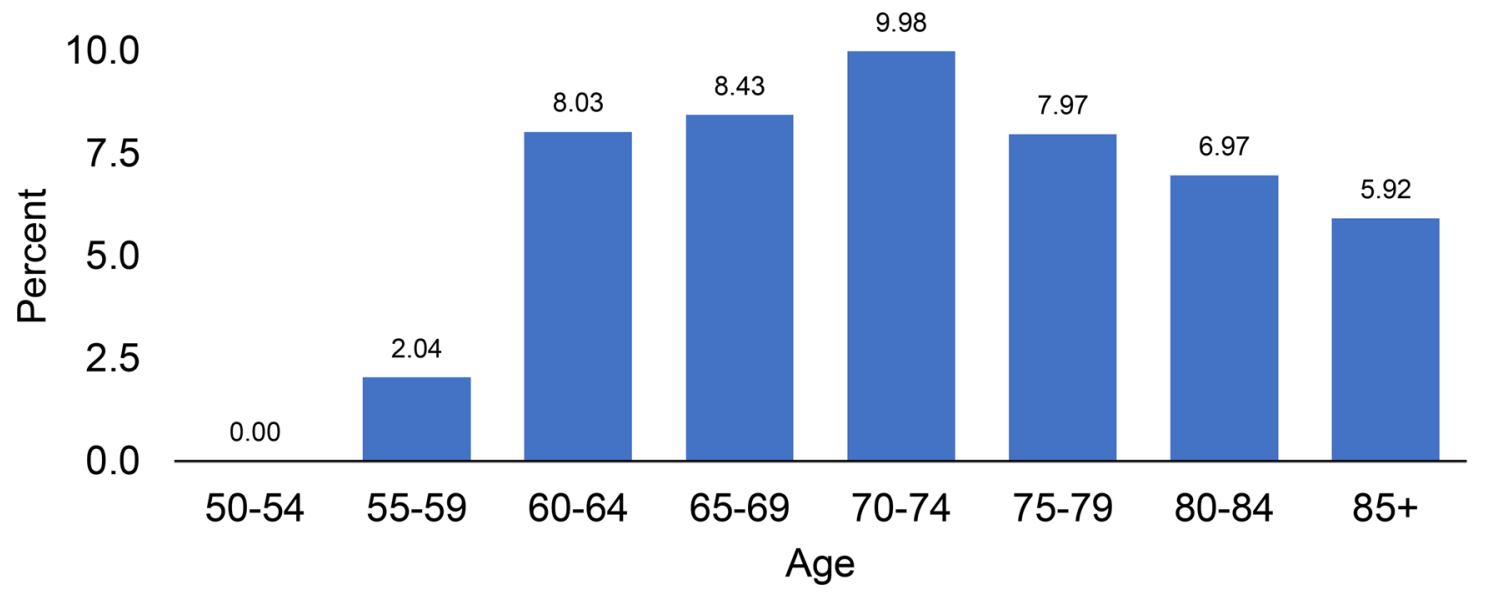

Table 2.23. Prevalence of any Antihypertensive usage in TILDA and the population of over50 s in Ireland by Age Group

\begin{tabular}{l|c|c|c|c|c|c|c|c|c|}
\hline $\begin{array}{l}\text { Antihypertensives } \\
\text { by Age }\end{array}$ & $\mathbf{5 0 - 5 4}$ & $\mathbf{5 5 - 5 9}$ & $\mathbf{6 0 - 6 4}$ & $\mathbf{6 5 - 6 9}$ & $\mathbf{7 0 - 7 4}$ & $\mathbf{7 5 - 7 9}$ & $\mathbf{8 0 - 8 4}$ & $\mathbf{8 5 +}$ & TOTAL \\
\hline $\begin{array}{l}\text { Number Cases in } \\
\text { TILDA }\end{array}$ & 16 & 119 & 363 & 422 & 490 & 433 & 359 & 200 & 2,402 \\
\hline $\begin{array}{l}\text { Estimated } \\
\begin{array}{l}\text { Prevalence in } \\
\text { Population }\end{array}\end{array}$ & $0.00 \%$ & $2.04 \%$ & $8.03 \%$ & $8.43 \%$ & $9.98 \%$ & $7.97 \%$ & $6.97 \%$ & $5.92 \%$ & $49.34 \%$ \\
\hline $\begin{array}{l}\text { Estimated Number } \\
\text { of Cases in } \\
\text { Population }\end{array}$ & 0 & 29,508 & 116,151 & 121,937 & 144,357 & 115,283 & 100,818 & 85,630 & 713,683 \\
\hline
\end{tabular}

Table 2.23 shows the actual numbers of cases in TILDA and the estimated number of people in the population using any antihypertensives. NOTE: The population prevalence is weighted to the population of over-50s in Ireland and so will not correspond to the \% of cases in TILDA. 


\subsubsection{ACE Inhibitors}

Figure 2.23. Percentage prevalence of any ACE Inhibitors by Age Group

Total Pop Percent 17.14\%; Pop Number 247,923

10.0

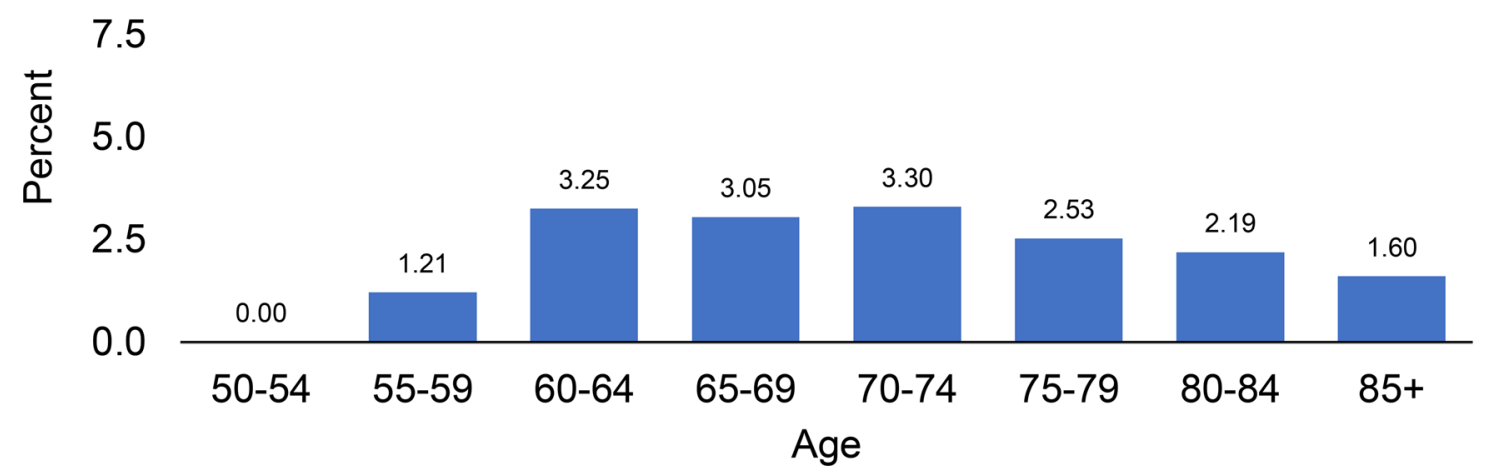

Table 2.24. Prevalence of any ACE Inhibitor usage in TILDA and the population of over50 s in Ireland by Age Group

\begin{tabular}{l|c|c|c|c|c|c|c|c|c|}
\hline $\begin{array}{l}\text { ACE Inhibitors by } \\
\text { Age }\end{array}$ & $\mathbf{5 0 - 5 4}$ & $\mathbf{5 5 - 5 9}$ & $\mathbf{6 0 - 6 4}$ & $\mathbf{6 5 - 6 9}$ & $\mathbf{7 0 - 7 4}$ & $\mathbf{7 5 - 7 9}$ & $\mathbf{8 0 - 8 4}$ & $\mathbf{8 5 +}$ & TOTAL \\
\hline $\begin{array}{l}\text { Number Cases in } \\
\text { TILDA }\end{array}$ & 7 & 60 & 147 & 151 & 153 & 136 & 119 & 58 & 831 \\
\hline $\begin{array}{l}\text { Estimated } \\
\begin{array}{l}\text { Prevalence in } \\
\text { Population }\end{array}\end{array}$ & $0.00 \%$ & $1.21 \%$ & $3.25 \%$ & $3.05 \%$ & $3.30 \%$ & $2.53 \%$ & $2.19 \%$ & $1.60 \%$ & $17.14 \%$ \\
\hline $\begin{array}{l}\text { Estimated Number } \\
\text { of Cases in } \\
\text { Population }\end{array}$ & 0 & 17,502 & 47,010 & 44,117 & 47,733 & 36,595 & 31,677 & 23,143 & 247,923 \\
\hline
\end{tabular}

Table 2.24 shows the actual numbers of cases in TILDA and the estimated number of people in the population using any ACE Inhibitors. NOTE: The population prevalence is weighted to the population of over-50s in Ireland and so will not correspond to the \% of cases in TILDA. 


\subsubsection{Angiotensin II Antagonist}

Figure 2.24. Percentage prevalence of any Angiotensin II Antagonist by Age Group Total Pop Percent 15.08\%; Pop Number 218,126

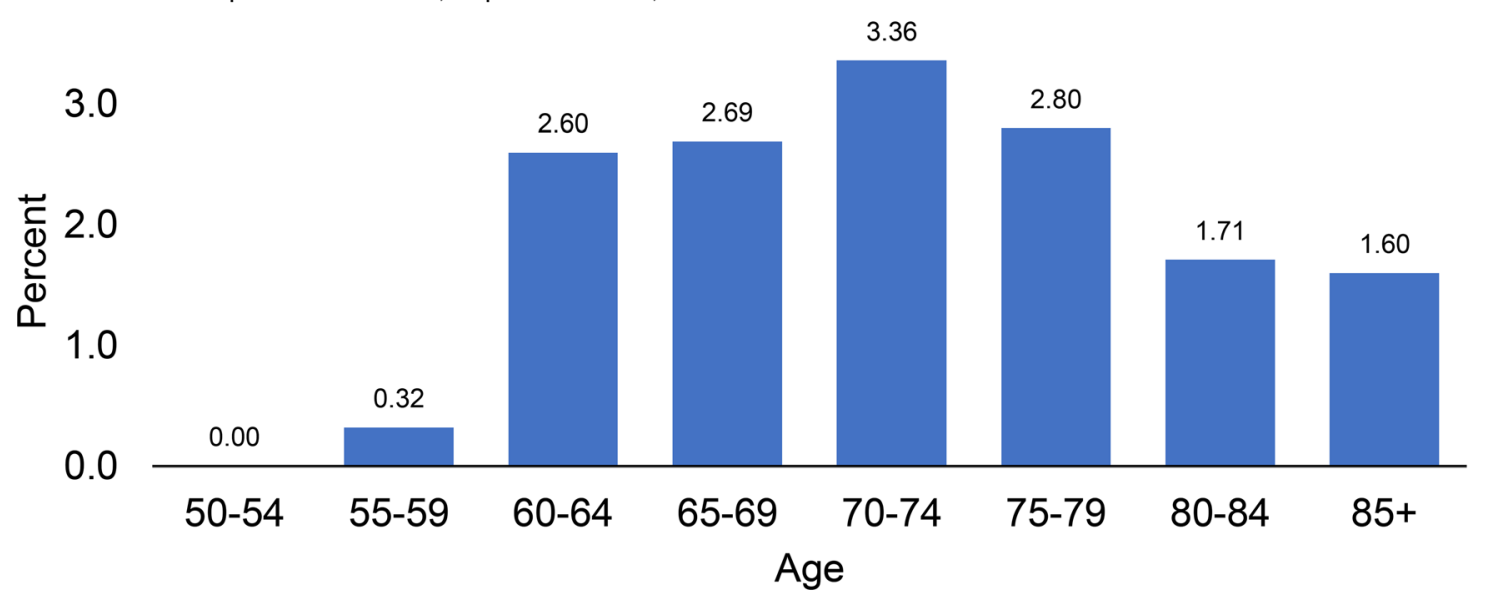

Table 2.25. Prevalence of any Angiotensin II Antagonist usage in TILDA and the population of over-50s in Ireland by Age Group

\begin{tabular}{|l|c|c|c|c|c|c|c|c|c|}
\hline $\begin{array}{l}\text { Angiotensin II } \\
\text { Antagonist by Age }\end{array}$ & $\mathbf{5 0 - 5 4}$ & $\mathbf{5 5 - 5 9}$ & $\mathbf{6 0 - 6 4}$ & $\mathbf{6 5 - 6 9}$ & $\mathbf{7 0 - 7 4}$ & $\mathbf{7 5 - 7 9}$ & $\mathbf{8 0 - 8 4}$ & $\mathbf{8 5 +}$ & TOTAL \\
\hline $\begin{array}{l}\text { Number Cases in } \\
\text { TILDA }\end{array}$ & 5 & 23 & 121 & 130 & 170 & 150 & 90 & 55 & 744 \\
\hline $\begin{array}{l}\text { Estimated } \\
\begin{array}{l}\text { Prevalence in } \\
\text { Population }\end{array}\end{array}$ & $0.00 \%$ & $0.32 \%$ & $2.60 \%$ & $2.69 \%$ & $3.36 \%$ & $2.80 \%$ & $1.71 \%$ & $1.60 \%$ & $15.08 \%$ \\
\hline $\begin{array}{l}\text { Estimated Number } \\
\text { of Cases in } \\
\text { Population }\end{array}$ & 0 & 4,629 & 37,608 & 38,910 & 48,601 & 40,501 & 24,734 & 23,143 & 218,126 \\
\hline
\end{tabular}

Table 2.25 shows the actual numbers of cases in TILDA and the estimated number of people in the population using any Angiotensin II Antagonists. NOTE: The population prevalence is weighted to the population of over$50 \mathrm{~s}$ in Ireland and so will not correspond to the \% of cases in TILDA. 


\subsubsection{Oral Ibuprofen}

Figure 2.25. Percentage prevalence of any Oral Ibuprofen by Age Group Total Pop Percent 1.05\%; Pop Number 15,188

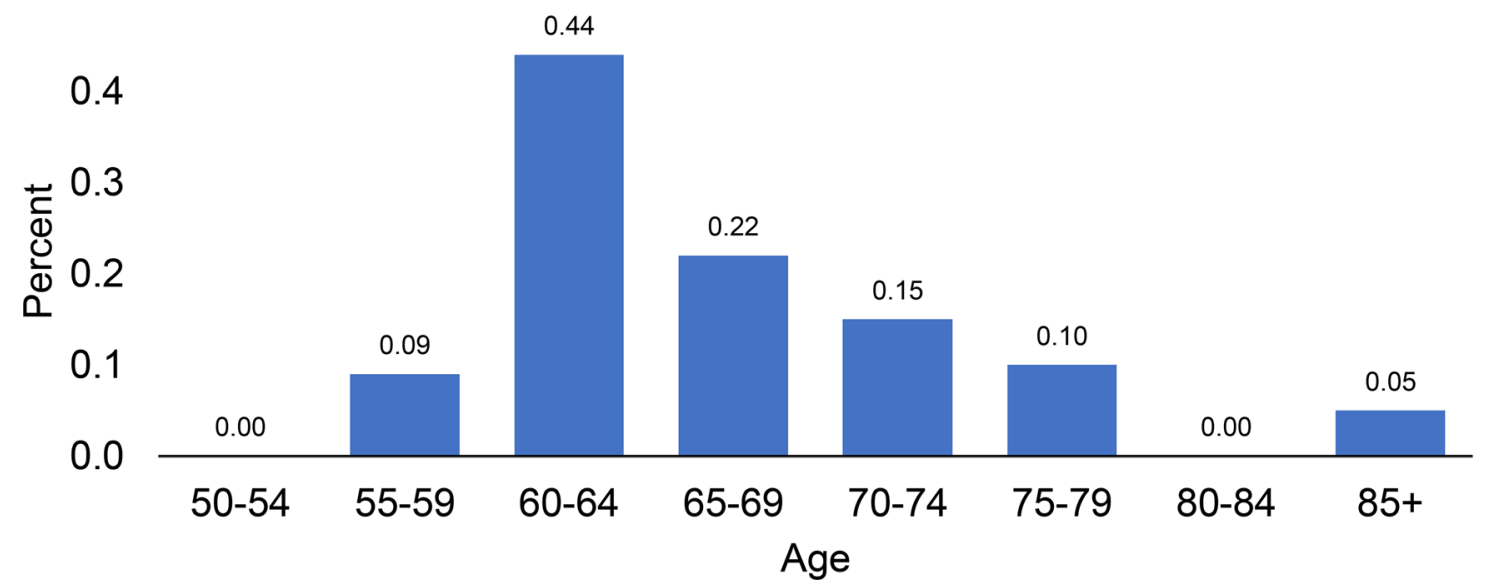

Table 2.26. Prevalence of any Oral Ibuprofen usage in TILDA and the population of over50 s in Ireland by Age Group

\begin{tabular}{l|c|c|c|c|c|c|c|c|c|}
\hline $\begin{array}{l}\text { Oral lbuprofen by } \\
\text { Age }\end{array}$ & $\mathbf{5 0 - 5 4}$ & $\mathbf{5 5 - 5 9}$ & $\mathbf{6 0 - 6 4}$ & $\mathbf{6 5 - 6 9}$ & $\mathbf{7 0 - 7 4}$ & $\mathbf{7 5 - 7 9}$ & $\mathbf{8 0 - 8 4}$ & $\mathbf{8 5 +}$ & TOTAL \\
\hline $\begin{array}{l}\text { Number Cases in } \\
\text { TILDA }\end{array}$ & 2 & 6 & 13 & 11 & 6 & 6 & 0 & 4 & 48 \\
\hline $\begin{array}{l}\text { Estimated } \\
\begin{array}{l}\text { Prevalence in } \\
\text { Population }\end{array}\end{array}$ & $0.00 \%$ & $0.09 \%$ & $0.44 \%$ & $0.22 \%$ & $0.15 \%$ & $0.10 \%$ & $0.00 \%$ & $0.05 \%$ & $1.05 \%$ \\
\hline $\begin{array}{l}\text { Estimated Number } \\
\text { of Cases in } \\
\text { Population }\end{array}$ & 0 & 1,229 & 6,364 & 3,182 & 2,170 & 1,446 & 0 & 723 & 15,188 \\
\hline
\end{tabular}

Table 2.26 shows the actual numbers of cases in TILDA and the estimated number of people in the population using any Oral Ibuprofen. NOTE: The population prevalence is weighted to the population of over-50s in Ireland and so will not correspond to the \% of cases in TILDA. 


\section{Grandchild care, family caregivers and disability in the population of over-50s in Ireland}

\section{Author: Christine McGarrigle}

\subsection{Introduction}

The following section gives an overview of the number of people over 50 in Ireland who provide care for grandchildren, and the numbers of hours provided by grandparents. We also examine household composition and determine the numbers of older people who live alone, by their functional disability status and proximity to their children.

Functional disability is measured as self-reported limitations in the activities of daily living (ADLs: help with walking across a room, dressing, bathing, eating, getting in and out of bed, and using the toilet) and instrumental activities of daily living (IADLs: preparing meals, shopping for groceries, making telephone calls, taking medications and managing money).

Finally, we present who receives home help, both state-provided and privately funded, and describe the family caregivers who help the older population with functional disability.

All estimates are based on data from the most recent Wave 5 of TILDA (collected in 2018, $n=5,206$ participants); total population estimates are based on figures collected from the most recent 2016 census data (which reported a total of 1,446,460 people over 50 living in Ireland). In all cases population numbers have been rounded to the nearest 100.

Overall, $31.5 \%$ of the population aged over 50 provide childcare for their grandchildren, with the mean number of hours in the last month being 2.5 hours (interquartile range 1-4), although $8 \%$ provided more than 40 hours in the past month. This equates to 352,100 people, with 93,000 providing more than 40 hours in the past month.

We find that 126,300 people aged over 50 live alone, 36,000 of whom are living with an ADL functional disability, and 57,800 are aged over 70 years. In total, $16.1 \%$ equivalent to 234,200 have no children. For the majority of those who do have children, their children live either in the same house $(26.1 \%)$ or in the same county $(44.5 \%)$.

Overall, $9 \%$ receive help from a family caregiver, the equivalent of 75,800 people. The majority of these were aged over $70(54,500)$. 


\subsection{Provision of grandchild care and the numbers of hours provided}

Table 3.1. Proportion of people aged 50 and over who take care of grandchildren for at least an hour in the past month by age group, The Irish Longitudinal Study on Ageing (TILDA)

\begin{tabular}{|c|c|c|c|c|c|c|c|c|}
\hline & \multicolumn{2}{|c|}{ No children } & \multicolumn{2}{|c|}{ Provide grandchild care } & \multicolumn{2}{|c|}{ No grandchild care } & \multicolumn{2}{|c|}{ No grandchilden } \\
\hline & $\%$ & $95 \% \mathrm{Cl}$ & $\%$ & $95 \% \mathrm{Cl}$ & $\%$ & $95 \% \mathrm{Cl}$ & $\%$ & $95 \% \mathrm{Cl}$ \\
\hline $\mathbf{N}$ & 663 & & 1,714 & & 2,351 & & 474 & \\
\hline $50-54$ & 0.2 & {$[0.0,1.1]$} & 0 & & 0 & & 0 & \\
\hline $55-59$ & 13.9 & {$[10.0,19.0]$} & 22 & {$[17.0,27.9]$} & 39.3 & {$[33.3,45.7]$} & 24.8 & {$[19.6,30.9]$} \\
\hline $60-64$ & 18.8 & {$[16.0,21.8]$} & 31.5 & {$[28.2,35.0]$} & 35.4 & {$[32.0,38.9]$} & 14.3 & {$[12.0,17.0]$} \\
\hline $65-69$ & 15 & {$[12.5,17.9]$} & 40.6 & {$[36.9,44.5]$} & 36 & {$[32.3,39.8]$} & 8.4 & {$[6.5,10.8]$} \\
\hline $70-74$ & 13.8 & {$[11.1,17.0]$} & 45.4 & {$[41.5,49.2]$} & 38.2 & {$[34.5,42.0]$} & 2.7 & {$[1.8,4.1]$} \\
\hline 75-79 & 13.2 & {$[10.4,16.7]$} & 32.9 & {$[28.6,37.5]$} & 51 & {$[46.5,55.4]$} & 2.9 & {$[1.7,4.9]$} \\
\hline $80-84$ & 19.1 & {$[14.7,24.4]$} & 20.1 & {$[15.9,25.0]$} & 59.1 & {$[53.2,64.7]$} & 1.8 & {$[0.8,4.0]$} \\
\hline $85+$ & 17.4 & {$[13.1,22.7]$} & 5.5 & {$[3.0,9.7]$} & 75.1 & {$[69.1,80.2]$} & 2.1 & {$[0.9,4.9]$} \\
\hline Total & 16 & {$[14.7,17.4]$} & 31.5 & {$[29.6,33.4]$} & 44.7 & {$[42.7,46.7]$} & 7.9 & {$[6.9,9.0]$} \\
\hline
\end{tabular}

Table 3.1 Data from Wave 5 (2018) TILDA weighted to account for population.

Table 3.2. Estimated numbers of people aged 50 and over who take care of grandchildren for at least an hour in the past month by age group. Populations estimated using The Irish Longitudinal Study on Ageing (TILDA) and 2016 Census population

\begin{tabular}{|c|c|c|c|c|c|}
\hline \multicolumn{6}{|c|}{ Estimated Population } \\
\hline & No children & $\begin{array}{c}\text { Provide } \\
\text { grandchild care }\end{array}$ & $\begin{array}{c}\text { No grandchild } \\
\text { care }\end{array}$ & No grandchilden & Total \\
\hline $50-54$ & 600 & 0 & 0 & 0 & 0 \\
\hline $55-59$ & 37,500 & 59,00 & 106,100 & 67,000 & 270,100 \\
\hline $60-64$ & 44,900 & 75,200 & 84,600 & 34,200 & 238,900 \\
\hline $65-69$ & 31,700 & 85,800 & 76,000 & 17,700 & 211,200 \\
\hline $70-74$ & 22,400 & 73,700 & 62,000 & 4,400 & 162,300 \\
\hline $75-79$ & 15,200 & 38,000 & 59,000 & 3,300 & 115,500 \\
\hline $80-84$ & 15,500 & 16,300 & 47,900 & 1,500 & 81,000 \\
\hline $85+$ & 11,800 & 3,700 & 50,700 & 1,400 & 67,600 \\
\hline Total & 179,600 & 352,100 & 486,300 & 129,500 & $1,146,500$ \\
\hline
\end{tabular}

Table 3.2 Data from Wave 5 (2018) TILDA weighted to account for population, rounded to nearest 100 . Totals may vary due to rounding. 


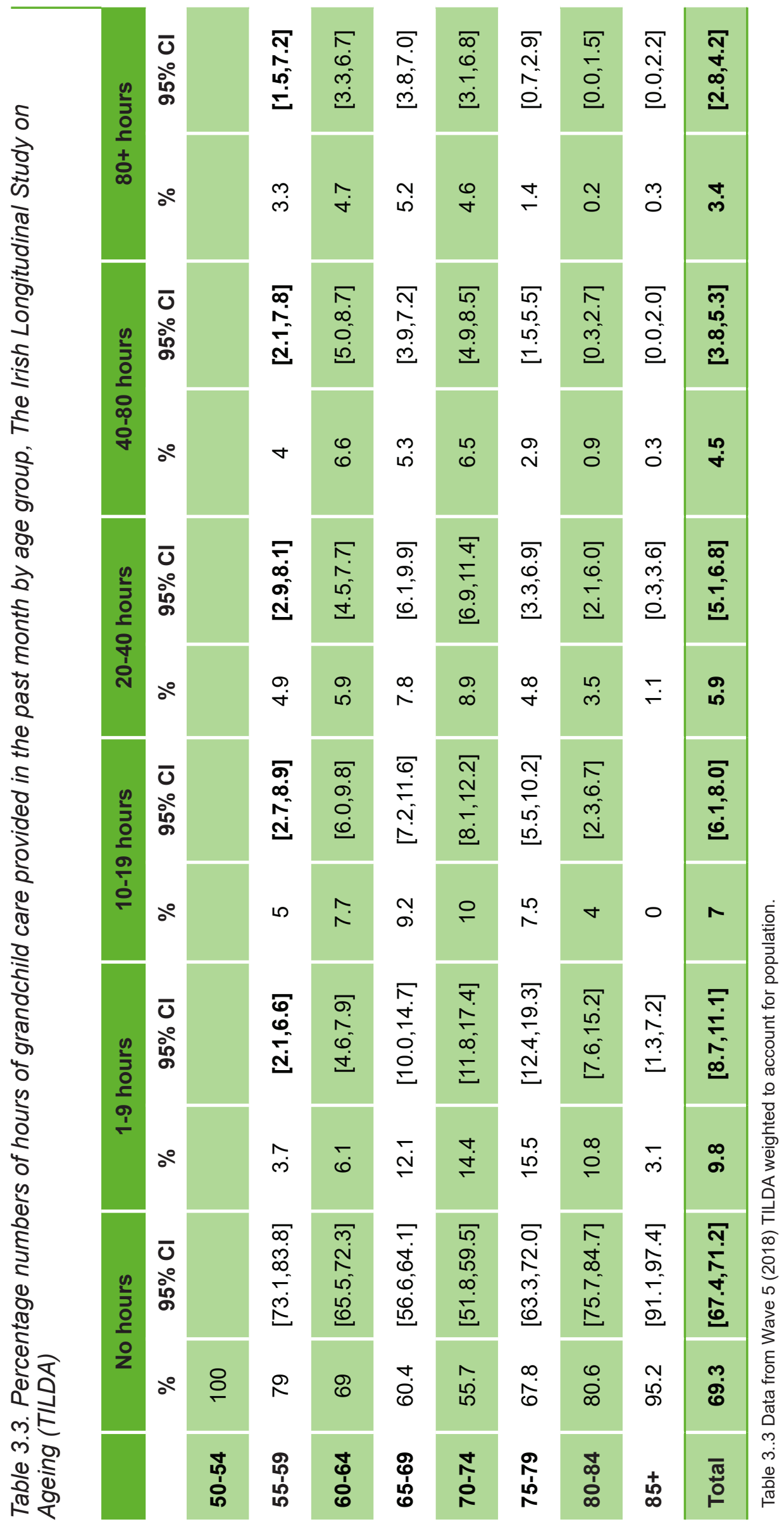


Table 3.4. Estimated numbers of people aged 50 and over who have taken care of their grandchildren for at least an hour in the past month by hours of grandchild care and age group. Populations estimated using The Irish Longitudinal Study on Ageing (TILDA) and 2016 Census population

\begin{tabular}{|c|c|c|c|c|c|c|c|}
\hline \multicolumn{8}{|c|}{ Estimated Population } \\
\hline Age Group & No hours & $\begin{array}{c}1-9 \\
\text { hours }\end{array}$ & $\begin{array}{l}10-19 \\
\text { hours }\end{array}$ & $\begin{array}{l}20-40 \\
\text { hours }\end{array}$ & $\begin{array}{l}40-80 \\
\text { hours }\end{array}$ & $\begin{array}{c}80+ \\
\text { hours }\end{array}$ & Total \\
\hline $50-54$ & 299,900 & 0 & 0 & 0 & 0 & 0 & 299,900 \\
\hline $55-59$ & 213,400 & 10,000 & 13,500 & 13,200 & 10,800 & 8,900 & 269,800 \\
\hline $60-64$ & 164,800 & 14,600 & 18,400 & 14,100 & 15,800 & 11,200 & 238,900 \\
\hline $65-69$ & 127,600 & 25,600 & 19,400 & 16,500 & 11,200 & 11,000 & 211,200 \\
\hline $70-74$ & 90,400 & 23,400 & 16,200 & 14,400 & 10,500 & 7,500 & 162,400 \\
\hline $75-79$ & 78,300 & 17,900 & 8,700 & 5,500 & 3,300 & 1,600 & 115,400 \\
\hline $80-84$ & 65,300 & 8,800 & 3,200 & 2,800 & 700 & 200 & 81,000 \\
\hline $85+$ & 64,300 & 2,100 & 0 & 700 & 200 & 200 & 67,600 \\
\hline Total & $1,104,000$ & 102,200 & 79,500 & 67,400 & 52,600 & 40,570 & $1,446,200$ \\
\hline
\end{tabular}

Table 3.4 Data from Wave 5 (2018) TILDA weighted to account for population, rounded to nearest 100 . Totals may vary due to rounding. 


\subsection{Household composition by functional disability status and proximity to children}

The following section examines the numbers of people over 50 in Ireland who live alone, or with their spouse, by age group and by functional disability status. Also presented are the numbers of people who live close to at least one of their children, either as co-resident or resident within the same county.

Table 3.5. Household composition by age group, The Irish Longitudinal Study on Ageing (TILDA)

\begin{tabular}{|c|c|c|c|c|c|c|}
\hline \multirow[b]{2}{*}{ Age Group } & \multicolumn{2}{|c|}{ Living Alone } & \multicolumn{2}{|c|}{ Living with spouse only } & \multicolumn{2}{|c|}{$\begin{array}{l}\text { Living with others (including } \\
\text { children and spouse) }\end{array}$} \\
\hline & $\%$ & $95 \% \mathrm{Cl}$ & $\%$ & $95 \% \mathrm{Cl}$ & $\%$ & $95 \% \mathrm{Cl}$ \\
\hline $\mathbf{N}$ & 526 & & 633 & & 5,205 & \\
\hline $50-54$ & 0 & & 0 & & 0 & \\
\hline $55-59$ & 8 & {$[4.9,12.8]$} & 8.7 & {$[5.6,13.3]$} & 83.3 & {$[77.4,87.9]$} \\
\hline $60-64$ & 9.90 & {$[7.8,12.4]$} & 11.70 & {$[9.6,14.2]$} & 78.4 & {$[75.3,81.3]$} \\
\hline $65-69$ & 11.00 & {$[8.9,13.6]$} & 13.40 & {$[11.0,16.2]$} & 75.6 & {$[72.1,78.8]$} \\
\hline $70-74$ & 9.30 & {$[7.2,11.9]$} & 12.10 & {$[9.9,14.7]$} & 78.6 & {$[75.2,81.7]$} \\
\hline 75-79 & 10.80 & {$[8.2,14.2]$} & 13.30 & {$[10.6,16.6]$} & 75.8 & {$[71.7,79.6]$} \\
\hline $80-84$ & 15.60 & {$[11.7,20.5]$} & 8.90 & {$[6.4,12.3]$} & 75.5 & {$[70.4,79.9]$} \\
\hline $85+$ & 26.1 & {$[21.3,31.5]$} & 5.9 & {$[3.4,10.0]$} & 68 & {$[62.1,73.3]$} \\
\hline Total & 12.3 & {$[11.2,13.6]$} & 11.2 & {$[10.1,12.5]$} & 76.5 & {$[74.8,78.0]$} \\
\hline
\end{tabular}

Table 3.5 Data from Wave 5 (2018) TILDA weighted to account for population.

Table 3.6. Household composition by age group, The Irish Longitudinal Study on Ageing (TILDA)

\begin{tabular}{|l|c|c|c|c|}
\hline & $\begin{array}{c}\text { Living } \\
\text { Alone }\end{array}$ & $\begin{array}{c}\text { Living with } \\
\text { spouse only }\end{array}$ & $\begin{array}{c}\text { Living with others (including } \\
\text { children and spouse) }\end{array}$ & Total \\
\hline $\mathbf{5 0 - 5 4}$ & & & & 299,900 \\
\hline $\mathbf{5 5 - 5 9}$ & 21,600 & 23,500 & 225,000 & 270,100 \\
\hline $\mathbf{6 0 - 6 4}$ & 23,600 & 27,900 & 187,300 & 238,900 \\
\hline $\mathbf{6 5 - 6 9}$ & 23,200 & 28,300 & 159,700 & 211,200 \\
\hline $\mathbf{7 0 - 7 4}$ & 15,100 & 19,600 & 127,500 & 162,300 \\
\hline $\mathbf{7 5 - 7 9}$ & 12,500 & 15,400 & 87,500 & 115,500 \\
\hline $\mathbf{8 0 - 8 4}$ & 12,600 & 7,200 & 61,200 & 81,000 \\
\hline $\mathbf{8 5 +}$ & 17,600 & 4,000 & 46,000 & 67,600 \\
\hline Total & $\mathbf{1 2 6 , 3 0 0}$ & $\mathbf{1 2 5 , 9 0 0}$ & $\mathbf{8 9 4 , 1 0 0}$ & $1,446,500$ \\
\hline
\end{tabular}

Table 3.6 Data from Wave 5 (2018) TILDA weighted to account for population, rounded to nearest 100 . Totals may vary due to rounding. 
Table 3.7. Household composition by age group, The Irish Longitudinal Study on Ageing (TILDA)

\begin{tabular}{|c|c|c|c|c|c|c|}
\hline \multicolumn{7}{|c|}{ Functional disability } \\
\hline & \multicolumn{2}{|c|}{ No disability } & \multicolumn{2}{|c|}{ IADL only disability } & \multicolumn{2}{|c|}{ Any ADL disability } \\
\hline Age Group & $\%$ & $95 \% \mathrm{Cl}$ & $\%$ & $95 \% \mathrm{Cl}$ & $\%$ & $95 \% \mathrm{Cl}$ \\
\hline $\mathbf{N}$ & 526 & & 633 & & 5,205 & \\
\hline \multicolumn{7}{|l|}{ Living alone } \\
\hline 50-54 & 0 & & & & & \\
\hline $55-59$ & 79.8 & {$[46.4,94.7]$} & 0 & & 20.2 & {$[5.3,53.6]$} \\
\hline $60-64$ & 91.7 & {$[82.9,96.2]$} & 1.9 & {$[0.6,5.7]$} & 6.4 & {$[2.5,15.8]$} \\
\hline $65-69$ & 86.2 & {$[75.3,92.8]$} & 2.7 & {$[0.7,10.3]$} & 11.1 & {$[5.3,21.8]$} \\
\hline $70-74$ & 91.5 & {$[80.8,96.5]$} & 2.2 & {$[0.5,10.1]$} & 6.3 & {$[2.1,17.0]$} \\
\hline 75-79 & 66.1 & {$[50.7,78.7]$} & 6.2 & {$[2.0,17.4]$} & 27.7 & {$[16.2,43.2]$} \\
\hline $80-84$ & 50.9 & {$[35.0,66.7]$} & 9.5 & {$[3.3,24.1]$} & 39.6 & {$[25.1,56.2]$} \\
\hline $85+$ & 26.2 & {$[17.3,37.5]$} & 11 & {$[5.3,21.3]$} & 62.9 & {$[50.7,73.6]$} \\
\hline Total & 67.2 & {$[61.9,72.2]$} & 5.5 & {$[3.3,8.8]$} & 27.3 & {$[22.6,32.5]$} \\
\hline
\end{tabular}

\begin{tabular}{|c|c|c|c|c|c|c|}
\hline \multicolumn{7}{|c|}{ Living with spouse only } \\
\hline $50-54$ & 0 & & & & & \\
\hline $55-59$ & 97.8 & {$[85.2,99.7]$} & 0 & & 2.2 & {$[0.3,14.8]$} \\
\hline $60-64$ & 91.4 & {$[84.3,95.4]$} & 2.7 & {$[0.9,8.1]$} & 6 & {$[2.7,12.5]$} \\
\hline $65-69$ & 93.6 & {$[86.3,97.1]$} & 0.8 & {$[0.1,5.8]$} & 5.6 & {$[2.3,12.8]$} \\
\hline $70-74$ & 86.7 & {$[79.1,91.7]$} & 3.7 & {$[1.2,10.7]$} & 9.6 & {$[5.6,16.0]$} \\
\hline $75-79$ & 85.2 & {$[76.2,91.2]$} & 2.8 & {$[0.9,8.9]$} & 11.9 & {$[6.5,20.9]$} \\
\hline $80-84$ & 77.8 & {$[62.8,87.9]$} & 8.2 & {$[2.8,21.3]$} & 14 & {$[6.1,29.0]$} \\
\hline $85+$ & 37.6 & {$[20.6,58.4]$} & 25.9 & {$[12.2,46.9]$} & 36.5 & {$[15.9,63.4]$} \\
\hline Total & 86.3 & {$[82.5,89.4]$} & 4.1 & {$[2.5,6.7]$} & 9.6 & {$[7.1,13.0]$} \\
\hline
\end{tabular}

\section{Living with others}

\begin{tabular}{|l|c|c|c|c|c|c|}
\hline $\mathbf{5 0 - 5 4}$ & 0 & & & & & \\
\hline $\mathbf{5 5 - 5 9}$ & 94.1 & {$[89.4,96.8]$} & 0.4 & {$[0.1,3.0]$} & 5.4 & {$[2.9,10.1]$} \\
\hline $\mathbf{6 0 - 6 4}$ & 92.3 & {$[89.8,94.3]$} & 1.5 & {$[0.8,2.9]$} & 6.2 & {$[4.4,8.5]$} \\
\hline $\mathbf{6 5 - 6 9}$ & 93.6 & {$[91.2,95.3]$} & 1.3 & {$[0.7,2.6]$} & 5.1 & {$[3.6,7.4]$} \\
\hline $\mathbf{7 0 - 7 4}$ & 89.9 & {$[87.1,92.2]$} & 2.5 & {$[1.4,4.3]$} & 7.6 & {$[5.6,10.1]$} \\
\hline $\mathbf{7 5 - 7 9}$ & 86.3 & {$[82.3,89.5]$} & 3 & {$[1.7,5.1]$} & 10.8 & {$[7.9,14.4]$} \\
\hline $\mathbf{8 0 - 8 4}$ & 80.1 & {$[74.8,84.5]$} & 7.5 & {$[4.9,11.2]$} & 12.5 & {$[8.9,17.1]$} \\
\hline $\mathbf{8 5 +}$ & 58.4 & {$[51.1,65.4]$} & 12 & {$[8.1,17.4]$} & 29.6 & {$[23.2,36.8]$} \\
\hline Total & $\mathbf{8 7 . 1}$ & {$[85.6,88.4]$} & $\mathbf{3 . 3}$ & {$[\mathbf{2 . 6 , 4 . 1}]$} & $\mathbf{9 . 6}$ & {$[\mathbf{8 . 5} \mathbf{1 1 . 0}]$} \\
\hline
\end{tabular}

Table 3.7 Data from Wave 5 (2018) TILDA weighted to account for population. 
Table 3.8. Estimated numbers of people aged 50 and over by by household composition and functional disability status. Populations estimated using The Irish Longitudinal Study on Ageing (TILDA) and 2016 Census population

\begin{tabular}{|c|c|c|c|c|}
\hline \multicolumn{5}{|c|}{ Estimated population } \\
\hline & No disability & IADL only disability & Any ADL disability & Total \\
\hline \multicolumn{5}{|l|}{ Living alone } \\
\hline \multicolumn{5}{|l|}{$50-54$} \\
\hline $55-59$ & 17,200 & 0 & 4,400 & 21,600 \\
\hline $60-64$ & 21,700 & 400 & 1,500 & 23,600 \\
\hline $65-69$ & 20,000 & 600 & 2,600 & 23,200 \\
\hline $70-74$ & 13,800 & 300 & 1,000 & 15,100 \\
\hline $75-79$ & 8,200 & 800 & 3,500 & 12,500 \\
\hline $80-84$ & 6,400 & 1,200 & 5,000 & 12,600 \\
\hline $85+$ & 4,600 & 1,900 & 11,100 & 17,600 \\
\hline Total living alone & 91,900 & 5,200 & 29,100 & 126,200 \\
\hline \multicolumn{5}{|l|}{ Living with spouse only } \\
\hline \multicolumn{5}{|l|}{$50-54$} \\
\hline $55-59$ & 23,000 & 0 & 500 & 23,500 \\
\hline $60-64$ & 25,500 & 800 & 1,700 & 28,000 \\
\hline $65-69$ & 26,500 & 200 & 1,600 & 28,300 \\
\hline $70-74$ & 17,000 & 700 & 1,900 & 19,600 \\
\hline $75-79$ & 13,100 & 400 & 1,800 & 15,300 \\
\hline $80-84$ & 5,600 & 600 & 1,000 & 7,200 \\
\hline $85+$ & 1,500 & 1,000 & 1,500 & 4,000 \\
\hline Total living with spouse only & 112,200 & 3,700 & 12,100 & 125,900 \\
\hline \multicolumn{5}{|l|}{ Living with others } \\
\hline \multicolumn{5}{|l|}{$50-54$} \\
\hline $55-59$ & 211,700 & 900 & 12,100 & 224,700 \\
\hline $60-64$ & 172,800 & 2,800 & 11,600 & 187,200 \\
\hline $65-69$ & 149,500 & 2,100 & 8,100 & 159,700 \\
\hline $70-74$ & 114,700 & 3,200 & 9,700 & 127,600 \\
\hline $75-79$ & 75,500 & 2,600 & 9,500 & 87,600 \\
\hline $80-84$ & 49,000 & 4,600 & 7,600 & 61,200 \\
\hline $85+$ & 26,800 & 5,500 & 13,600 & 45,900 \\
\hline Total living with others & 800,000 & 21,700 & 72,200 & 893,900 \\
\hline Total & 126,300 & 125,900 & 894,100 & $1,446,500$ \\
\hline
\end{tabular}

Table 3.8 Data from Wave 5 (2018) TILDA weighted to account for population. 


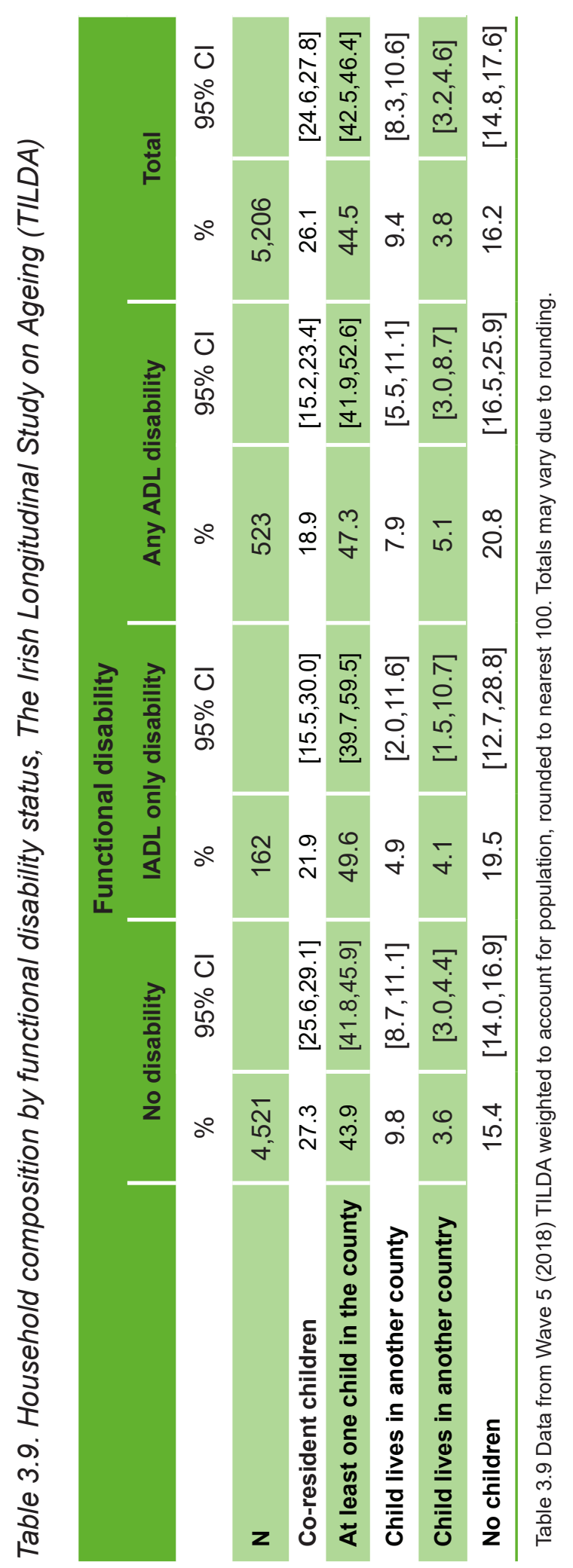


Table 3.10. Estimated numbers of people aged 50 and over by proximity to children and functional disability. Populations estimated using The Irish Longitudinal Study on Ageing (TILDA) and 2016 Census population

\begin{tabular}{|c|c|c|c|c|}
\hline \multicolumn{5}{|c|}{ Functional disability } \\
\hline & No disability & $\begin{array}{l}\text { IADL only } \\
\text { disability }\end{array}$ & $\begin{array}{l}\text { Any ADL } \\
\text { disability }\end{array}$ & Total \\
\hline \multicolumn{5}{|l|}{ Total } \\
\hline Co-resident children & 333,700 & 11,700 & 32,300 & 377,700 \\
\hline At least one child in the county & 536,600 & 26,500 & 80,700 & 643,900 \\
\hline Child lives in another county & 119,800 & 2,600 & 13,500 & 135,900 \\
\hline Child lives in another country & 44,000 & 2,200 & 8,700 & 54,900 \\
\hline No children & 188,200 & 10,400 & 35,500 & 234,200 \\
\hline Total & $1,222,300$ & 53,500 & 170,700 & $1,446,500$ \\
\hline
\end{tabular}

Table 3.10 Data from Wave 5 (2018) TILDA weighted to account for population, rounded to nearest 100 . Totals may vary due to rounding. 


\subsection{Home help, functional disability and family care giving}

This section presents the numbers of people aged 50 and over in Ireland who receive home help and those who receive help with the functional disabilities from family caregivers, and their relationship to the caregivers.

Table 3.11. Proportion of the population aged 50 years and older receiving any home help (private and state-provided) by age group, The Irish Longitudinal Study on Ageing (TILDA)

\begin{tabular}{|c|c|c|c|c|}
\hline \multirow[t]{2}{*}{ Age Group } & \multicolumn{2}{|c|}{ No home help } & \multicolumn{2}{|c|}{$\begin{array}{l}\text { Any home help (both private and state- } \\
\text { provided) }\end{array}$} \\
\hline & $\%$ & $95 \% \mathrm{Cl}$ & $\%$ & $95 \% \mathrm{Cl}$ \\
\hline $\mathbf{N}$ & 1,696 & & 1,969 & \\
\hline $50-54$ & 100 & & & \\
\hline $55-59$ & 98.3 & {$[94.3,99.5]$} & 1.7 & {$[0.5,5.7]$} \\
\hline $60-64$ & 99.6 & {$[99.0,99.9]$} & 0.4 & {$[0.1,1.0]$} \\
\hline $65-69$ & 97.9 & {$[96.5,98.8]$} & 2.1 & {$[1.2,3.5]$} \\
\hline $70-74$ & 96.5 & {$[94.4,97.8]$} & 3.5 & {$[2.2,5.6]$} \\
\hline $75-79$ & 90.3 & {$[87.2,92.7]$} & 9.7 & {$[7.3,12.8]$} \\
\hline $80-84$ & 82.6 & {$[78.0,86.3]$} & 17.4 & {$[13.7,22.0]$} \\
\hline $85+$ & 60.5 & {$[54.0,66.7]$} & 39.5 & {$[33.3,46.0]$} \\
\hline Total & 91.8 & {$[90.7,92.8]$} & 8.2 & {$[7.2,9.3]$} \\
\hline
\end{tabular}

Table 3.11 Data from Wave 5 (2018) TILDA weighted to account for population.

Table 3.12. Estimated numbers of people aged 50 and over receiving any home help (private and state-provided) by age group. Populations estimated using The Irish Longitudinal Study on Ageing (TILDA) and 2016 Census population

\begin{tabular}{|c|c|c|c|}
\hline \multicolumn{4}{|c|}{ Estimated Population } \\
\hline Age group & No home help & $\begin{array}{l}\text { Any home help (both private } \\
\text { and state-provided) }\end{array}$ & Total \\
\hline $\mathbf{N}$ & 1,696 & 1,969 & \\
\hline $50-54$ & 299,900 & 0 & 299,900 \\
\hline $55-59$ & 265,500 & 4,600 & 270,100 \\
\hline $60-64$ & 237,900 & 1,000 & 238,900 \\
\hline $65-69$ & 206,800 & 4,400 & 211,200 \\
\hline $70-74$ & 156,600 & 5,700 & 162,300 \\
\hline $75-79$ & 104,300 & 11,200 & 115,500 \\
\hline $80-84$ & 66,900 & 14,100 & 81,000 \\
\hline $85+$ & 40,900 & 26,700 & 67,600 \\
\hline Total & $1,378,800$ & 118,600 & $1,446,500$ \\
\hline
\end{tabular}

Table 3.12 Data from Wave 5 (2018) TILDA weighted to account for population, rounded to nearest 100 . Totals may vary due to rounding. 
Table 3.13 Proportion of the population aged 50 years and older receiving any care from a family caregiver by age group, The Irish Longitudinal Study on Ageing (TILDA)

\begin{tabular}{|c|c|c|c|c|}
\hline \multicolumn{5}{|c|}{ Family caregiving } \\
\hline Age Group & \multicolumn{2}{|c|}{ No family caregiver } & \multicolumn{2}{|c|}{ Any family caregiver } \\
\hline & $\%$ & $95 \% \mathrm{Cl}$ & $\%$ & $95 \% \mathrm{Cl}$ \\
\hline $\mathbf{N}$ & 4,832 & & 393 & \\
\hline $50-54$ & 100 & 0 & & \\
\hline $55-59$ & 98.1 & {$[94.2,99.4]$} & 1.9 & {$[0.6,5.8]$} \\
\hline $60-64$ & 96.3 & {$[94.7,97.4]$} & 3.7 & {$[2.6,5.3]$} \\
\hline $65-69$ & 96.5 & {$[94.8,97.6]$} & 3.5 & {$[2.4,5.2]$} \\
\hline $70-74$ & 94.7 & {$[92.7,96.2]$} & 5.3 & {$[3.8,7.3]$} \\
\hline $75-79$ & 92 & {$[89.1,94.1]$} & 8 & {$[5.9,10.9]$} \\
\hline $80-84$ & 84.5 & {$[79.8,88.2]$} & 15.5 & {$[11.8,20.2]$} \\
\hline $85+$ & 64.3 & {$[58.6,69.7]$} & 35.7 & {$[30.3,41.4]$} \\
\hline Total & 91 & {$[89.8,92.0]$} & 9 & {$[8.0,10.2]$} \\
\hline
\end{tabular}

Table 3.13 Data from Wave 5 (2018) TILDA weighted to account for population.

Table 3.14 Estimated numbers of people aged 50 and over receiving any care from a family caregiver by age group. Populations estimated using The Irish Longitudinal Study on Ageing (TILDA) and 2016 Census population

\begin{tabular}{|l|c|c|c|}
\hline \multicolumn{3}{c}{} & \multicolumn{2}{c|}{ Estimated Population } & Total \\
\hline Age group & No family caregiver & Any family caregiver & 5,206 \\
\hline $\mathbf{N}$ & 4,813 & 393 & 299,900 \\
\hline $\mathbf{5 0 - 5 4}$ & 299,900 & 0 & 270,100 \\
\hline $\mathbf{5 5 - 5 9}$ & 265,00 & 5,100 & 238,900 \\
\hline $\mathbf{6 0 - 6 4}$ & 230,000 & 8,800 & 211,200 \\
\hline $\mathbf{6 5 - 6 9}$ & 203,800 & 7,400 & 162,300 \\
\hline $\mathbf{7 0 - 7 4}$ & 153,700 & 8,600 & 115,500 \\
\hline $\mathbf{7 5 - 7 9}$ & 106,200 & 9,200 & 81,000 \\
\hline $\mathbf{8 0 - 8 4}$ & 68,500 & 12,600 & 67,600 \\
\hline $\mathbf{8 5 +}$ & 43,400 & 24,100 & $\mathbf{1 , 4 4 6 , 5 0 0}$ \\
\hline Total & $\mathbf{1 , 3 7 0 , 6 0 0}$ & $\mathbf{7 5 , 8 0 0}$ & \\
\hline
\end{tabular}

Table 3.14 Data from Wave 5 (2018) TILDA weighted to account for population, rounded to nearest 100 . Totals may vary due to rounding. 
Table 3.15. Proportion of population aged 50 years and older receiving help with activities of daily living $(A D L)$ from a family caregiver by relationship to caregiver and age group, The Irish Longitudinal Study on Ageing (TILDA)

\begin{tabular}{|c|c|c|c|c|c|c|c|c|}
\hline \multicolumn{9}{|c|}{ Family caregiving } \\
\hline \multirow{2}{*}{$\begin{array}{l}\text { Age } \\
\text { group }\end{array}$} & \multicolumn{2}{|c|}{ No family caregiver } & \multicolumn{2}{|c|}{ Spouse } & \multicolumn{2}{|c|}{ Child } & \multicolumn{2}{|c|}{ Other relative } \\
\hline & $\%$ & $95 \% \mathrm{Cl}$ & $\%$ & $95 \% \mathrm{Cl}$ & $\%$ & $95 \% \mathrm{Cl}$ & $\%$ & $95 \% \mathrm{Cl}$ \\
\hline $\mathbf{N}$ & 5,100 & & 61 & & 27 & & 18 & \\
\hline $50-54$ & 100 & & & & & & & \\
\hline $55-59$ & 100 & & & & & & & \\
\hline $60-64$ & 98.6 & {$[97.3,99.2]$} & 0.9 & {$[0.4,1.8]$} & 0.5 & {$[0.2,1.8]$} & 0 & \\
\hline $65-69$ & 98.6 & {$[97.3,99.2]$} & 1.1 & {$[0.6,2.2]$} & 0.1 & {$[0.0,0.6]$} & 0.2 & {$[0.0,1.5]$} \\
\hline $70-74$ & 98.3 & {$[97.2,99.0]$} & 1.6 & {$[0.9,2.7]$} & 0.1 & {$[0.0,0.7]$} & 0 & \\
\hline $75-79$ & 98.1 & {$[96.3,99.1]$} & 0.9 & {$[0.4,2.0]$} & 0.7 & {$[0.2,2.6]$} & 0.3 & {$[0.0,2.0]$} \\
\hline $80-84$ & 96.9 & {$[94.5,98.3]$} & 2.2 & {$[1.1,4.3]$} & 0.7 & {$[0.2,3.0]$} & 0.1 & {$[0.0,1.0]$} \\
\hline $85+$ & 94.1 & {$[90.5,96.4]$} & 1.1 & {$[0.4,3.0]$} & 3.5 & {$[1.8,6.4]$} & 1.4 & {$[0.4,4.4]$} \\
\hline Total & 97.9 & {$[97.3,98.4]$} & 1.1 & {$[0.9,1.5]$} & 0.7 & {$[0.4,1.1]$} & 0.2 & {$[0.1,0.6]$} \\
\hline
\end{tabular}

Table 3.15 Data from Wave 5 (2018) TILDA weighted to account for population.

Table 3.16. Estimated numbers of people aged 50 and over receiving help with activities of daily living $(A D L)$ from a family caregiver by relationship to caregiver and age group. Populations estimated using The Irish Longitudinal Study on Ageing (TILDA) and 2016 Census population

\begin{tabular}{|c|c|c|c|c|c|}
\hline \multicolumn{6}{|c|}{ Estimated Population } \\
\hline $\begin{array}{l}\text { Age } \\
\text { group }\end{array}$ & $\begin{array}{l}\text { No family } \\
\text { caregiver }\end{array}$ & Spouse & Child & Other relative & Total \\
\hline $50-54$ & 299,900 & & & & 299,900 \\
\hline $55-59$ & 270,100 & 0 & 0 & 0 & 270,100 \\
\hline $60-64$ & 238,900 & 0 & 0 & 0 & 238,900 \\
\hline 65-69 & 208,300 & 1,900 & 1,100 & 0 & 211,200 \\
\hline 70-74 & 160,000 & 1,800 & 200 & 300 & 162,300 \\
\hline 75-79 & 113,500 & 1,800 & 100 & 0 & 115,500 \\
\hline $80-84$ & 79,500 & 700 & 600 & 200 & 81,000 \\
\hline $85+$ & 65,500 & 1,500 & 500 & 100 & 67,600 \\
\hline Total & $1,135,700$ & 7,700 & 2,400 & 600 & $1,446,500$ \\
\hline
\end{tabular}

Table 3.16 Data from Wave 5 (2018) TILDA weighted to account for population, rounded to nearest 100 . Totals may vary due to rounding. 
Table 3.17. Proportion of population aged 50 years and older receiving help with instrumental activities of daily living (IADL) from a family caregiver by relationship to caregiver and age group, The Irish Longitudinal Study on Ageing (TILDA)

\begin{tabular}{|c|c|c|c|c|c|c|c|c|}
\hline \multicolumn{9}{|c|}{ Family caregiving } \\
\hline \multirow[t]{2}{*}{$\begin{array}{l}\text { Age } \\
\text { group }\end{array}$} & \multicolumn{2}{|c|}{ No family caregiver } & \multicolumn{2}{|c|}{ Spouse } & \multicolumn{2}{|c|}{ Child } & \multicolumn{2}{|c|}{ Other relative } \\
\hline & $\%$ & $95 \% \mathrm{Cl}$ & $\%$ & $95 \% \mathrm{Cl}$ & $\%$ & $95 \% \mathrm{Cl}$ & $\%$ & $95 \% \mathrm{Cl}$ \\
\hline $\mathbf{N}$ & 5,100 & & 61 & & 27 & & 18 & \\
\hline $50-54$ & 100 & & & & & & & \\
\hline $55-59$ & 99.1 & {$[97.3,99.7]$} & 0.9 & {$[0.3,2.7]$} & 0 & & 0 & \\
\hline $60-64$ & 97.1 & {$[95.7,98.1]$} & 2 & {$[1.3,3.2]$} & 0.8 & {$[0.3,2.0]$} & 0 & \\
\hline $65-69$ & 98 & {$[96.7,98.8]$} & 1.5 & {$[0.9,2.6]$} & 0.3 & {$[0.1,1.1]$} & 0.2 & {$[0.0,1.5]$} \\
\hline $70-74$ & 96.9 & {$[95.4,97.9]$} & 2.2 & {$[1.4,3.4]$} & 0.9 & {$[0.4,2.1]$} & 0 & \\
\hline 75-79 & 94.9 & {$[92.5,96.6]$} & 3.5 & {$[2.2,5.6]$} & 1.3 & {$[0.6,2.9]$} & 0.3 & {$[0.0,2.0]$} \\
\hline $80-84$ & 91.3 & {$[87.9,93.8]$} & 4.7 & {$[2.9,7.6]$} & 3.5 & {$[2.0,6.0]$} & 0.5 & {$[0.2,1.7]$} \\
\hline $85+$ & 77.7 & {$[72.5,82.2]$} & 10 & {$[7.0,14.1]$} & 11.2 & {$[7.9,15.6]$} & 1.1 & {$[0.3,3.6]$} \\
\hline Total & 94.4 & {$[93.5,95.2]$} & 3.2 & {$[2.6,3.9]$} & 2.2 & {$[1.7,2.8]$} & 0.2 & {$[0.1,0.5]$} \\
\hline
\end{tabular}

Table 3.17 Data from Wave 5 (2018) TILDA weighted to account for population.

Table 3.18 Estimated numbers of people aged 50 and over receiving any help with instrumental activities of daily living (IADL) from a family caregiver by relationship to caregiver and age group. Populations estimated using The Irish Longitudinal Study on Ageing (TILDA) and 2016 Census population.

\begin{tabular}{|c|c|c|c|c|c|}
\hline \multicolumn{6}{|c|}{ Estimated Population } \\
\hline $\begin{array}{l}\text { Age } \\
\text { group }\end{array}$ & $\begin{array}{l}\text { No family } \\
\text { caregiver }\end{array}$ & Spouse & Child & Other relative & Total \\
\hline $50-54$ & 299,900 & & & & 299,900 \\
\hline $55-59$ & 267,700 & 2,400 & 0 & 0 & 270,100 \\
\hline $60-64$ & 231,900 & 4,800 & 1,900 & 0 & 238,600 \\
\hline 65-69 & 207,000 & 3,200 & 650 & 400 & 211,200 \\
\hline $70-74$ & 157,200 & 3,600 & 1,500 & 0 & 162,300 \\
\hline $75-79$ & 109,600 & 4,000 & 1,500 & 400 & 115,500 \\
\hline $80-84$ & 74,000 & 3,800 & 2,800 & 400 & 81,000 \\
\hline $85+$ & 52,500 & 6,800 & 7,600 & 700 & 67,600 \\
\hline Total & $1,399,900$ & 28,600 & 15,900 & 1,900 & $1,446,200$ \\
\hline
\end{tabular}

Table 3.18 Data from Wave 5 (2018) TILDA weighted to account for population, rounded to nearest 100 . Totals may vary due to rounding. 


\section{Appendix}

\subsection{TILDA sampling frame and methods summary}

Sampling for the first wave of TILDA was conducted using the RANSAM random sampling procedure (Whelan and Savva 2010 \& ESRI RANSAM citation), with the Irish Geodirectory as a sampling frame. The Geodirectory is a complete listing of all residential addresses in the Republic of Ireland recorded by the Irish Postal Service (An Post) (Donoghue 2018). The addresses sampled were selected by first grouping addresses into clusters, based on District Electoral Divisions, then a number of clusters were randomly selected, and finally, 50 addresses were randomly selected from each cluster (Whelan and Savva 2010). The final sample was of 8,174 individuals aged 50 and over, from 6,279 households, as well as 330 partners aged under 50 (young partners) (total $=8,504)$. This constituted a $62 \%$ response rate for households with an eligible participant. Wave 1 interviews were completed between October 2009 and February 2011. Data were collected through three different formats: Computer Assisted Personal Interview (CAPI), Self-Completion Questionnaire (SCQ), and Health Assessment.

All participants at each wave completed a CAPI interview. CAPI interviews were completed in the participant's own home by a trained social interviewer and included items on the participant's health, economic and social circumstances, as well as some cognitive measures. All participants were invited to complete a health assessment at Waves 1 and 3 and forthcoming Wave 6. Detailed health assessments were not carried out at Waves 2, 4 and 5 but the participants completed some objectives measures in these waves important for frailty. At Wave 1, participants were invited to attend a dedicated health centre. Participants who preferred not to travel to attend a health assessment due to mobility or other issues were offered a health assessment at home. Home health assessments measured a reduced number of health measures due to the practicalities of completing the assessment at home. All health assessments were carried out by trained research nurses, and included anthropometric measures such as height and weight, physical function measures such as Timed-Up-and-Go and grip strength, detailed cardiovascular, mood and cognitive measures. The in-centre health assessment also collected more detailed measures of cardiovascular, bone, and eye health and other senses (Cronin et al., 2013). During Wave 1, a total of 5,894 over-50s participants completed a health assessment (72.1\%), 860 of which completed a health assessment at home. 